\title{
EVALUATION OF HEAT CHECKING AND WASHOUT OF HEAT RESISTANT SUPERALLOYS AND COATINGS FOR DIE INSERT APPLICATIONS
}

\section{Final Technical Report}

David Schwam

John F. Wallace

Yulong Zhu

Department of Materials Science

Case Western Reserve University

Cleveland, Ohio
Edward Courtright

Harold Adkin

Battelle PNNL

Richland, WA

Work Performed Under Contract DE-FC07-01ID14034

US Department of Energy

Assistant Secretary for

Energy Efficiency and Renewable Energy

Washington DC

January 2005 


\section{LIST OF CONTENTS}

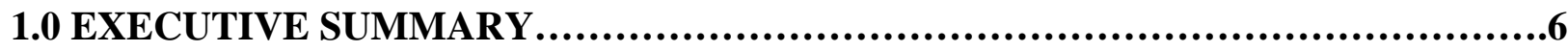

2.0 REVIEW OF TECHNOLOGY STATUS...........................................8

2.1 Die Casting................................................................................8

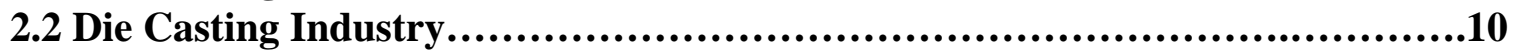

2.3 Die Life............................................................................11

2.4 Failure Mechanisms of Dies...................................................12

3.0 EXPERIMENTAL PROCEDURE.........................................................16

3.1 Accelerated Evaluation of Soldering and Washout $\ldots . \ldots \ldots \ldots \ldots \ldots \ldots \ldots \ldots \ldots \ldots \ldots . . . . .16$

3.2 Pin materials.....................................................................18

3.3 Evaluation of Soldering Resistance.............................................18

3.4 Evaluation of Washout................................................................19

3.5 Examination of Test Pins.............................................................20

3.6 Evaluation of Thermal Fatigue...................................................20

3.7 Evaluation of Coatings.........................................................22

4.0 RESULTS AND DISCUSSION.....................................................23

4.1 Potential Superalloys for Use as Die Materials.................................23

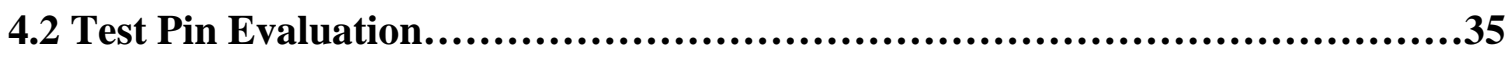

4.3 Soldering Results................................................................36

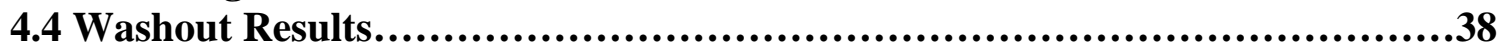

4.5 Thermal Fatigue Results.....................................................41

4.6 Relationship Between Thermal Fatigue, Soldering and Washout................42

4.7 Performance of Protective Coatings............................................43

5.0 GENERAL CONCLUSIONS AND RECOMMENDATION FOR FUTURE WORK...46

6.0 REFERENCES.................................................................53

7.0 FIGURES......................................................................56 


\section{LIST OF TABLES AND FIGURES}

Table 1: Chemical Composition of Copper Base Pin (wt\%)

Table 2: Chemical Composition of Pins (wt\%)

Table 3: Nominal Superalloy Compositions in wt $\%$

Table 4: Types of coating tested and their relative thickness.

Table 5: Qualitative Ranking of Heat Checking Resistance

Table 6: Characteristics of PVD Coatings

Figure 1: UBE VSC 315 Ton Squeeze Cast Machine at CWRU

Figure 2: Schematic Diagram of the Accelerated Soldering Test

Figure 3: Schematic of the Washout/Soldering Testing Set-up

Figure 4a: Sub-Insert for Soldering and Washout Experiments

Figure 4b:Test Pin Design and Position

Figure 5: Thermal Fatigue Immersion Test and Equipment

Figure 6: Dissolution at the Corners of Nickel Alloy Specimens

Figure 7: Temperature dependent yield strength of superalloys compared with H-13

Figure 8: Temperature dependent thermal conductivity of superalloys compared with H-13

Figure 9: Percent linear expansion of $\mathrm{H}-13$ and several superalloys

Figure 10: Elastic Modulus as a function of temperature for several superalloys and H-13

Figure 11: Equilibrium amounts of various oxide compounds calculated to form when 1 mole of $\mathrm{H}-13$ alloy is reacted with oxygen at 450 Centigrade

Figure 12: Equilibrium amounts of various oxide compounds calculated to form when 1 mole of IN-718 alloy is reacted with oxygen at 450 Centigrade

Figure 13: Equilibrium amounts of various oxide compounds calculated to form when 1 mole of IN-718 alloy with $30 \% \mathrm{Cr}$ is reacted with oxygen at 450 Centigrade

Figure 14:Equilibrium amounts of various oxide compounds calculated to form when 1 mole of IN-706 alloy is reacted with oxygen at 450 Centigrade

Figure 15: Equilibrium amounts of various oxide compounds calculated to form when 1 mole of Incoloy 901 alloy is reacted with oxygen at 450 Centigrade

Figure 16: Equilibrium amounts of various oxide compounds calculated to form when 1 mole of Incoloy 909 alloy is reacted with oxygen at 450 Centigrade

Figure 17: Equilibrium amounts of various oxide compounds calculated to form when 1 mole of $\mathrm{H}-13$ alloy is reacted with oxygen at 565 Centigrade showing the formation of FeO.

Figure 18: Broken Test Pins

Figure 19: Appearance of Pins after 50 Shots (with Soldered Al Dissolved in $\mathrm{NaOH}$ )

Figure 20: Effect of Pin Material on Soldering

Figure 21: Effects of Pin Material \& Number of Shots on \% Area Covered with Soldering

Figure 22: Effects of the Pin Material on Soldering

Figure 23: Washout in the Hard H13 Pin Impinged Directly by the Al (50 shots)

Figure 24: Effects of Pin Material on Washout

Figure 25: Washout Induced Weight Loss

Figure 26: Percentage of Weight Loss

Figure 27: Soldering-Washout \& Thermal Fatigue Ranking

Figure 28: Hardness Distribution in Nitro-Carburized Diffusion Layers

Figure 29: Hardness Distribution in Nitro-Carburized Diffusion Layers 
Figure 30: Hardness Distribution in Nitro-Carburized Diffusion Layer

Figure 31: Effect of the Nitro-Carburizing Treatment on Soldering

Figure 32: Effect of Nitro-carburizing on Soldering After 50 Shots

Figure 33: Appearance of H13 and Nitro-Carburized Pins after 30 Shots

Figure 34: Appearance of H13 and Nitro-Carburized Pins after the Test (Al Dissolved in $\mathrm{NaOH}$ )

Figure 35: Effect of Nitro-Carburizing on Washout

Figure 36: Impingement Surface of Thin Nitro-Carburized layer in "B” Pin (after 50 Shot Soldered Al Dissolved in $\mathrm{NaOH}$ )

Figure 37: Impingement Surface of Thin Nitro-Carburized layer in "B” Pin (after 150 ShotsSoldered Al Dissolved in $\mathrm{NaOH}$ )

Figure 38: Impingement Surface of Thick Nitro-Carburized Layer in "U”" Pin (after 150 Shots and Soldered $\mathrm{Al}$ Dissolved in $\mathrm{NaOH}$ )

Figure 40: Average Max Crack Length of Nitrocarburized H13

Figure 41: Total Crack Area of Nitrocarburized H13

Figure 42: Cross- Section of PVD Coatings and Pin Substrates

Figure 43: Appearance of PVD Coated Pins before Testing \& after 30 Shots

Figure 44: Soldering Appearance of H13 Pin with CrN+W PVD Coating

Figure 45: Soldering Appearance of H13 Pin with CrN PVD Coating

Figure 46: Soldering Appearance of H13 Pin with (TiAl)N PVD Coating

Figure 47: Soldering Appearance of H13 Pin with CrC PVD Coating

Figure 48: Effect of PVD Coating on Soldering

Figure 49: Effect of PVD Coating Materials on Soldering (after 30 shots)

Figure 50: Effect of PVD Coatings on Washout Resistance

Figure 51: Washout Comparison of PVD Coatings and Nitrocarburizing

Figure 52: Degradation of H13 Pin with CrN+W PVD Coating

Figure 53: Degradation of H13 Pin with $\mathrm{CrN}+\mathrm{W}$ PVD Coating (magnified)

Figure 54: Degradation of H13 Pin with CrN PVD Coating

Figure 55: Degradation of H13 Pin with CrN PVD Coating (magnified)

Figure 56: Degradation of H13 Pin with (TiAl)N PVD Coating

Figure 57: Degradation of H13 Pin with (TiAl)N PVD Coating (magnified)

Figure 58: Degradation of H13 Pin with CrC PVD Coating

Figure 59: Degradation of H13 Pin with CrC PVD Coating (magnified)

Figure 60: Degradation of H13 Pin with CrN+W PVD Coating (Pin Holes and Worn off)

Figure 61: Degradation of H13 Pin with CrN+W PVD Coating after 210 Shots

Figure 62: Degradation of H13 Pin with (TiAl)N PVD Coating

Figure 63: Degradation of H13 Pin with (TiAl)N PVD Coating after 210 Shots

Figure 64: Degradation of H13 Pin with CrC PVD Coating(Only Pin Holes)

Figure 65: Degradation of H13 Pin with CrC PVD Coating after 240 Shots (Only Pin Holes)

Figure 66: Cross Section View \& Failure Mode of CrN+W PVD Coated H13 Pin after 120 Shots

Figure 67: Cross Section View \& Failure Mode of CrN+W PVD Coated H13 Pin after 120 Shots 


\section{ACKNOWLEDGEMENTS}

This research investigation was supported by the Department of Energy, Office of Industrial Technology through the Cast Metal Coalition program. The Die Materials Committee of the North American Die Casting Association provided guidance for this work. The efforts of Mr. Steve Udvardy, Director of Research and Education at NADCA and the members of the committee are gratefully acknowledged.

This publication was prepared with the support of the U.S. Department of Energy (DOE), Award No. DE-FC07-01ID14034. However, any opinions, findings, conclusions or recommendations expressed herein are those of the authors and do not necessarily reflect the views of the DOE. 


\subsection{EXECUTIVE SUMMARY}

The project had two main objectives:

- To design, fabricate and run a full size test for evaluating soldering and washout in die insert materials. This test utilizes the unique capabilities of the 350 Ton Squeeze Casting machine available in the Case Metal Casting Laboratory. Apply the test to evaluate resistance of die materials and coating, including heat resistant alloys to soldering and washout damage.

- To evaluate materials and coatings, including heat resistant superalloys, for use as inserts in die casting of aluminum alloys.

An accelerated washout test was initially set up on a commercial UBE VSC 315 tone squeeze casting machine. A testing procedure was established to evaluate the soldering and washout resistance of die materials for aluminum die-casting dies. This arrangement simulates well the actual die casting conditions in a production environment. It allows parametric evaluation, as well as accurate and quick evaluation of soldering and washout. A wide range of die materials and coatings were subjected to the test and ranked for soldering and washout resistance. These materials include Anviloy1150 (a refractory tungsten-based alloy, H13, Mo-785, Ti-6Al-4V, IN718, cast iron and copper base alloys. These have been tested for evaluating not only their resistances to soldering and washout but also their resistance to thermal fatigue. Anviloy1150 shows the best soldering and washout resistance, followed by Ti-6Al-4V, Mo-785, H13 and IN718. Anviloy1150 and Mo-785 show the best resistance to thermal fatigue while Ti-6Al-4V shows poor thermal fatigue resistance. The thermal fatigue resistance of H13 is better than Ti6Al-4V but worse than Anviloy1150 and Mo-785. It is hard to evaluate the thermal resistance of 
IN-718 because of its severe dissolution in molten aluminum, which makes it difficult to identify any cracks. However, the absence of cracks on all evaluated samples points at superior thermal fatigue resistance. Mechanisms of soldering and washout previously reported in the literature have been confirmed in the present investigation. Formation of intermetallic layers with mechanical interlocking are the primary reasons for soldering in both heat resistant, nickel-based alloys and in steels. Washout is caused by erosion-enhanced corrosion and dominated by corrosion rate.

This investigation determined that nitro-carburizing improves significantly the resistance of H13 pins to washout (loss of base metal). Thicker nitro-carburized layers provide better resistance to washout. However, they tend to crack more readily than thin coatings. Thick nitrocarburized coatings are desirable in "soldering intensive" applications; thin nitro-carburized coatings may be desirable in "thermal fatigue intensive" applications that can induce cracking.

The "thick" CrC PVD coating was the best performer among the PVD coatings evaluated so far. However, this coating is primarily recommended for small cores; it is more susceptible to thermal fatigue cracking than the thin coatings. The thin PVD coatings fail at surface imperfections in the substrate and at defect sites in the coating (pin-holes). Good coatings practices are essential in ensuring a high performance coating. 


\subsection{TECHNOLOGY REVIEW}

\subsection{Die Casting}

In the die casting process, molten metal is injected at high pressure into a water cooled steel die, where it solidifies as a net shape product $(13,14)$. When solidification is completed and the casting has cooled sufficiently, the die is opened and the part is ejected. The die is subsequently sprayed with a lubricant, closed and molten metal is injected again into the die to start a new cycle.

Very complex shapes ranging in size from less than one inch to fifty inches and more can be made by die casting of aluminum, magnesium, zinc and copper with no additional machining. Die-casting can produce castings with close dimensional tolerances, smooth surface finishes and fine, intricate details at high production rates $[15,16]$. This is a net-shape fabrication method that requires limited or no finishing operations. These advantages are offset to some extent by the relatively high cost of die. Die life is therefore a major consideration in a die casting operations; Depending on the complexity of the part being produced, a die may cost more than the die casting machine itself [17]. Usually, dies comprise about $20 \%$ of the total cost of producing an aluminum die casting. Increasing die life could therefore result in significant savings. Typical die life in aluminum die-casting ranges from 100,000 to 250,000 parts [15]. As the numbers of parts that can be cast with a single die increases, the process becomes more economical. Increasing the production life of a die through the prevention of die failure can make a major contribution toward the profitability of die casting operation. Likewise, reducing die costs can 
be beneficial in reducing the costs of the process. Die cast parts have very broad applications in automotive, aerospace, electronics and household consumer products. Thin section components can be made to very tight tolerances that few other shaping processes can meet.

The performance and durability of the die material is critical in meeting these engineering requirements. The die controls not only the dimensions and tolerances of the final part but also the surface quality of the products. Many dies end their useful life when tiny cracks develop on the surface, leading to unacceptable marks on the cast part. Other parts are more tolerant to small cracks, but as these increase in severity the die becomes unserviceable. Improvement in die materials have a major impact on the dimensional stability, reproducibility and surface quality of the product.

Die casting competes most favorably with other metal shaping methods for large volume production. In some cases it also competes with injection-molded plastics. In high-strength, high-stiffness applications, or when high temperature resistance, creep resistance or thermal conductivity are required, die casting parts are preferred. In many instances, the technical requirements are equally satisfied by more than one fabrication method, and the selection is based on cost per part consideration. Die cast parts have a broad range of applications in automotive, aerospace, electronic and household products. The automotive industry is the single largest market. In this market, die casting competes with cast iron and injection molded parts. Weight savings is a major driver in this industry. Translated into performance, any weight saving increases the miles per gallon and the energy savings. The Corporate Average Fuel Economy (CAFE) standards set by the US government currently specifies a minimum of 27.5 miles per gallon. It is expected to increase to $35 \mathrm{mpg}$ by 2003. To meet these demands, lighter 
materials will have to be used. In 1991, the average weight of aluminum used in an automobile was 191 pounds; only 2.2 pounds of magnesium was used. The weight of aluminum parts used in automobiles is expected to more than double by 2010. An even larger increase is anticipated for magnesium parts. These projections assume no other substitutes will become available at a more attractive cost/performance. To a large extent, it is up to the die casting industry to maintain and increase its competitiveness. The cost and life expectancy of the die often tilts the balance to one side or another. The cost of the die contributes at least $20 \%$ of the final price. Any design problem or subsequent dimensional modification add to this price. The cost of a die can exceed one million dollars and it can take months or even years to take it from design to production. The US alone spends approximately one billion dollars per year on die casting dies. Improvements in die technology have a direct, significant impact on the profitability and competitiveness of the die casting industry.

\subsection{Die Casting Industry}

Die casting is the second largest foundry industry in the US, second only to sand casting. Die casting produces about one third of all metal castings. In 2004 US die casters sold over 1,500 million pounds of castings, contributing over $\$ 7.3$ billion to the nation's economy. There are roughly 400 die casting plants in the US, providing about 65,000 jobs directly or indirectly. The average plant has 70 employees, with most employing less than 50 people. These small plants have to cope with high capital cost and limited engineering staff yet utilize a sophisticated and technologically demanding process. Moreover, they have to compete with foreign firms in an increasingly global economy. Development of better dies is an undertaking that no single plant 
will assume. Only by a joint effort with support from federal sources, such as the U.S. DOE Metal Research Casting Program can such an issue be addressed.

\subsection{Die Life}

Good thermal fatigue resistance and thermal shock resistance are essential for long die life. These are considered "technological properties" and depend in turn on "basic" materials properties such as:

- Elevated temperature yield strength: the die has to resist high mechanical and thermal stresses without deforming. Hot tools steels have good elevated temperature properties; most superalloys have even better elevated temperature properties; refractory metals have by far the best elevated temperature properties.

- Temper resistance: excessive softening of the die during use, in the $1100-1300^{\circ} \mathrm{F}$ temperature range is detrimental and will cause premature heat checking. Temper resistant steels retain their hardness better after prolonged exposure to such temperatures. Increasing the alloying content of steels makes them more temper resistant. However, even the most temper resistant steels eventually soften under the high temperatures and thermal fatigue cycles experienced by aluminum die casting dies. Superalloys are known to retain their strength at high temperatures for much longer. The strengthening mechanism of superalloys are based on constituents that are still stable in the $1250-1350^{\circ} \mathrm{F}$ range of die casting. 
- Impact toughness: die materials have to withstand severe mechanical and thermal shock. The impact strength of most steels decreases significantly at low temperatures due to the ductile-brittle transition encountered in Body Centered Cubic type materials. Mechanical shock at low temperatures, before the die has been preheated can be very damaging. Refractory alloys belong to the same class of materials and also suffer from low impact strength when cold. Superalloys belong mostly to the Face Center Cubic category and do not exhibit the ductile-brittle transition behavior.

All these properties are strongly connected. Finding the right balance of properties is the key to extending the life of the die. Material properties are strongly linked to microstructural features, which, in turn, depend on the chemistry and processing of the material. Non-metallic inclusions and cleanliness of the alloy are of particular importance: non-metallic inclusions are generally considered undesirable constituents are required to be held at a minimum within practical limits. Cleanliness is ensured by refining processes such as the Vacuum Arc Remelting (VAR) and Electro Slag Remelting (ESR); these have become common practice in fabrication of high quality superalloys and Premium Grade steels.

\subsection{Failure Mechanisms of Dies}

Die failure is mostly caused by thermal cracks, washout and soldering on the surfaces that come in contact with the molten metal $[18,19]$. The hot metal coming in contact with the water-cooled die surface generates large thermal gradients. The surface of the die expands due to the temperature increase. At the same time, the colder zone below the surface resists movement. As a result, the hot working surface goes under compressive stress condition. This 
cycle is reversed during cooling; when water is circulated to cool the casting, the working surface of the die becomes colder than the inside. The working surface of the die is then subjected to tensile stresses. Repetition of this cycles eventually leads to thermal fatigue failure of the die, often designated as "heat checking". A network of fine cracks develops gradually on the working cavity surface of the die, deteriorating the surface quality of the cast product and eventually destroying the integrity of the die.

Occasionally, long and deep cracks cause catastrophic failure of a die, particularly when a thermal shock occurs. Named "gross-cracking", this failure mode is primarily related to the toughness of the die material. Consequently, the toughness of the material has to be monitored as well as its thermal fatigue resistance, particularly under thermal shock conditions.

Erosion or washout is encountered in areas of fast flow such as runners, in particular where the metal emerges from a restricted section or it changes direction. It first appears as small pits. Gradually, the size of the pits increases until it develops into a rough surface. The traditional approach interprets erosion as a wash-away of metal caused by the impinging, turbulent action of the incoming metal. Detailed analyses have however shown that most of the erosion occurs at locations that are not directly impinged by the metal stream, but rather downstream of separation sites. Voids formed at these separation sites are swept downstream and eventually collapse causing a momentary spike in pressure at the die surface.

Washout in aluminum die-casting dies usually is caused by a combination of corrosive wear, erosive wear and soldering. It involves the gradual removal of die material by the impinging jet 
of an incoming molten metal stream. Continuous washout can result in severe damage to the die surface and finally lead to the failure of the die.

Corrosive wear is defined as the dissolution of die material in the melt and the formation of intermetallic layers. Corrosion is enhanced by the following factors:

(1) Iron and most of the alloying elements in the die steel are more or less dissolvable in liquid aluminum.

(2) The high casting temperatures may cause oxidation of the die surface.

(3) Intermetallic layers may form at the die surface.

Erosive wear is defined as the gradual removal of material from the die substrate with every liquid aluminum impingement. This takes place as a result of the rapid flow of the aluminum melt, which can reach velocities within the range of 20 to $60 \mathrm{~m} / \mathrm{s}$ in gate area. The three main erosion mechanisms are:

(1) Liquid-impingement erosion that creates pits on the eroded sample surfaces.

(2) Cavitation, which is the result of the formation and collapse of bubbles (cavities) in a fluid due to local pressure fluctuations.

(3) Solid erosion, which is caused by the impact of solidified particles (Si particles, oxide particles and impurities and intermetallic particles) during filling.

Soldering is defined as the adhesion of the cast metal to the die or core surface. Soldering of the casting to the steel surface inside the cavity takes place during solidification. Chemical and mechanical reactions occur during the filling and solidification stage due to the affinity of the 
aluminum alloy atoms and die substrate atoms for each other. The chemical reaction often results in the formation of intermetallic layers at the die substrate/ aluminum alloy interface. When the molten aluminum comes in contact with die surface, mechanical interlocking due to surface roughness can also result in aluminum buildup on the die surface [20]. The buildup of aluminum alloy that occurs at the interface is called soldering. Soldering will cause sticking problems when the casting is ejected and it can also give rise to adhesive wear when the casting is separated from the die.

In order to extend the die life, die materials in aluminum die-casting should be resistant to heat checking, washout and soldering in molten aluminum flow. To resist heat checking, die materials should have a low coefficient of thermal expansion, high thermal conductivity, high hot yield strength, good temper softening resistance, high creep strength, and adequate ductility. To resist the washout and soldering, die materials should have high hardness, high temper resistance, low solubility in molten aluminum and good oxidation resistance. It is difficult for one material to satisfy with all above requirements. In practice, H13 is the most popular materials for production dies in aluminum die-casting, followed by H11 and H21 [17].

Instead of depending solely on conventional die steels, efforts have been made to develop new die materials with higher resistance to thermal fatigue, soldering and washout. Some copper-base alloys, nickel-base alloys, titanium-base alloys, molybdenum base alloys, tungstenbase alloys are occasionally used as die materials. Other metal materials, such as yttrium-base alloys and niobium alloys have also been considered for die material applications. 
An accelerated immersion thermal fatigue testing method was developed for evaluation of thermal fatigue performance of die materials at the Case Metal Casting Laboratory at Case Western Reserve University. This testing method closely simulates the realistic environment encountered in aluminum die casting dies [21-24]. Previous work in this area was done by immersing and/or rotating test pins in molten aluminum alloys [25-29]. However, immersing or rotating tests do not subject the pin to the molten aluminum impingement and the ejection forces encountered in production of casting. A key aspect of this investigation was to establish a realistic method to evaluate the soldering, washout and thermal fatigue resistance of heat resistance nickel-base and other new die materials in aluminum die casting.

\section{EXPERIMENTAL PROCEDURE}

\subsection{Accelerated Evaluation of Soldering and Washout}

This evaluation was carried out on a commercial UBE VSC 315 tone squeeze casting machine at Case Western Reserve University shown in Figure 1. A special insert was designed and fabricated to generate a fast jet of molten metal. The volume of the cavity has been maximized to allow for a large amount of metal to be shot. A sub-insert is bolted to this insert holding two test core pins positioned side by side in front of a narrow slit gate entry to the die cavity (see Fig. 2 - 4). Molten metal is injected at a high velocity through the narrow slit and impinges onto the pins. Each shot weighs about seven pounds of aluminum. The molten metal is cast into the cavity and after it solidifies the entire part is ejected. During ejection the test pins are subjected 
to high friction and wear. This experimental set-up provides direct line-of-sight allowing the operator to observe the tested core pin and examine the development of soldering and washout.

In order to accelerate the soldering and washout effects and to allow for quantifying soldering and washout damage after a reasonable number of shots, a testing procedure was developed. The operating conditions chosen to accelerate the soldering and washout rate are listed below:

a) Aluminum alloy: A356 was chosen as the impinging molten aluminum alloys. The chemical composition of A356 is $7.5 \% \mathrm{Si}, 0.3 \% \mathrm{Mg}, 0.1 \% \mathrm{Fe} .600$ pounds of standard A 356 ingot was melted in a $75 \mathrm{KW}$ electricity heater furnace. The UBE squeeze caster is equipped with an automated transfer ladle that scoops molten metal from the furnace and pours it into the shot sleeve. A plunger then pushes the metal into the cavity.

b) Test pin design: A special test pin was designed with a flat plane and sharp corners facing the impinging flow of molten aluminum. The test pin and its position in die are also shown in Fig.3 and 4.

c) Gate dimension: In order to accelerate the jetting velocity, a narrow gate was designed with a $2.5 \mathrm{~mm}$ in thick and $50 \mathrm{~mm}$ width slit.

d) Die lubricant: No die lubricant was sprayed on the pin surface during the experiment. A graphite lubricant was sprayed only on the shot sleeve, shot block, plunger tip and die cavity.

e) Other parameters:

$\begin{array}{ll}\text { Melting temperature } & 1,350{ }^{\circ} \mathrm{F} \\ \text { Plunger velocity } & 5 \mathrm{in} / \mathrm{s}(127 \mathrm{~mm} / \mathrm{s}) \\ \text { Impinging velocity } & 240 \mathrm{in} / \mathrm{s}\left(6000 \mathrm{mms}^{-1}\right)\end{array}$




$\begin{array}{ll}\text { Applied pressure } & 70 \mathrm{MPa} \\ \text { Die hold time } & 40 \mathrm{~s} \\ \text { Cycle time } & 110-130 \mathrm{~s}\end{array}$

\subsection{Pin materials}

Several die materials were selected because they have known applications in high pressure die casting or permanent mold casting. These include soft H13 with a hardness of 34-36 HRC, standard H13 (51-54 HRC), a copper-base alloy, a gray cast iron, IN-718 alloy, Ti-6Al-4V alloy, Mo-785 alloy and Anviloy1150 alloy. Their chemical compositions and physical properties are shown in Tables 1 and 2.

All pins were machined to the same dimensions, ground to size and finally polished to 1200 grit. Fig.4b shows the design of the pin.

\subsection{Evaluation of Soldering Resistance}

After a preset number of shots, the test pins were removed from the machine and erosion was measured by profilometry. In this method, a fine tip stylus is moved on the measured surface and the up-down motion is recorded by a sensitive optical sensor. The resolution of such measurements is in the 0.000001" range. Eroded areas show as a "trough" in the otherwise linear motion of the stylus. This high sensitivity method allows erosion damage evaluation after a relatively small number of shots. Additional parameters were chosen to evaluate the soldering resistance: The literature reports [19,20,25,26,28], two parameters as often used for this purpose: "Percentage of Soldering Area with aluminum on pin surface (PSA)" and "Weight of Soldered 
Aluminum alloy on pin surface (WSA)". Sometimes, the parameter of "Thickness of the Soldered Aluminum Layer on pin surface (TSAL)" was also selected [18]. However, the thickness of soldered aluminum on the pin surface varies from place to place, making it difficult to measure and compare. Therefore, PAS and WSA were selected to evaluate the soldering resistance. The greater the PAS or WSA, the lower is the resistance to soldering or the more severe the soldering tendency of the test material is for the same shots. In order to measure PSA, the pin surface condition was observed and recorded for every cycle. The soldered aluminum is silver in color while the pin surface is black or dark in color. This difference allows for easy and accurate determination of the PSA. The weight of test pins was measured before the test, after a pre-set number of shots with soldering, and after removing the soldered aluminum from the pin surface with a strong $\mathrm{NaOH}$ solution. WSA equals to the weight difference between the weight after a pre-set number of casting shots with soldering and without soldering.

\subsection{Evaluation of Washout}

Quantitative parameters are also needed to evaluate the washout resistance. Usually two major parameters were applied [19,30] and they are " Weight Loss of the pin (WL)" and " Dimension Reduction of the pin (DR)". A greater of WL and DR means a lower resistance to washout or more severe corrosive-erosive material losses of the test material for the same cycles. Sometimes the dimensional changes of the pin vary from location to location making it difficult to compare between pins. Therefore WL was selected to evaluate the washout resistance. WL equals to the weight difference before and after a pre-set number of shots with soldered aluminum cleaned by a strong $\mathrm{NaOH}$ solution. WL can be directly used to evaluate materials with the same or similar density. In order to evaluate materials with different density, WL is 
normalized to "Volume Loss of the pin (VL)" by being divided by the density of the test material. Greater values of VL show a lower resistance or more severe washout tendency of the material for the same cycles.

\subsection{Examination of Test Pins}

All the core pins were visually examined during the testing cycle. Optical photographs were taken of the surface of pins facing the gate. The percentage of area soldered with aluminum was measured after a pre-set number cycles using a computer image analysis system. A $50-70^{\circ} \mathrm{C}$ $50 \%-60 \% \mathrm{NaOH}$ solution was used to remove the soldered aluminum. The WSA and WL were measured using a Mettler AE 240 electron balance that can be read to $0.00001 \mathrm{~g}$ and is accurate within $0.0001 \mathrm{~g}$. WL was divided by density to calculate the VL. Before measuring, the pins were cleaned with methanol and ethyl alcohol and dried with a heat gun. Cross-sections of some pins were metallographically examined in the areas where most soldering was evident, using a S450 Hitachi scanning electron microscope.

\subsection{Evaluation of Thermal Fatigue [32-36]}

The standard thermal fatigue specimen used in the evaluation of relative behavior of die materials has been employed successfully for this purpose for 25 years. The specimen is processed to the dimensions shown in Figure 5. It has been used to evaluate a large number of potential die materials for aluminum die casting dies. It is $2 \times 2 \times 7$ inch rectangular parallepiped specimen with a 1.5 inch diameter hole in the center for internal water cooling. The test produces considerable constraint and high thermal fluctuations during immersion and removal from the 380 alloy bath. The equipment used for the immersion is illustrated in Figure 
5. The four corners have a constant 0.010 inch radius that intensifies the predominately uniaxial stress at this location. The outer surface of the specimen is sprayed with a commercial waterbase lubricant just before it enters the molten aluminum bath. Water flows through the central hole at a constant rate of 85 gallons per minute. The molten bath is maintained at $1350^{\circ} \mathrm{F}$ and the specimen is immersed for 12 seconds and then removed from the bath for 22 seconds to produce the thermal cycle shown above.

The standard procedure is to operate the test for 5,000 immersion cycles, measure the cracking pattern and follow this method for 10,000 and 15,000 total cycles. Since the maximum temperature that is attained is at the corner or edge of the immersion specimen and the stress state is uniaxial at the edge, thermal fatigue cracks initiate at the corner and then propagate internally. The cracking pattern is characterized by two parameters, the average maximum crack length $L_{a}$ and the total crack area $A_{t}$ to evaluate the thermal fatigue behavior of the specimens. The average maximum crack length is the average length of the longest crack of each of the four corners within the middle three inches of the corners. The total crack area is the sum of the product of the number of cracks in each 100 micron size range and the square of the midpoint of that range for all the four corners within the middle three inches of the corners. The more severe the crack pattern and the lower the thermal fatigue resistance of the tested material. The results of this test have correlated closely with the behavior of dies in industry. 


\subsection{Evaluation of Coatings}

A number of commercially available coatings were evaluated. All these diffusion, PVD and CVD coatings are used to combat soldering and washout in die casting. A list of the coating included in the study and their respective thickness is shown in Table 4.

Table 4: Types of coating tested and their relative thickness.

\section{Type of Coating}

B-thin

U-thick

D-thin

D-thick

$\mathrm{CrN}$

PVD CrC

PVD CrN + W

PVD (TIAI)N
Thickness of coating in microns

50

165

50

100

5.0

6.25

3.5

2.0 


\subsection{RESULTS AND DISCUSSION}

\subsection{Potential Superalloys for Use as Die Materials}

Nickel based superalloys have superior high temperature strength and yield strength retention properties and should have the potential of reducing the amount of cracking and extend die life. This section examines the properties of Inconel 718 and several closely related nickeliron superalloys for potential improved resistance to heat-checking relative to $\mathrm{H}-13$.

The second most prevalent method of failure in die casting dies is the soldering that results from a reaction between molten aluminum and iron. This process produces $\mathrm{Al}_{5} \mathrm{Fe}_{2}$ and other intermetallics . The rate of solder formation is determined by the rate of diffusion of iron and aluminum atoms through the intermetallic layer [3]. There are two competing processes which control the soldering process. One is the rate of intermetallic layer growth and the other is the rate of its dissolution in the liquid aluminum. These two processes will not necessarily have the same temperature dependency. If the rate of dissolution exceeds the rate of growth, then the surface of the die can recede rapidly. This phenomenon, known as "washout" has been discussed in the previous sections and it appears to accelerate in alloys of high nickel content.

The iron base H-13 alloy forms a native film composed of the oxide, magnetite, that provides protection against further dissolution and solder formation [4]. This magnetite $\left(\mathrm{Fe}_{3} \mathrm{O}_{4}\right)$ film is much more protective than the $\mathrm{NiO}$ or $\mathrm{CoO}$ that forms on most nickel and cobalt containing superalloys. However, if the temperature of a H-13 die surface exceeds $1050^{\circ} \mathrm{F}$, then the oxide $\mathrm{FeO}$ forms at the metal interface and the rate of soldering increases dramatically. The 
relationships between alloy composition and protective oxide formation are discussed for several candidate superalloys, and a few preliminary recommendations are offered.

\subsubsection{Heat-Checking Resistance}

Superalloys were primarily developed to provide functional strength at high temperatures for use in gas turbine engines. Eventually, the development of vacuum-melted, $\gamma$ '-strengthened nickel-base alloys developed during the 1950-1970 time frame displaced the cobalt base alloys which lack a comparable precipitation hardening mechanism. The cobalt alloys rely on solid solution strengthening from molybdenum and tungsten additions, and lack the high temperature strength retention provided by $\gamma^{\prime}$ strengthening.

Precipitation-strengthened alloys containing substantial quantities of both nickel and iron form another distinct class of superalloys, and include the important commercial tooling alloy Inconel 718. These alloys retain their strength to temperatures near $1200^{\circ} \mathrm{F}$, which is an important attribute for die casting applications. Inconel 718 has proven to be quite resistant to heat-checking in the CWRU thermal cycle test. Unfortunately, Inconel 718 can be severely attacked by molten aluminum as illustrated in Figure 6. The problem appears to be related to nickel dissolution and the lack of a protective film to prevent the attack., thus other nickel base alloys could also be susceptible to washout corrosion. The purpose of this discusion is to examine alternate nickel-iron compositions that might be more resistant to corrosion, but still maintain the same level of resistance to heat-checking as Inconel 718. 
Table 4 presents the nominal compositions for each of the alloys considered in this discussion. The baseline $\mathrm{H}-13$ alloy contains 5\% chrome and a little molybdenum to provide solution hardening. Vanadium is also added to provide some solid solution strengthening and this element combines with other carbide formers to provide for a good dispersion of carbides in the martensitic structure. H-13 can be heat treated to strengths in excess of $300 \mathrm{ksi}$, with reasonably good ductility and impact strength.

Inconel 718 is a niobium hardened nickel-chromium-iron alloy. The main strengthening effect comes from a body centered tetragonal coherent precipitate of composition $\mathrm{Ni}_{3} \mathrm{Nb}$, called $\gamma$ ”. This alloy has excellent welding characteristics and good tensile, creep, fatigue, creep rupture properties. If the alloy is heated above $700^{\circ} \mathrm{C}, \gamma$ " transforms into an orthorhombic precipitate of the same $\mathrm{Ni}_{3} \mathrm{Nb}$ composition (called delta phase). The delta phase is invariably incoherent and does not confer the same strength as $\gamma$ ”. Inconel 706 has essentially the same hardening mechanism as Inconel 718 and exhibits similar properties to Inconel-718, but with improved machinability.

Incoloy 901 is another nickel-iron-base superalloy designed for high strength and corrosion resistance in the temperature range $1000-1400{ }^{\circ} \mathrm{F}$. This alloy is hardened by the precipitation of coherent $\mathrm{Ni}_{3}(\mathrm{Al}, \mathrm{Ti})$ precipitates. This precipitate phase is also considered to be $\gamma^{\prime}$. The scaling resistance of Incoloy 901 is slightly less than that of an AISI type 310 stainless steel. Alloy 909 is another iron rich superalloy that contains cobalt, but is strengthened by $\gamma^{\prime}$ precipitates. It has an unusually low thermal expansion coefficient as a result of eliminating the 
ferrite-stabilizing elements. The high temperature oxidation resistance of this alloy is somewhat questionable, however, because of the lack of chrome additions.

A-286 is another $\gamma^{\prime}$ precipitation hardening autsenitic Fe-Ni-Cr steel with good high temperature strength properties up to $1300^{\circ} \mathrm{F}$. This alloy offers high ductility in notched sections. The oxidation resistance is equivalent to that of an AISI type 310 stainless.

Analytical studies suggest that the most important variable in resistance to heat-checking is hot yield strength [2]. Figure 7 shows how yield strength declines with increasing temperature for Inconel 718, H-13, and several other superalloys. It is very important for the die to have the highest possible resistance to yielding in the temperature range between 1000 to 1200 ${ }^{\circ} \mathrm{F}$. Temperatures of this magnitude are achieved in the surface layers of the die at the same time the highest compressive stresses develop as a result of contact with molten aluminum during the injection phase of the die casting cycle. Compressive stresses can reach values of the order of $120 \mathrm{ksi}$ at the peak temperature, or even higher if the die is in an initial state of residual compression. The stresses then reverse and become tensile during the cool-down portion of the cycle. The maximum tensile stresses occur when the die is about $700{ }^{\circ} \mathrm{F}$, and again, a high yield strength is needed to prevent plastic deformation from occurring. On the basis of the yield strength curves presented in Figure 7, it would appear than Inconel 718 should provide the best resistance to heat checking. A relative order of ranking suggests that: IN-718 > Incoloy $909>$ IN-706 > Incoloy $901>\mathrm{H}-13>$ A286. The H-13 alloy exhibits comparable strength to the superalloys at $700{ }^{\circ} \mathrm{F}$ and is stronger than Incoloy 901 and A 286 at this temperature. The iron 
base A-286 alloy retains a high fraction of its room temperature strength between 1000 and 1200 ${ }^{\circ} \mathrm{F}$, but it is not as intrinsically strong as the other alloys.

Thermal conductivity is another important consideration in heat-checking resistance. The stresses that develop in the surface layers of the die, where the damage occurs, are a result of the thermal gradients between the surface of the die and the interior cooling channels. A high conductivity enables the die to disperse the heat better and this reduces the magnitude of the gradients. The thermal conductivity's of the six alloys are compared in Figure 8. Only one data point was found for Incoloy 909. The temperature dependency of this alloy should be similar to Incoloy 901 . H-13 has a significantly higher thermal conductivity than the superalloys. This advantage helps to offset its lower high temperature yield strength. The five superalloy compositions exhibit very similar properties with the slightly higher values corresponding with the higher iron contents. Accordingly, IN-718 exhibits the lowest thermal conductivity of the group.

Another property of importance is thermal expansion. The stresses that develop in dies are a product of the thermal gradient and the linear expansion. If the die material has a very low thermal expansion, it will experience a lower stress. A curve of percent linear expansion as a function of temperature for the six alloys is shown in Figure 9. Incoloy 909 has the lowest thermal expansion value of all the alloys. Only one data point was found for this alloy, but the curve is expected to have the same temperature dependency as Incoloy 901. H-13 has the next lowest expansion and A-286 exhibits the highest expansion. The other alloys are intermediate between A-286 and H-13. 
Elastic modulus can be another factor in heat-checking resistance, but it is not, perhaps, as important as the other three discussed above. A higher modulus will yield a higher stress level for the same thermally induced strain. The temperature dependent elastic moduli for five of the six alloys are shown in Figure 10. No data was found for Incoloy 909. The differences between alloys are not large. H-13 exhibits a larger decline in modulus as a function of temperature, but has the highest value at $700{ }^{\circ} \mathrm{F}$ where the tensile stresses reach their maximum values.

A qualitative evaluation of Heat Checking Resistance, HCR, is shown in Table 5. The evaluation criteria include yield strength (YS), thermal expansion (CTE), thermal conductivity (TC), and elastic modulus (E). More credit was given to hot yield strength and less to elastic modulus. On this basis, Inconel 718 and Incoloy 909 were judged to have potentially the best resistance to heat-checking with Inconel 706 a very close third. H-13 would be fair to marginal and A-286 would be considered poor. Thermal fatigue tests performed at Case Western Reserve University, CWRU, reported H-13 to be significantly better than A-286 [5]. Recent tests at CWRU have found IN 718 to be very resistant to heat-checking and perhaps better than high quality, and optimally heat-treated H-13. 
Table 5: Qualitative Ranking of Heat Checking Resistance

\begin{tabular}{|l|l|l|l|l|l|}
\hline Alloy & YS & CTE & TC & E & HCR \\
\hline H-13 & F-P & F-G & G & F-P & F \\
\hline Inconel 706 & F-G & F & F-G & F & G \\
\hline Inconel 718 & G & F & F & F & G \\
\hline A-286 & P & P & F-G & F & P \\
\hline Incoloy 901 & F & F & F & F & F-G \\
\hline Incoloy 909 & F-G & G & F-G & F? & G \\
\hline & & & & & \\
\hline
\end{tabular}

$\mathrm{G}=$ Good, $\mathrm{F}=$ Fair, $\mathrm{P}=$ Poor

\subsubsection{Soldering Resistance}

Thermal fatigue tests performed at CWRU have revealed that Inconel 718 is attacked much more severely by molten aluminum than $\mathrm{H}-13$ under essentially identical conditions as illustrated in Figure 1. Experimental tests performed by Fraser and Jahedi [4] revealed that when the oxide magnetite, i.e. $\mathrm{Fe}_{3} \mathrm{O}_{4}$, was formed on $\mathrm{H}-13$ by steam tempering, it prevented the formation of intermetallic phases to a great extent. When other oxides of iron, e.g. FeO and $\mathrm{Fe}_{2} \mathrm{O}_{3}$, were present, the steel surface was much more susceptible to soldering. The oxide wustite or $\mathrm{FeO}$ can only form on iron alloys at temperatures in excess of $1050^{\circ} \mathrm{F}$. Field observations of commercial dies confirm that excessive soldering begins to occur at or above this 
temperature in conjunction with the development of nonprotective FeO films. X-ray diffraction measurements made on commercial dies have shown that $\mathrm{Fe}_{3} \mathrm{O}_{4}$ will fortunately be favored under most die casting conditions. This oxide will develop at temperatures below $1050^{\circ} \mathrm{F}$, and in the presence of the steam like conditions that envelope die casting machines, but the initial density and adherence of the film are probably not optimum.

In nickel base alloys or alloys with high nickel content, the monooxide, $\mathrm{NiO}$, is often the predominant film, but unlike FeO, nickel oxide can develop at relatively low temperatures. It is concluded, therefore, that the poor soldering resistance exhibited by Inconel 718 is most likely due to the development of a nickel oxide film, which provides little or no protection from molten aluminum.

In order to examine this possibility further, thermochemical calculations were made with the HSC chemistry software [6] to determine the equilibrium oxides. Preliminary calculations revealed very little or no temperature dependence over the range of interest up to $1050^{\circ} \mathrm{F}$, but a very strong oxygen dependency. The calculations for H-13 and IN 718 , at a temperature of $450^{\circ} \mathrm{C}\left(842{ }^{\circ} \mathrm{F}\right)$, are presented in Figures 11 and 12 for comparison. These computations basically involve the reaction of one mole of alloy composition with up to one mole of oxygen, $\mathrm{O}_{2}$. The HSC software does not account for adjustments in activity due to solution of the various elements in the base alloy. In order to compensate for this shortcoming, adjustments were made to the activity coefficient's based on the thermodynamic data reported by Mazandarany and Pehlke for Ni-Cr, Fe-Cr, and Ni-Fe-Cr alloys. [7]. 
In Figure 11, it can be seen that magnetite, $\mathrm{Fe}_{3} \mathrm{O}_{4}$, is favored at low oxygen content and $\mathrm{Fe}_{2} \mathrm{O}_{3}$ is favored at high oxygen content for $\mathrm{H}-13$. These results are consistent with the findings of Fraser and Jahedi [4]. When $\mathrm{H}-13$ is oxidized in air at $1000^{\circ} \mathrm{F}$, the predominant oxide is $\mathrm{Fe}_{2} \mathrm{O}_{3}$, but when the steel is oxidized in steam, consisting of a reduced partial pressure of oxygen, $\mathrm{Fe}_{3} \mathrm{O}_{4}$, is formed. Fortunately, the steam atmosphere generated in die casting operation when water is used to cool the surface of the dies favors the reformation and repair of the magnetite film. The corresponding calculation for In 718 show that $\mathrm{NiO}$ is the predominant film except at very low oxygen amounts where $\mathrm{Cr}_{2} \mathrm{O}_{3}$ and a magnetite like spinel of composition $\mathrm{FeCr}_{2} \mathrm{O}_{4}$ might be favored, see Figure 6 .

The actual morphological of development of oxide scales on nickel- iron alloys show a layered structure [8]. The outermost layer consists of a two-phase mixture of nickel oxide, i.e. $\mathrm{NiO}$ and a nickel oxide spinel. Underneath this is a single phase layer of nickel oxide, NiO. Finally, there is an internal oxidation zone containing spinel precipitates.

The oxidation behavior of nickel-chromium alloys has been extensively studied at high temperatures. When the chromium concentrations were between 5 and 30 percent, external scales of chromia, $\mathrm{Cr}_{2} \mathrm{O}_{3}$, are formed over alloy grain boundaries while internal $\mathrm{Cr}_{2} \mathrm{O}_{3}$ precipitates and external scales of $\mathrm{NiO}$ are formed at other areas of the alloy surface [9]. Under the oxidizing conditions employed, which were performed at an atmosphere of 0.1 atmosphere of oxygen, lateral diffusion of chromium occurred from those areas covered with a continuous layer of $\mathrm{Cr}_{2} \mathrm{O}_{3}$ to areas where a subscale was present. For alloys with chromium concentrations 
equal to or greater than 30 percent, chromia formed as a continuous layer over the entire alloy surface, and the oxidation rates were controlled by diffusion through the $\mathrm{Cr}_{2} \mathrm{O}_{3}$ film

On the basis of these observations, it would appear that the goal for protecting $\mathrm{Ni}-\mathrm{Cr}$ and Ni-Cr-Fe alloys is to grow a continuous scale of $\mathrm{Cr}_{2} \mathrm{O}_{3}$. The conditions that favor chromia films are low $\mathrm{PO}_{2}$ and high chrome concentrations in the alloy that exceed 30 weight percent. When the concentration in IN-718 is arbitrarily increased from 19 to $30 \mathrm{w} / \mathrm{o}$, the equilibrium amount of $\mathrm{Cr}_{2} \mathrm{O}_{3}$ increases by about $50 \%$, as shown in Figure 7. It is interesting to note that a slightly higher oxygen amount is needed to start $\mathrm{NiO}$ formation at the higher chrome level.

It would probably be impractical and uneconomical to commercially produce an Inconel alloy with such a very high chrome content. However, it may be possible to chromize the surface of the alloy by applying a pack diffusion coating [10]. This was done by pack cementation on $\mathrm{H}-13$ with good results [11]. A protective adherent coating of $\mathrm{Cr}_{23} \mathrm{C}_{6}$ was formed. There is sufficient carbon in H-13 to support the formation of chrome carbide, but in Inconel, a dual pack process to add carbon or a second gas phase carburizing treatment would be required. In addition, the temperatures required for these operations would be in the range where the undesirable delta phase could form and degrade the properties of the base alloy.

If the chrome content in the outer layers of an Inconel 718 die can't be increased by a pack diffusion process or by laser alloying, which is another high temperature process, then the formation of a continuous chromia coating must be accomplished at a low oxygen partial pressure. This would have to be performed at the highest temperature possible consistent with 
maintaining the integrity of the desired precipitate microstructure. If this option, or other coating alternatives discussed later, is not viable, then alternative alloys with more favorable oxidation characteristics will have to be considered.

The equilibrium oxide amounts for Inconel 706, and Incoloy alloy 901 are shown in Figures 8 and 9 respectively. Inconel 706, see Figure 8, has a higher iron content than Inconel 718 and this promotes the formation of magnetite and $\mathrm{FeCr}_{2} \mathrm{O}_{4}$ along with $\mathrm{Cr}_{2} \mathrm{O}_{3}$ at low oxygen amounts. The oxygen range below which NiO will not form is much larger than for In 718 . Incoloy 901, which is shown in Figure 15, is very similar to Inconel-706. It is possible that steam tempering of these two alloys will produce a protective magnetite layer supplemented by a complimentary spinel phase. It is very difficult to produce a continuous spinel oxide because the oxide structure requires specific lattice locations for the cations. X-ray diffraction analysis of the magnetite on $\mathrm{H}-13$ suggests that the main film is $\mathrm{Fe}_{3} \mathrm{O}_{4}$ with $\mathrm{Cr}$ cations occupying partial spinel sites. The combined amounts of these two equilibrium phases may be enough to provide a completely protective layer in the case of Inconel-706 and Incoloy 901.

The equilibrium oxide that forms on Incoloy 909 at low oxygen amounts is $\mathrm{Fe}_{3} \mathrm{O}_{4}$ as shown in Figure 16. This alloy is not known for good high temperature oxidation resistance, but if a continuous layer of magnetite can be formed, perhaps initially by steam tempering, this oxide film might provide the necessary degree of protection under die casting conditions. When exposed to higher oxygen amounts, the formation of $\mathrm{NiO}$ and $\mathrm{CoO}$ are favored along with nickel ferrite, $\mathrm{NiFe}_{2} \mathrm{O}_{4}$. The formation of the monoxide's in a two phase mixture with nickel ferrite can be expected to degrade the protective nature of the oxide film. 
One of the significant differences between equilibrium calculations of alloy mixtures and the oxidation of an alloy surface exposed to oxygen from one side is the formation of layered structures, which in turn can influence the diffusion of both anions and cations and, thereby, affect subsequent formation and growth. When an adherent magnetite film forms on and iron base alloy, it will restrict to some extent the diffusion of iron to the oxide/gas interface and this will also favor the formation of $\mathrm{Fe}_{3} \mathrm{O}_{4}$. The most reduced oxide is thermodynamically favored at the metal/oxide interface.

When the temperature exceeds $1050^{\circ} \mathrm{F}$, the formation of the $\mathrm{FeO}$ phase becomes thermodynamically favored, see Figure 17, on high iron content alloys and will take oxygen away from the $\mathrm{Fe}_{3} \mathrm{O}_{4}$ layer to sustains it's development at the oxide/metal interface. The protective nature of the oxide film against attack by molten aluminum is quickly destroyed. However, when nickel is added to the iron, it will significantly reduce the stability range of wustite, which discourages $\mathrm{FeO}$ formation. In addition, if nickel ferrite , $\mathrm{NiFe}_{2} \mathrm{O}_{4}$, forms, it can reduce the rate of iron self-diffusion to the oxide/gas interface(12). This could help slow down oxidation at the oxide/gas interface, and help maintain the stability of the magnetite protective layer. These factors underscore the benefits of preoxidizing these superalloy compositions with the intent of providing the most protective surface at the very beginning of operation.

There are potential advantages to forming a native oxide protective film as opposed to an external coating of some other compound. As shown in Figure 9, magnetite exhibits a very good thermal expansion match with iron base alloys and this enables the film to expand and contract 
with base material and thereby remain adherent. Perhaps the greatest advantage, however, is the self healing characteristics. Virtually no coating, grown or applied, remains continuous without breaks flaws and defects. The ability to self repair during service is a distinct advantage. The oxygen dependency of the favored oxide forming compounds must somehow be maintained. Fortunately, the steam like atmosphere created in the die casting operation favors the formation of magnetite on ferritic steels. This condition could be greatly enhanced by using nitrogen as a cover gas. If the partial pressure of oxygen can be kept to a low level at the surface of the die, then $\mathrm{Fe}_{3} \mathrm{O}_{4}$ and $(\mathrm{Fe}, \mathrm{M})_{3} \mathrm{O}_{4}$ spinels will be favored.

\subsection{Test Pin Evaluation}

After a number of shots, a few of the following changes were usually noticeable (1) soldering on pin surface (2) washout on pin surface (3) pin breakage (4) pin elongation. After only three shots, the copper-based alloy showed severe washout and soldering. It broke during ejection due to material loss caused by the very high solubility of copper in molten aluminum, as illustrated in Fig.18. The gray cast iron also broke during ejection of the casting after the third cycle due to its low strength and ductility. This pin is also shown in Fig.18. These two materials were not investigated any further since they were deemed unsuitable as die materials in aluminum die casting. Severe soldering and washout were found on the pin surface of the IN-718 alloy and the soft H13 after several shots. Minimal soldering and washout occurred in Mo785, Ti-6Al-4V and Anviloy1150, as shown in Fig. 19. A change in length was noticeable in soft H13 and IN-718 alloys after 30 shots. No elongation of the pins occured in standard H13, Mo-785, Ti-6Al-4V and Anviloy1150 alloy due to their high thermal strength and higher soldering resistance. 


\subsection{Soldering Results}

The development of soldering on pin surface of some metal materials is shown in Fig.20. Soldering developed very fast on the surface of the IN-718 alloy pin. The entire surface of the pin showed severe soldering damage after only 10 shots. Soldering developed relatively slowly in Mo-785 alloy, Ti-6Al-4V and Anviloy1150. Soldering development has an initiation stage. After the initiation stage of a few shots, soldering developed very fast in soft and hard-H13 but still slowly in Mo-785, Ti-6Al-4V and Anviloy1150. According to the PAS measurements, Anviloy1150 had the best soldering resistance, followed by Ti-6Al-4V, Mo-785, hard-H13, softH13 and IN718. Fig.20 shows the Weight of Soldered Aluminum of some alloys after 50 shots. It shows the same soldering tendency as PAS. Similar results are reported in the literature [40]. The use of this system and the Percentage of Soldering Area and Weight of Soldered Aluminum variables to evaluate soldering resistance of die materials is therefore supported by similar studies.

Based on these experiments, soldering occurs not only when an intermetallic layer is formed at the interface of the casting/die, such as on the pin surfaces of IN-718, H13. It also occurs in the absence of an intermetallic layer, such as on the pin surfaces of Anvilloy1150 and Mo-785, as illustrated in Fig.20. It is therefore reasonable to conclude that soldering does not necessarily depend on the formation of an intermetallic layer at the casting /die interface. Soldering can be described as a strong bonding between casting and die surface [29]. Chemical or metallurgical reactions, mechanical interlocking or keying, physical adhesion, and diffusion phenomena all contribute to strong bonding [31]. If the bond strength is higher than the casting, the detachment 
of the casting and the die will occur on the side of the casting during ejection, leading to soldering. If the bonding strength is less than that of the casting, the detachment will occur at the interface, and less soldering or no soldering will occur. The strength of the bond depends on the bonding type and the bond area. Those in turn depend on the composition, temperature and die surface conditions [41]. Usually, a high bond strength results from the formation of intermetallic layers between casting and die surface. The mechanical keying is caused by molten aluminum penetrating surface defects in the die surface such as machining marks, cracks, pits and holes. Physical adhesion is due to the atomic affinity between the cast metal and the die-material. Normally, soldering is promoted by a high die surface temperature. Also, by a long contact time between the molten metal and the die surface.

For the first few shots, the bonding between the casting and pin surface is weak. No chemical reaction, mechanical interlocking and physical adhesion can occur due to the "protective" action of surface oxides and oil. After a few shots, the molten aluminum alloy will come in direct contact with the pin material. By then, the impinging jet of molten aluminum alloy will have removed any oxides and contaminants from the surface. The pin surface is heated to a relatively high temperature. This creates favorable conditions for forming high strength bonding between the molten aluminum and the surface of the pin. Metallurgical bonding forms in pins made of iron base and nickel base alloys due to the formation of intermetallic layers by diffusion [27]. Formation of the intermetallic layers for these pins leads to severe soldering on pin surface. On the other hand, no intermetallic phases are formed in tungsten and molybdenum alloys. Consequently, less soldering occurs in materials such as Anvilloy1150 and Mo-785. When it does occur, soldering originates from mechanical interlocking, diffusion and atomic attraction. The mechanical interlocking is exacerbated by surface roughness and wetting. Diffusion 
phenomena were confirmed by EDAX analysis of the interface, close to the soldering side. In the case of Ti-6Al-4V there is an intermetallic layer at the interface between the pin and the soldered aluminum but the soldering is minimal as illustrated in Figs. 21 and 22. According to SEM observations, there is a separation between the soldered aluminum alloy and the intermetallic phase. This indicates the bonding between the intermetallic layer and the soldered aluminum alloy is weak. Therefore, the intermetallic layer acts as a "protective" layer to reduce the soldering tendency. This finding is also confirmed by Mihelich et al [32] and Sujata et al [33].

Several steps can be taken to reduce or stop the soldering. The chemical bond strength can be reduced by preventing the formation of intermetallic layers. Decreasing die temperature and using better die lubricants will act in this direction. Changing die material by using Anviloy1150 instead of tool steel and coating the die surface with a PVD, CVD coating or diffussion layer is also a means to this end. The mechanical bonding can also be reduced by lowering the surface roughness, using better die lubricant, reducing die surface temperature and pouring temperature.

\subsection{Washout Results}

Due to the different density of IN-718, H13, Ti-6Al-4V, Mo-785 and Anviloy1150, Volume Loss was used to evaluate washout. The typical appearance of washout damage in hard-H13 is shown in Fig.23. In this case, the soldered aluminum was cleaned with a $\mathrm{NaOH}$ solution. Based on the Volume Loss, Anviloy1150 had the best washout resistance, followed by Ti-6Al4V, Mo-785, Hard-H13 and Soft-H13 and IN-718 as illustrated in Figures 24-25. The high Volume Loss of Ni-base alloy is primarily due to the high solubility of nickel in liquid aluminum. The washout of $\mathrm{H13}$ in aluminum die-casting is caused primarily by erosive 
enhanced corrosive wear. This mechanism is manifested in the smooth surface observed in the area impinged by the molten metal stream (see Fig.23). Anviloy1150, Mo-785 and Ti-6Al-4V have very good washout resistance due to their high corrosion-erosion resistance in molten aluminum. In aluminum die-casting, the die surface is exposed to an impinging jet of molten aluminum. This results in washout of die material due to chemical corrosion and physical erosion. Corrosion results from the fact that tool steels and a few other alloys dissolve in liquid aluminum [19,27]; the high pouring temperature may cause oxidation of the die surface. Erosion is caused by the impingement of the molten metal onto the surface. Other contributors to erosion are cavitation and wear due to the high velocity motion of the molten aluminum (the gate velocity usually reaches to 20-60 m/s) [30]. The concepts of "Erosion-Enhanced Corrosion" or "Corrosion-Affected Erosion" in flowing fluids [36] can be used to describe the washout mechanism in aluminum die-casting. These two concepts refer to any synergy between corrosion and erosion, such that the result of material loss rates is greater than the sum of the individual processes. According to Coulon [35], the corrosion-erosion mechanisms in the presence of flowing fluids can be categorized by the velocity of the flow causing them: Pure corrosion occurs at velocities up to $10 \mathrm{~m} / \mathrm{s}$; Erosion-enhanced corrosion between $10-50 \mathrm{~m} / \mathrm{s}$; Corrosionaffected erosion at 50-200m/s. Pure erosion occurs at velocities higher than $200 \mathrm{~m} / \mathrm{s}$ depending on the material, temperature, as well as geometry factors.

Based on the impinging velocity in aluminum die-casting, the mechanism of washout can be separated into two regimes - "Erosion-Enhanced Corrosion (EEC)" and " Corrosion-Affected Erosion (CAE)". Erosion-enhanced corrosion prevails when the impinging velocity is not high enough to damage the die substrate. Under these circumstances, the mechanical damage zone is 
confined within the intermetallic layers or other layers (such as die lubricant layer and oxide layer). The materials loss rates are dominated by corrosion. Impingement increases die washout rates because erosion removes the intermetallic layer or other protective layers and therefore increases the corrosion rate. Corrosion is controlled by diffusion of atoms from the die materials into the aluminum alloy. Spallation of the intermetallic layer and the oxide layer can also be involved in EEC. Corrosion-affected erosion occurs when the impinging velocity is high enough to cause the mechanical damage in the intermetallic layer and in the die material itself. The material loss rates in CAE are dominated by erosion and are increased by exposing the bare die surface repeatedly to corrosion. In CAE, the intermetallic layer is fully damaged by molten aluminum jet stream, thus thick intermetallic layers cannot survive. If CAE occurs, plastic depression/ deformation should be found in the impinging area of die surface [20].

The thickness of the intermetallic layer in hard-H13 is thinner in the impinged area than in the back area without impinging. This demonstrates that an impinging jet erodes the intermetallic layer and results in a thinner intermetallic layer. This causes higher washout rate in the impingement zone of the H13 pin. These results agree with Shivpuri et al [30] who showed higher rotating velocities leads to thinner intermetallic layer. This finding can be fully explained by EEC. No CAE occurs in our experiment due to low impinging velocity $(6 \mathrm{~m} / \mathrm{s})$. No CAE occurs even with impinging velocities as high as $50 \mathrm{~m} / \mathrm{s}$ [20]. Actually, CAE should be avoided when the die is designed while EEC can not be avoided when tool steel is used as die material in aluminum die-casting. 
The mechanism of washout in aluminum die-casting can therefore be explained by "Erosion-Enhanced Corrosion" where washout rates are dominated by the corrosion rate (which is controlled by transport/diffusion atoms of die material and aluminum alloy). Erosion increases the washout rate by increasing the corrosion rate because erosion reduces or removes the intermetallic layer or other protective layers. This allows the molten aluminum to impinge directly on the fresh die surface without any protection layers. The low washout rate of Ti-6Al4V, Mo-785 and Anviloy1150 results primarily from their low corrosion rate in molten aluminum.

Several preventive methods can be used to reduce or stop washout damage in aluminum diecasting. Good design and materials selection of dies should avoid CAE and pure erosion or reduce them to the lowest level. Reducing corrosion can also be promoted by decreasing die surface temperature, better die lubrication, changing die material from tool steels to high corrosion resistant alloys (such as Anviloy1150, Mo-base alloys or Ti base alloys), and by die surface treating [36-38].

\subsection{Thermal Fatigue Results}

The thermal fatigue behavior of these pin materials are shown in Fig.27. The work shows that anviloy1150, Mo-785 and copper base alloy were the best. However, Ti-6Al-4V cracks more easily in thermal fatigue testing. IN-718 has no crack but with the corner dissolved. The good thermal fatigue resistance of copper base alloy results from its excellent thermal conductivity. The low thermal conductivity leads to the bad thermal fatigue behavior of Ti-6Al$4 \mathrm{~V}$. The extreme thermal fatigue resistance of anviloy1150, Mo-785 result from the combination 
of high thermal conductivity, small thermal expansion, and very high melting point temperature (this will result in very high softening resistance at the tested temperature).

\subsection{Relationship Between Thermal Fatigue, Soldering and Washout}

As already been pointed out that soldering results from strong interface bonding between die and casting due to the formation of intermetallic layers, severe mechanical interlocking and physical adhesion while washout is usually caused by erosion-enhanced corrosion. Therefore it is difficult to say which leads to which. But severe soldering and severe washout usually occur together. For example, the affinity of aluminum atoms and most of the die material atoms will results in both severe soldering and washout due to the formation of high strength bond and high corrosion rate. The high die surface temperature, as well as the high impinging velocity, may also cause both severe soldering and washout. Coating protected die with high surface roughness will probably get severe soldering after several shots but is not likely to get severe washout if the hard coating is not been worn off.

Usually, soldering is a short-term phenomenon because soldering will form as soon as the die surface is heated up to form strong bond. On the contrary, washout is a long-term thing and obvious washout is not likely to occur before the formation of the soldering because the damage of "erosion enhanced corrosion" caused by the diffusion of atoms needs time. However, soldering and washout need to be controlled for extending die life and getting high quality casting by better die design, optimized casting processing, better cooling, better die lubricant, better die materials and good surface treating. 
Thermal fatigue will lead to cracking on the die surface. The crack will increase the roughness of the die surface. The increased surface roughness will increase the tendency of soldering and washout. However, there is no intrinsic relationship between thermal fatigue, soldering and washout.

\subsection{Performance of Protective Coatings}

The next group of materials tested were those with nitrided and nitro-carburized surfaces. Figures 27-30 shows the typical thin and thick diffusion layers in these nitrided and nitro-carburized materials. The micro-hardness distribution is also shown and clearly identifies the transition from the diffusion layer to the substrate. Figures 31-32 shows the overall effect of the nitriding and nitro-carburizing treatments on the resistance of the material to soldering built up. While all the coatings outperformed the uncoated H13 in terms of resistance to soldering they seem to provide the same level of protection. Figures 33-35 illustrate the effects of nitriding and nitro-carburizing treatments on the washout of the different coatings after a large number of shots. These diffusion coatings increase the resistance of the H13 to soldering and washout. The thicker coatings last longer and provide better protection from washout but may initiate thermal fatigue cracking. This conclusion is based on the presence of long cracks in the thicker coatings, as shown in Figure 38. This type of cracks were not found in the thinner coatings. However, thinner coatings show larger areas where the coating has been completely removed and washout of the substrate has occurred, as seen in Figures 36, 37. The overall behavior of the coating in thermal fatigue is illustrated in Figures 40, 41. Based on this evaluation, the following conclusions were reached: 
o Nitro-carburizing improves somewhat the resistance of $\mathrm{H} 13$ pins to soldering (sticking of Al) but does not prevent it.

o Nitro-carburizing improves significantly the resistance of H13 pins to washout (loss of base metal).

o Thick nitro-carburized layers provide better resistance to washout. However, they tend to crack more readily than thin coatings.

o Thick nitro-carburized coatings are desirable in “soldering intensive” applications; thin nitro-carburized coatings may be desirable in "thermal fatigue intensive" applications that can induce cracking.

The final group that was tested were the H 13 pins PVD coated with various coatings for improved soldering and washout resistance. This group included $\mathrm{CrC}$ at 6.25 microns, $\mathrm{CrN}+\mathrm{W}$ at 3.5 microns, $\mathrm{CrN}$ at 5 microns and (TIAI)N at 2.0 microns. Table 6 shows the characteristics of the PVD coatings. Figure 42 illustrates the thickness of the coatings, shown here in a crosssection of the coated specimens. Figures $43-47$ show the appearance of the coated pins after increasing number of shots. Figures 48-49 show the effect of the coatings on the resistance to soldering. Figures 50-51 show the effect of the coatings on the resistance to washout. .It is noted from this group that the weight of soldered aluminum and washout of the pin was less for the $\mathrm{CrC}$ than the other coating materials. When these coatings were tested for longer periods, the CrC held up the best, as shown in figure 51. The relative washout resistance of the various 
coatings in figure 50 show that the $\mathrm{CrN}+\mathrm{W}$ as the second best coating. The $\mathrm{CrC}$ is a thicker coating than the others and is more likely to crack in thermal fatigue. Figures 52-58 show the damage to the coatings with increasing number of shots. The $\mathrm{CrC}$ coating shows least damage. Figures 60-65, 66-68 are scanning electron micrographs of the surface and cross-section of the coated specimens. They illustrate the failure mechanism of the coatings. Essentially, these coatings fail at defect sites, primarily pinholes in the coating. Once the aluminum penetrates under the coating, it starts undercutting it by dissolving the underlying substrate. The area of the damage increases gradually until the part by formation of new sites and coalescence of the damaged areas. The main conclusions from the evaluation of the PVD coatings are:

o The "thick" CrC PVD coating was the best performer among the PVD coatings evaluated so far.

o However, this coating is primarily recommended for small cores; It is more susceptible to thermal fatigue cracking than the thin coatings.

o The thin PVD coatings fail at surface imperfections in the substrate and at defect sites in the coating (pin-holes). Good coatings practices are essential in ensuring a high performance coating. 


\section{GENERAL CONCLUSIONS AND RECOMMENDATION FOR FUTURE WORK}

(1) An accelerated experimental arrangement and a testing procedure have been established to evaluate the soldering and washout resistance for aluminum die-casting.

(2) Percentage of soldering area with aluminum on pin impinging surface (PSA) and weight of soldered aluminum on pin surface (WSA) can be used accurately and conveniently for evaluating the resistance to soldering. Weight loss of pin (WL) or volume loss of pin (VL) can be used to evaluate the resistance to washout accurately and conveniently.

(3) Anviloy1150 has the best resistance to soldering and washout, followed by Mo-785, Ti-6Al4V, hard-H13, soft-H13, Ni718 and cast iron. Copper base alloy has the worst.

(4) Anviloy1150, Mo-785 and copper base alloy have the best thermal fatigue resistance while Ti-6Al-4V has very bad thermal fatigue behavior.

(5) The mechanism of soldering and washout has been proposed. Soldering results from strong bond between die and casting due to the formation of intermetallic layers, mechanical interlocking and physical attraction. Washout usually is caused by erosion-enhanced corrosion and dominated by corrosion rate. 


\subsection{Recommendations}

If Inconel 718 is to be used in aluminum die casting service, either a suitable protective coating system must be found or a protective native oxide must be developed.

\section{$\underline{\text { Potential Coatings for Inconel } 718}$}

The Thermo-Reactive Deposition and Diffusion , TRD, developed in Japan, and offered in the US by the Arvin TD Center in Columbus, Indiana is arguably the most successful commercial coating in use today for $\mathrm{H}-13$. The dies or inserts to be coated are immersed in a borax salt, typically $\mathrm{Na}_{2} \mathrm{~B}_{4} \mathrm{O}_{7}$, containing carbide forming elements such as vanadium, chromium, and niobium. These diffuse into the substrate and react with the carbon to form a dense adherent carbide protective layer. This works quite well for $\mathrm{H}-13$ which has a carbon content of 0.4 weight percent. Inconel 718 and most of the other candidate superalloys have carbon levels that are on the order of ten times lower, i.e. 0.04 weight percent, which is probably insufficient to support a continuous coating. In addition, this salt bath process is carried out at temperatures on the order of $1000-1050^{\circ} \mathrm{C}\left(1832-1922^{\circ} \mathrm{F}\right)$. Immersion times of $4-8$ hours are required for $\mathrm{H}-13$ to produce carbide layers of 5-10 microns in thickness. This type of exposure could transform $\gamma$ " precipitates into the delta phase with some degree of loss in mechanical properties. 
If TRD coatings are desired, a gas carburizing step would probably be required to precede the coating step in order to dissolve sufficient carbon into the surface layers. This is generally done at temperatures of $850{ }^{\circ} \mathrm{C}\left(1560{ }^{\circ} \mathrm{F}\right)$ and above in a gas atmosphere consisting of a carrier gas, e.g. Endogas, and enriching gas, i.e. methane $\left(\mathrm{CH}_{4}\right)$ or propane $\left(\mathrm{C}_{3} \mathrm{H}_{3}\right)$.

Inconel 718 and many other nickel-iron superalloy compositions contain sufficient chromium to directly form a chrome carbide coating on the surface. Yu, Rapp and Shivpuri have shown that a coating of $\mathrm{Cr}_{23} \mathrm{C}_{6}$ can be quite protective against molten aluminum.(11) Thus, a gas carburizing treatment would offer a straightforward method of coating high chromium containing superalloys. A chrome carbide surface coating might be expected to oxidize to form a healing layer of $\mathrm{Cr}_{2} \mathrm{O}_{3}$ at defective locations in the original coating if the oxygen partial pressure is maintained at a low level.

There are a variety of other commercial coatings that have been tried in aluminum die casting service with various degrees of success. However, there is no coating systems that has afforded complete protection from soldering attack and most fail quickly if the surface temperatures exceed $1050{ }^{\circ} \mathrm{F}$. All coatings have cracks, pinholes, or areas of incomplete coverage. The aluminum quickly attacks these sites and intermetallics form. There is a large volume expansion associated with the formation of the intermetallic phase and this disrupts or lifts the adjacent coating, thereby allowing further reaction to spread laterally across the surface. If the coating has no mechanism to repair itself or if the underlying die alloy cannot form a native coating to protect itself, then soldering will rapidly develop and washout may become a 
threat. This problem presents a significant challenge to all nickel or cobalt containing alloys and conditions that favor the formation of a nonprotective $\mathrm{NiO}$ and $\mathrm{CoO}$ scales.

\section{Forming a Protective Oxide on Inconel 718}

The equilibrium thermochemical calculations presented in Figure 6, suggest that $\mathrm{Cr}_{2} \mathrm{O}_{3}$ and $\mathrm{FeCr}_{2} \mathrm{O}_{4}$ will form on Inconel 718 at low partial pressures of oxygen. The growth of a continuous $\mathrm{Cr}_{2} \mathrm{O}_{3}$ film could be insured by increasing the chromium content near the surface of the die. This could be accomplished with a halide-activated pack cementation process (10). A pre-oxidation step at temperatures up to $1000^{\circ} \mathrm{F}$ and at a pressure of $0.1 \mathrm{~atm}$ oxygen would help develop a dense and adherent initial layer. The enriched chromium reservoir would also aid in repairing the protective layer in service. Even a thin continuous layer of chrome oxide will reduce the oxygen activity at the oxide/metal interface and discourage, if not prevent, the formation of nonprotective films consisting of $\mathrm{NiO}$.

\section{Alternative Alloys}

Three alternative nickel-iron alloys have been identified that could have the potential of being more corrosion resistant than Inconel 718. These include, Incoloy 909, which contains cobalt, and exhibits both high strength as well as low thermal expansion, Inconel 706, which is similar to Inconel 718, and Incoloy 901. All of these alloys have higher iron contents than Inconel 718 . As a result, they are more likely to form native protective magnetite or spinel scales at low oxygen partial pressures It is recommended that these three alloys be tested in the 
CWRU thermal cycle test to determine if they are equivalent in heat-checking resistance to Inconel 718.

\section{Preoxidizing the Alternative Alloys}

Figures 8 and 9 suggest that a mixture of $\mathrm{Cr}_{2} \mathrm{O}_{3}, \mathrm{FeCr}_{2} \mathrm{O}_{4}$, and $\mathrm{Fe}_{3} \mathrm{O}_{4}$ can form on Inconel 706 and Incoloy 901 at low oxygen partial pressures. These alloys should be preoxidized at temperatures up $1000{ }^{\circ} \mathrm{F}$ in $0.1 \mathrm{~atm}$ of oxygen prior to being placed into service. The goal is to develop a dense adherent protective oxide scale before contact with molten aluminum is initiated. A low oxygen partial pressure is required to prevent the formation of NiO. It may also become necessary to maintain a low oxygen activity during service by using a nitrogen cover gas so that the oxide scale can repair itself when damaged. The high nickel contents in these alloys should raise the critical temperature for wustitie $(\mathrm{FeO})$ formation which means that oxidation at higher temperatures may be possible.

Incoloy 909 has no chrome which precludes the formation of chrome containing scales. The equilibrium oxide at low oxygen partial pressure is expected to be $\mathrm{Fe}_{3} \mathrm{O}_{4}$ as shown in Figure 10. This alloy should also be preoxidized prior to service to enable a dense adherent magnetite film to form. The low $\mathrm{PO}_{2}$ range required to maintain stability of the magnetite film would probably necessitate that dies be run under a nitrogen cover gas to prevent the formation of nickel oxide. The high nickel content in the alloy should also raise the temperature required for FeO formation. 


\section{Coating the Alternative Alloys}

Neither Inconel 706 nor Incoloy 901 have sufficient chrome to develop continuous protective $\mathrm{Cr}_{2} \mathrm{O}_{3}$ films. It should be possible to chromize both of these alloys and then preoxidize them to obtain a continuous film as well as provide a reservoir of chrome to assist in repair of the oxide film during service. However, both alloys have sufficient chrome to support the formation of chrome carbides, e.g. $\mathrm{Cr}_{23} \mathrm{C}_{6}$, if subjected to a gas carburizing treatment. Both these processes could produce the delta phase in Inconel 706 and Incoloy 909, but not Incoloy 901.

A coating process that has enjoyed some success in the die casting of aluminum is nitrocarburizing. One form of this process, called Dyna Blue ${ }^{\mathrm{TM}}$ is offered by Dynamic Metal Treating, Inc. of Canton Michigan. Dyna Blue ${ }^{\mathrm{TM}}$ is a fluidized bed process that combines gas phase diffusion of nitrogen and carbon into the surface and then follows this up with a steam bluing step to produce $\mathrm{Fe}_{3} \mathrm{O}_{4}$. The fluidized bed nitrocarburizing step emphasizes nitrogen over carbon. However, there is no compelling evidence to support the idea that nitrides are more protective than carbides. There is evidence that the steam tempering of steels to produce a dense $\mathrm{Fe}_{3} \mathrm{O}_{4}$ layer can significantly improve soldering resistance(4). This suggests that the real advantage of the Dyna Blue process may be the formation of a protective magnetite layer. The hard carbo-nitride underlayer could also provide some additional resistance to erosion in areas of the die, e.g. gates, where the metal velocity is very high during the injection step. Thus, this coating process could be very useful for alloys like Inconel 706 , Incoloy 901, and Incoloy 909 because of their higher iron content. In effect, it is equivalent to a preoxidation step. They key 
to a good coating will probably require careful control of the oxygen partial pressure for these alloys. The fluidized bed nitrocarburizing step can be performed at temperatures below $1200^{\circ} \mathrm{F}$ $\left(649^{\circ} \mathrm{C}\right)$ and the steam tempering step can be performed at $1000^{\circ} \mathrm{F}\left(537^{\circ} \mathrm{C}\right)$ so the danger of delta phase formation is significantly reduced. 


\subsection{REFERENCES}

(1) J.F. Wallace, Y. Wang, and D. Schwam, "Effect of Composition and Processing on the Thermal Fatigue and Toughness of High Performance Die Steels"” Die Casting Engineer, Sept./Oct., 1997, Vol. 41, No. 5, p 26.

(2) E.L. Courtright, and J.E. Deibler, “Analytical Modeling of Die Stresses and Their Affect On Die Life,” Transactions, $20^{\text {th }}$ International Die Casting Congress \& Exposition, Paper T99-034, pp109-119, November, 1999.

(3) V.N. Yermenko, Ya.V. Natanzon, and V.I. Dybkov, “The Effect of Dissolution on the Growth of the $\mathrm{Fe}_{2} \mathrm{Al}_{5}$ Interlayer in the Solid Iron-Liquid Aluminum System,” Journal of Materials Science , 16, pp 1748-1756, 1981.

(4) D. Fraser and M. Jahedi, "Magnetite Coating for Prevention of Soldering in Aluminum HPDC Tooling,” Die Casting Engineer, pp 96-100 March/April 2000.

(5) J.C. Benedyk, D.J. Moracz, and J.F. Wallace., "Thermal Fatigue Behavior of Die Materials for Aluminum Die Casting”, SDCE, Paper No. 111, 6 th SDCE International Die Casting Conference, 1970, pp 1-20.

(6) HSC Chemistry for Windows, Version 2.0, Outokumpu Research Oy, P.O Box 60, FIN-28101 PORI, Finland.

(7) F.N. Mazandarany and R.D. Pehlke, “Thermodynamic properties of Solid Alloys of Chromium with Nickel and Iron,” Metallurgical Transactions, Vol 4, September, 1973, pp 2067-2076

(8) A.D. Dalvi and W.W. Smeltzer, "The Kinetics and Morphological Development of the Oxide Scale on Nickel-Iron Alloys (0-25 w/o Fe) at $1000{ }^{\circ} \mathrm{C}$,” J. Electrochem. Soc., Vol. 118, No. 12, December 1981, pp 1978-1985.

(9) C.S. Giggins, and F.S. Pettit, “Oxidation of Ni-Cr Alloys Betweeen $800^{\circ}$ and $1200{ }^{\circ} \mathrm{C}$,” Transactions of the Metallurgical Society of AIME, Vol. 245, December 1969, pp 2495-2507.

(10) R.R. Bianco and R.A. Rapp, "Simultaneous Chromizing and Aluminizing of Nickel-Base Superalloys with Reactive Element Additions," High Temperature Materials Chemistry V, ed. W.B. Johnson and R.A. Rapp (Pennington, NJ: Electrochem. Soc, 1990), p 211.

(11) M.Y, R.Shivpuri and R.A. Rapp, "Effects of Molten Aluminum on H13 Dies and Coatings, Journal of Materials Engineering and Performance, Vol. 4(2), April 1995, pp175-181. 
(12) R.H. Condit, J.J. Brabers, and C.E. Birchenall, "Self-Diffusion of Iron In Nickel Ferrite," Transactions of The Metallurgical Society of AIME, Vol. 218, August 1960, P 768.

(13) A.Kaye, A. Street, Die casting metallurgy, Betterworth and Co. Ltd., 1982, p1-8, 262-273

(14) A. Street, The die casting book, Portcullis press Ltd., 1977, p3-7, 349-351

(15) S. Malm, J.Tidlund, Increased life for die casting dies, Transactions of 10th international die casting congress, Paper No. IG-T79-051, 1979.

(16) W. Young, Die casting failure and its prevention, precision metal, Vole.39,1979,p28-31

(17) Rajiv Shivpuri, Friction and wear of dies and die materials, ASM Handbook, Vol. 18 (Friction, lubrication and wear technology), 1990, p621-648

(18) Z.W.Chen, M.Z.Jahedi, Die erosion and its effect on soldering formation in high pressure die casting of aluminum alloys, Materials \& Design, 20(1999), p303-309

(19) Sandhya Gopal, Anup Lakare, Rajiv Shivpuri, Soldering in die casting: Aluminum alloy and die steel interactions, Die casting engineering, May/June 2000, p70-81

(20) S.Gulizia, M.Z.Jahedi, E.D.Doyle, Performance evaluation of PVD coatings for high pressure die casting, Surface \& Coating Technology, 140(2001), p200-205

(21) J. F. Wallace, D. Schwam, Mold materials for permanent molding of aluminum alloys, AFS Transactions, Vol.107 (1999), p479-483

(22) J. F. Wallace, D. Schwam, Development studies on selection and processing of die materials to extend die life, Die Casting Engineer (USA), Vol. 44(3), May-June, 2000, P50, 52, 54, 56-58

(23) J. F. Wallace, Y. Wang, D. Schwam, Effect of composition and processing on the thermal fatigue and toughness of high performance die steels, Die Casting Engineer (USA), Vol.41 (5), Sept.-Oct.1997, p26, 28, 30, 32

(24) J.F. Wallace, Improving Die Life, Die Cast. Manage., Vol.4(2), Mar.-Apr. 1986, p16-18, 20-21

(25) Z.M.Cen, D.T.Fraser, M.Z.Jahedi, Structures of intermetallic phases formed during immersion of $\mathrm{H} 13$ tool steel in an Al-11Si-3Cu die casting alloy melt, Materials Science \& Engineering A, A260(1999), P188-196

(26) M.Yan, Z.Fan, The erosion of H21 tool steel in molten A380 alloy, Journal of Materials Science, 35(2000), p1661-1667 
(27) M.Yan, Z.Fan, Review: Durability of materials in molten aluminum alloys, Journal of Materials Science, 36(2001), p285-295

(28) Sumanth Ahankar, Diran Apelian, Soldering tendencies of alternate nonferrous die materials, NADCA Meeting, November 2000, Chicago.

(29) Q.Han, E.A.Kenik, S.Viswanathan, Die soldering in aluminum die casting, Light metals 2000, Aluminum Committee at the 129th TMS Annual Meeting, Nashville, Tenne, 12-16 Mar.2000, p765-770

(30) R. Shivpuri, Y-L. Chu, K. Venkatesan, An evaluation of metallic coating for erosive wear resistance in die casting applications, Wear, Vol. 192(1996), p49-55

(31) K.L. Mittal, Adhesion aspects of metallization of organic polymer surface, Journal of vacuum science and technology, Vol.13 (1976), p19-25

(32) J. Mihelich, R.F.Decker, US Patent no.5711366, 1998.

(33) M.Sujata, S.Bhargava, S.Sangal, On the formation of $\mathrm{TiAl}_{3}$ during reaction between solid Ti and liquid Al, Journal of Materials Science Letters (UK). Vol.16(14), 15 July 1997, p11751178.

(34) D.M. Rishel, F.S. Petit, N. Birks, Some principal mechanisms in the simultaneous erosion and corrosion attack of metals at high temperature, Paper 16, Proceedings of corrosionerosion-wear of materials at elevated temperatures, A.V.Levy, Ed., NACE/EPRI/LBL/DOEFE, Berkeley, CA, 31 Jan.-2 Feb. 1990.

(35) P.A. Coulon, Erosion-corrosion in stream turbines Part II: a problem largely resolved, Lubricant engineering, Vol.42 (No.6), 1986, p357-362

(36) V.Joshi, K.Kulkarni, R.Shivpuri, R.S.Bhattachatya, S.J.Dikshit, D.Bhat, Dissolution and soldering behavior LAFAD PVD coatings, Surface and Coatings Technology, 146147(2001), P338-343

(37) Yucong Wang, A study of PVD coatings and die materials for extended die-casting die life, Surface and Coatings Technology, 94-95(1997), P60-63

(38) C. Mitter, F.Holler, F.Ustel, D.Heim, Application of hard coatings in aluminum die castingsoldering, erosion and thermal fatigue behavior, Surface and Coatings Technology, 125(2000), P233-239 


\section{FIGURES}


Table 1: Chemical Composition of Copper Base Pin (wt\%)

\begin{tabular}{|c|c|c|c|}
\hline Alloy Type & Be & Co & Cu \\
\hline Cu Base & 1.7 & 0.2 & 98.1 \\
\hline
\end{tabular}

Table 2: Chemical Composition of Pins (wt\%)

\begin{tabular}{|c|c|c|c|c|c|c|c|c|c|c|c|c|c|c|}
\hline Alloy Type & C & Mn & Si & Cr & Mo & Ti & Al & Fe & Ni & Nb & V & W & Hf & Zr \\
\hline Ni-718 & 0.02 & 0.05 & 0.05 & 17.6 & 2.86 & 1.01 & 0.48 & 18.7 & 53.6 & 5.09 & & & & \\
\hline Ni-625 & 0.052 & 0.06 & 0.2 & 20.9 & 8.45 & 0.32 & 0.23 & 4.38 & 61.1 & 3.36 & & & & \\
\hline H13 & 0.4 & 0.35 & 1 & 5.25 & 1.5 & & & & & & 1 & & & \\
\hline Mo-785 & & & & & 97.5 & 0.65 & & & & & & & 1.18 & 0.13 \\
\hline Ti-6Al-4V & & & & & & 90 & 6 & & & & 4 & & & \\
\hline Anv. 1150 & & & & & 4 & & & 2 & 4 & & & 90 & & \\
\hline
\end{tabular}


Figure 1: UBE VSC 315 Ton Squeeze Cast Machine at CWRU

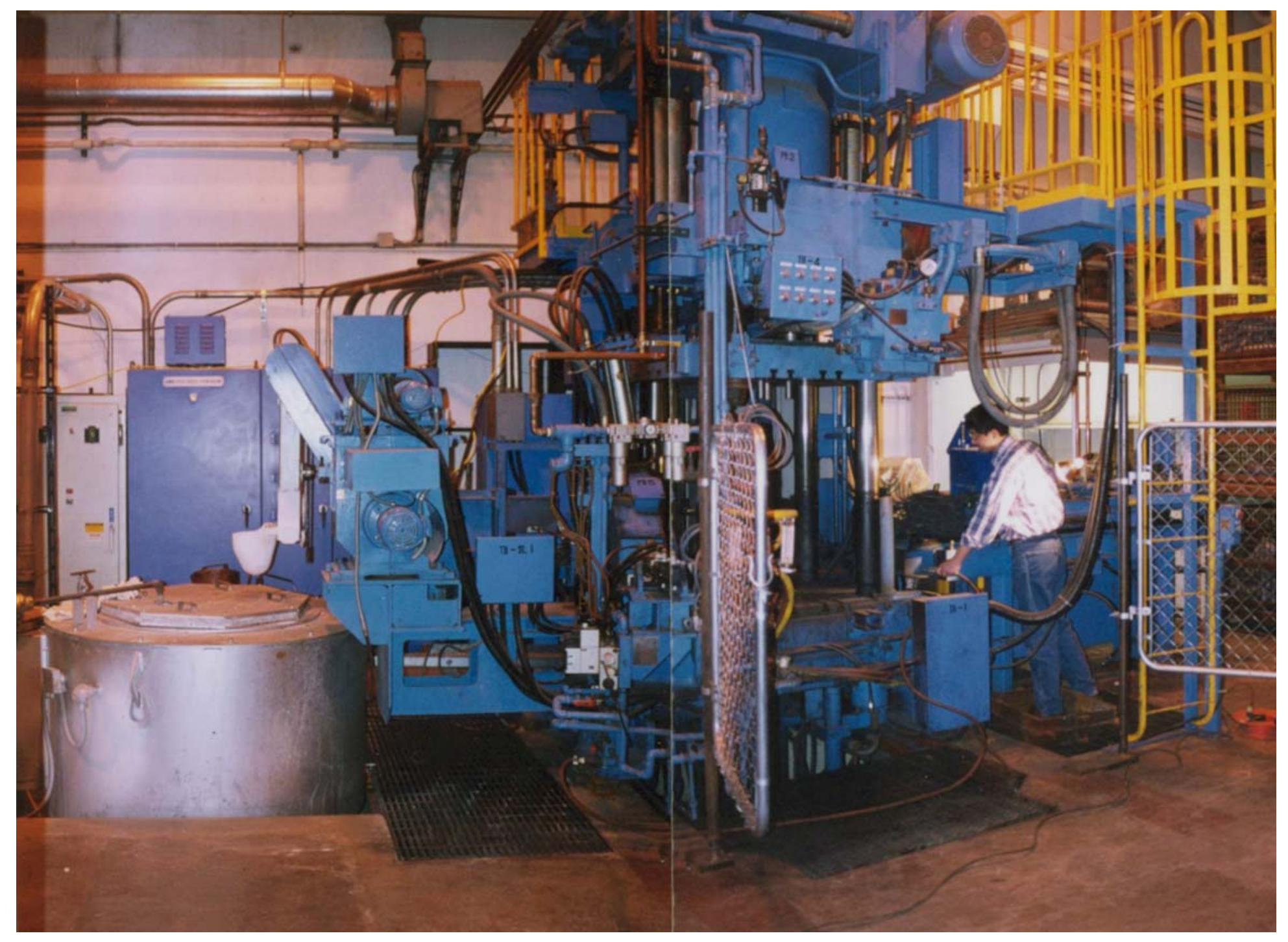


Figure 2: Schematic Diagram of the Accelerated Soldering Test

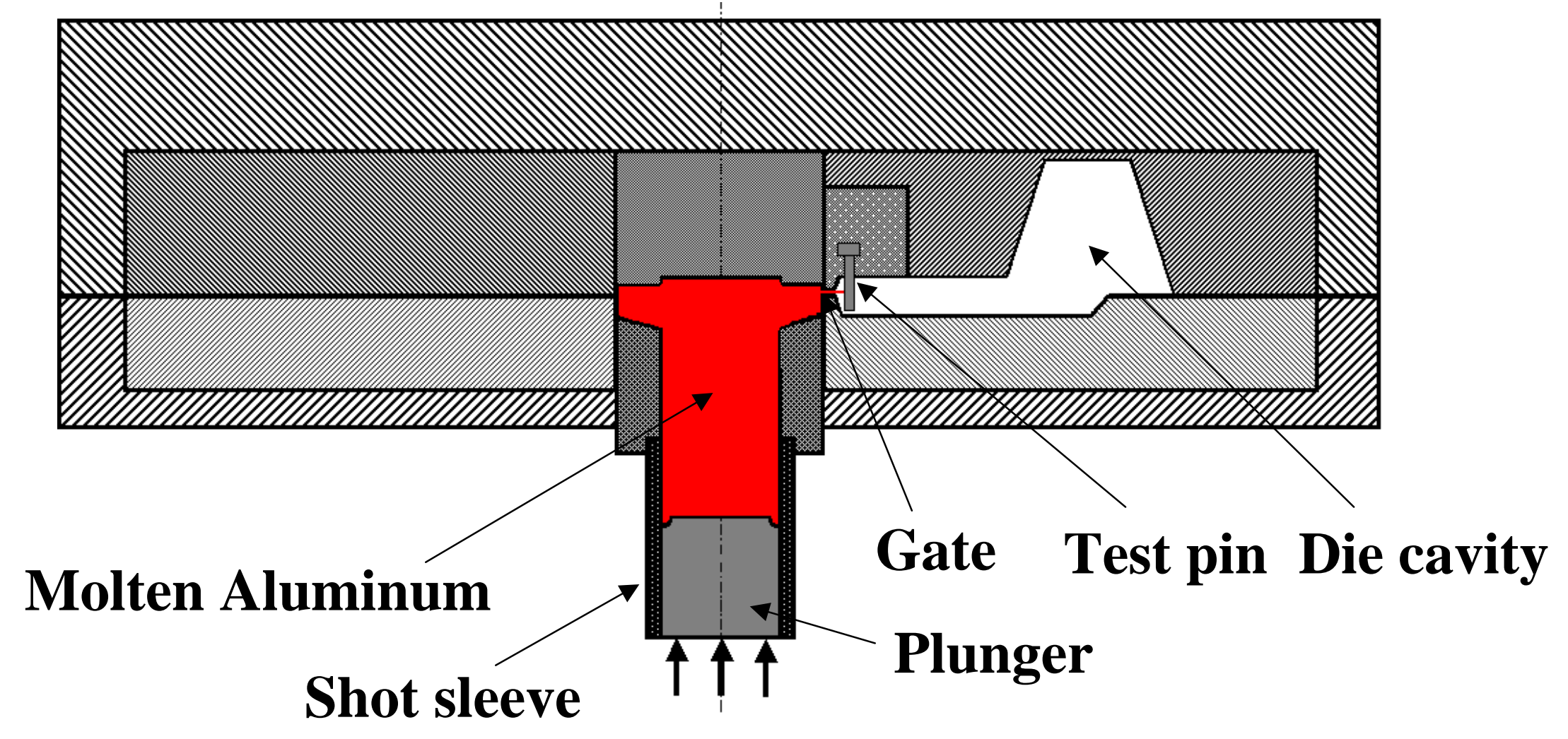


Figure 3: Schematic of the Washout/Soldering Testing Set-up

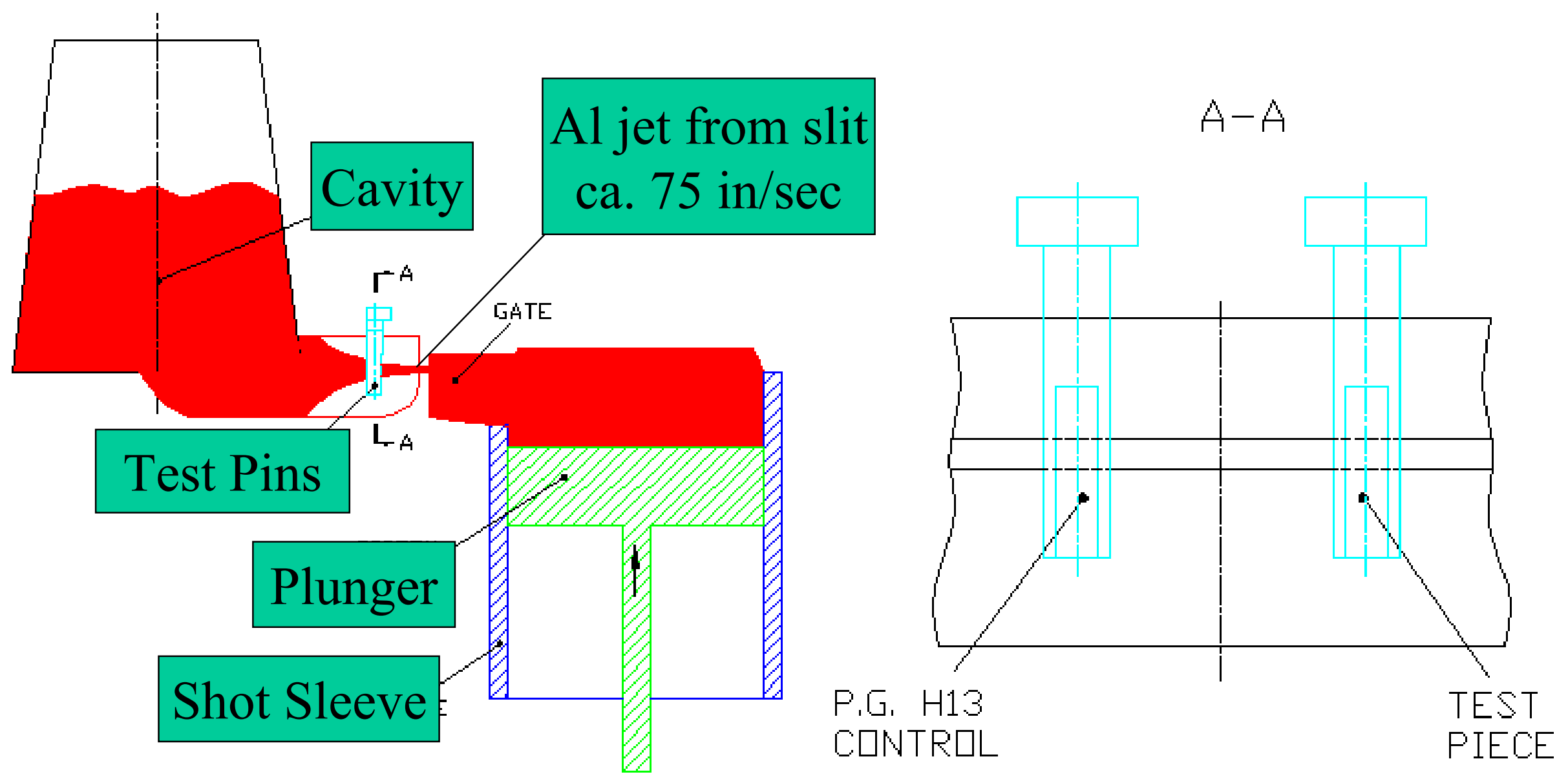


Figure 4a: Sub-Insert for Soldering\&Washout Experiments

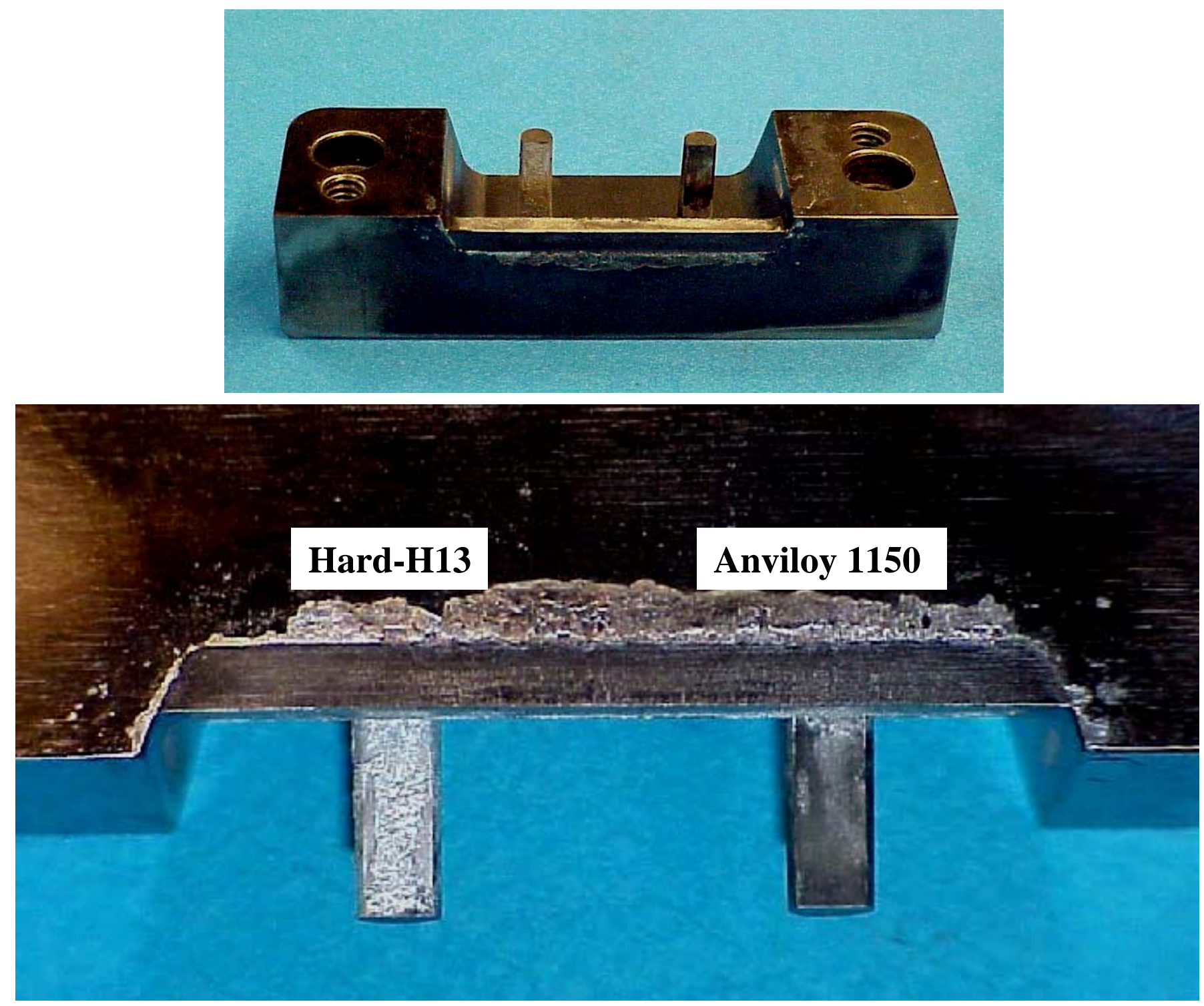

The hard H-13 pin is coated with a silvery soldered layer of Al 61 
Figure 4b: Test Pin Design and Position

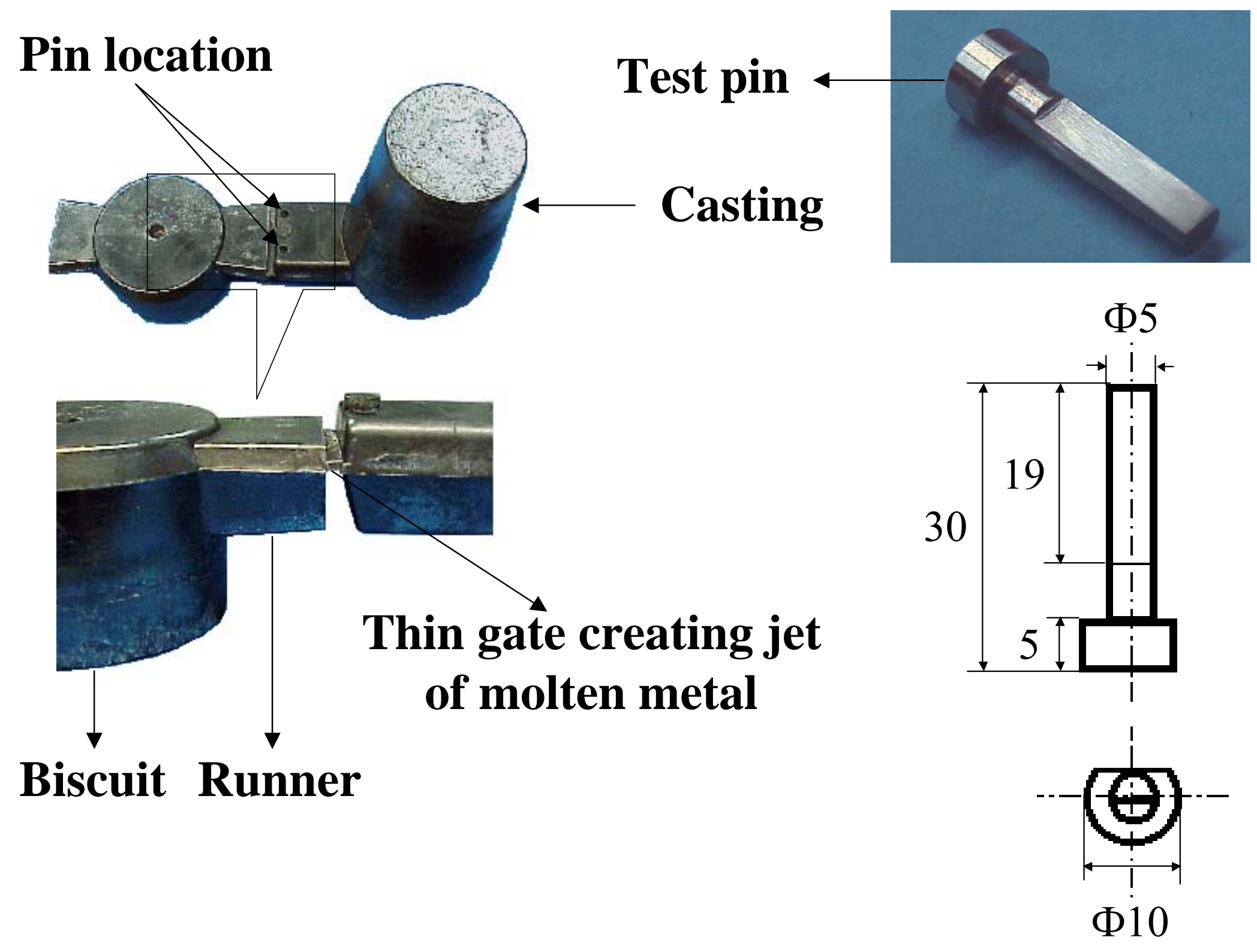




\section{Figure 5: Thermal Fatigue Immersion Test and Equipment}
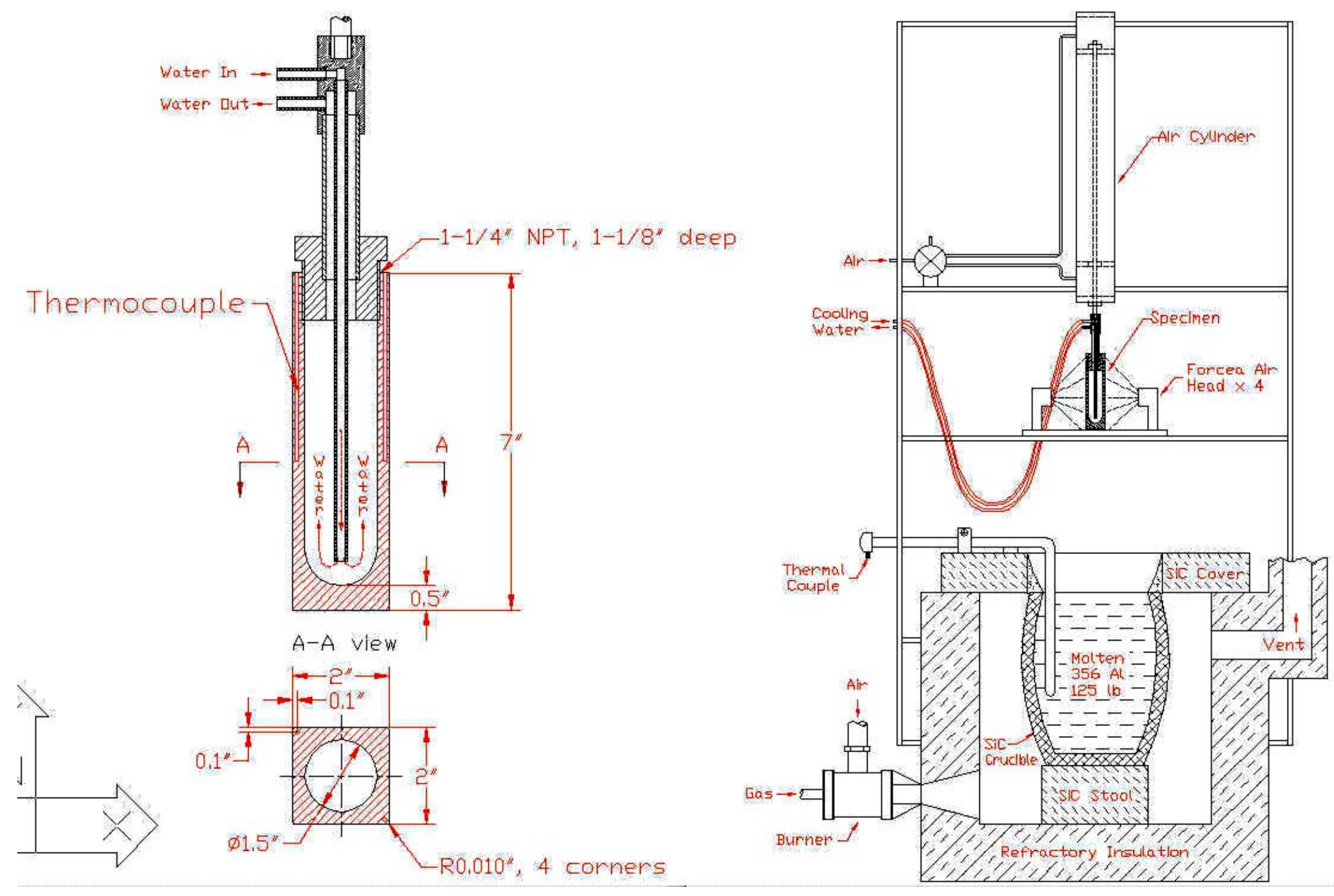
Figure 6: Dissolution at the Corners of Nickel Alloy Specimens

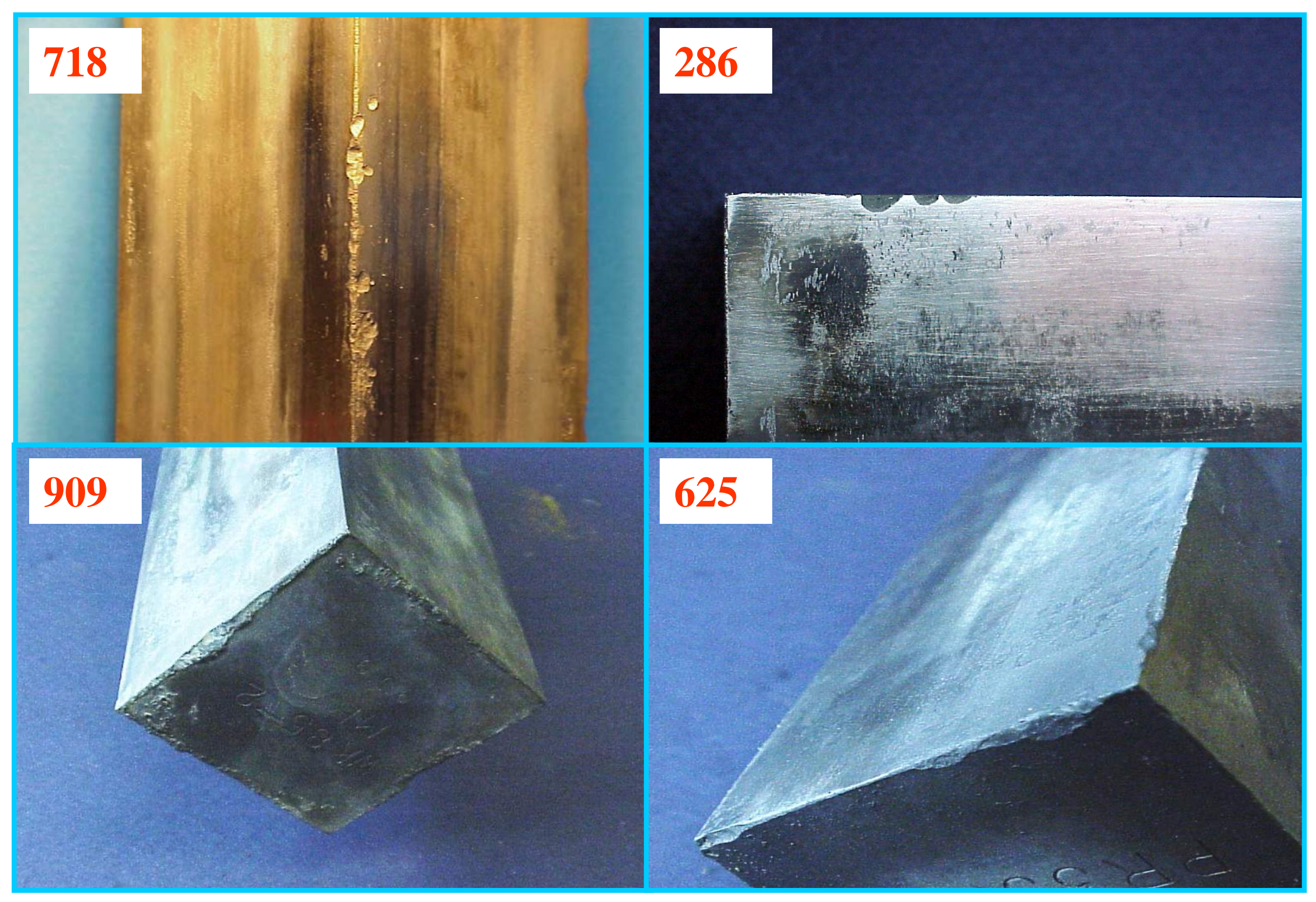




\section{Table 3: Nominal Superalloy Compositions in wt\%}

\begin{tabular}{l|c|c|c|c|c|c|c|c|c|c|c|c|c|}
\hline Alloy & $\mathrm{Fe}$ & $\mathrm{Ni}$ & $\mathrm{Cr}$ & $\mathrm{Co}$ & $\mathrm{C}$ & $\mathrm{Mo}$ & $\mathrm{V}$ & $\mathrm{Nb}$ & $\mathrm{Ti}$ & $\mathrm{Al}$ & $\mathrm{B}$ & $\mathrm{Mn}$ & $\mathrm{Si}$ \\
\hline $\mathrm{H}-13$ & 90.5 & 0.3 & 5.0 & & 0.4 & 1.4 & 1.0 & & & & & 0.35 & 1.0 \\
\hline Inconel 706 & 37.6 & 40.0 & 16.0 & & 0.06 & & & 3.0 & 2.0 & 0.4 & & 0.35 & 0.35 \\
\hline Inconel 718 & 18.5 & 52.5 & 19.0 & & 0.04 & 3.0 & & 5.1 & 0.9 & 0.5 & & 0.20 & 0.2 \\
\hline A-286 & 55.0 & 26.0 & 15.0 & & 0.04 & 1.25 & 0.3 & & 2.0 & 0.2 & .005 & & \\
\hline Incoloy 901 & 35.0 & 42.5 & 12.5 & & 0.1 & 5.9 & & & 2.9 & 0.35 & .015 & & \\
\hline Incoloy 909 & 42.0 & 38.0 & & 13.0 & 0.01 & & & 4.7 & 1.5 & & & & 0.4 \\
\hline
\end{tabular}


Figure 7: Temperature dependent yield strength for several superalloys compared with H-13.

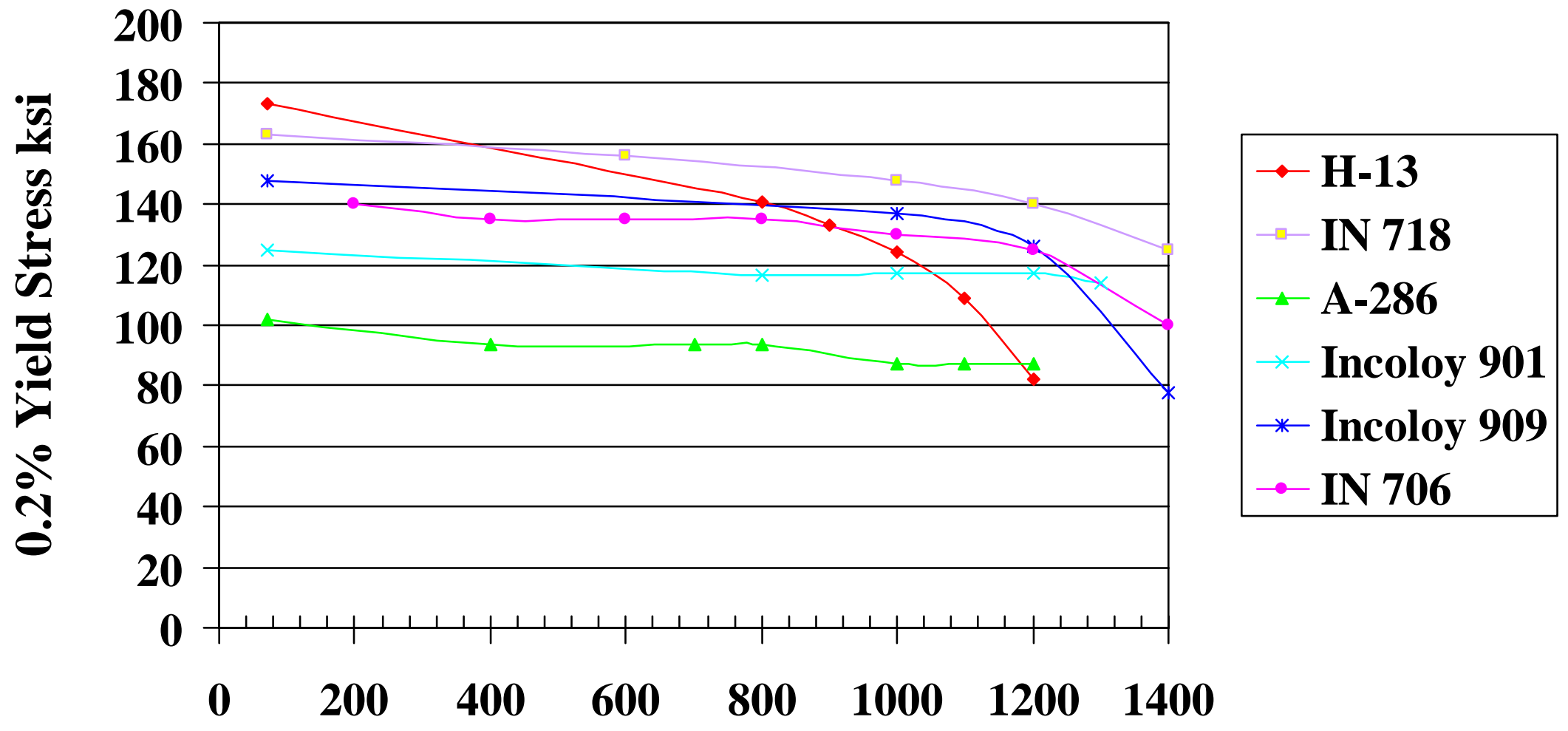

Temperature ${ }^{\circ} \mathbf{F}$ 
Figure 8: Temperature dependent thermal conductivity for several superalloys compared with H-13.

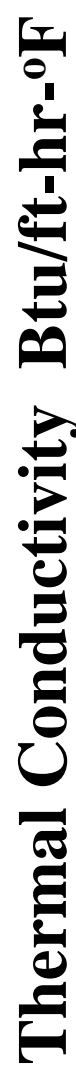

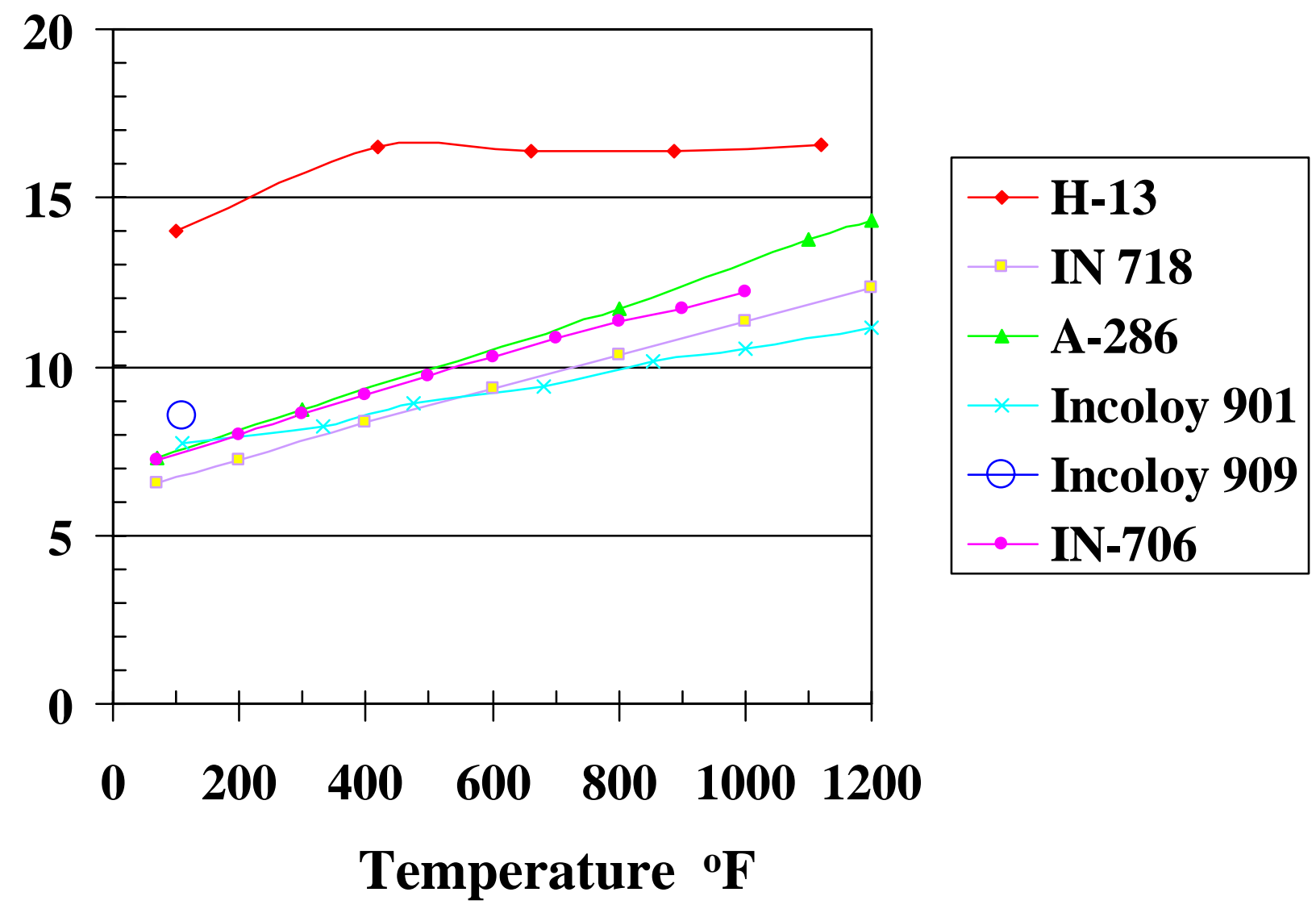


Figure 9: Percent linear expansion of $\mathrm{H}-13$ and several superalloys.

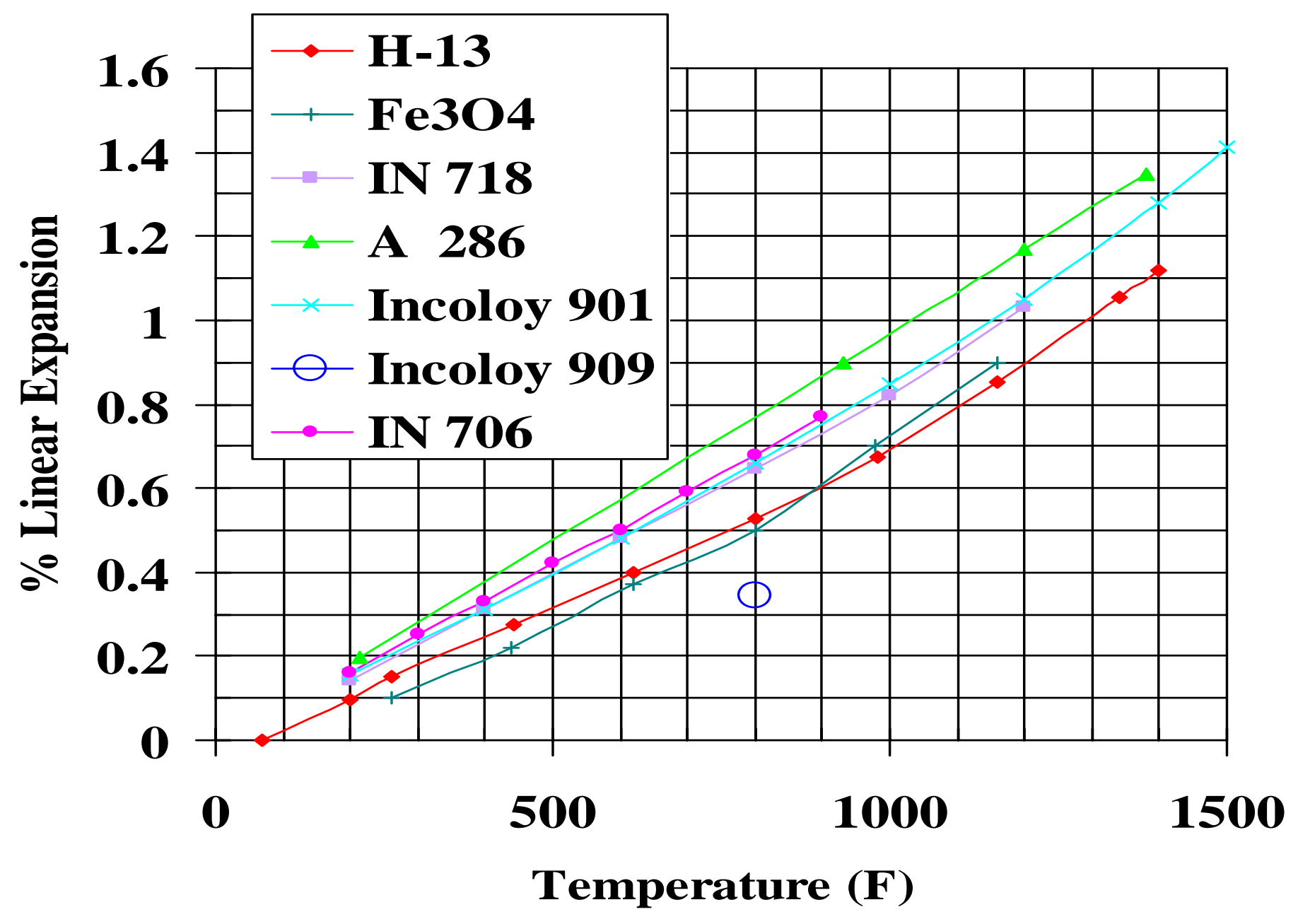


Figure 10: Elastic Modulus as a function of temperature for several superalloys and $\mathbf{H}-13$.

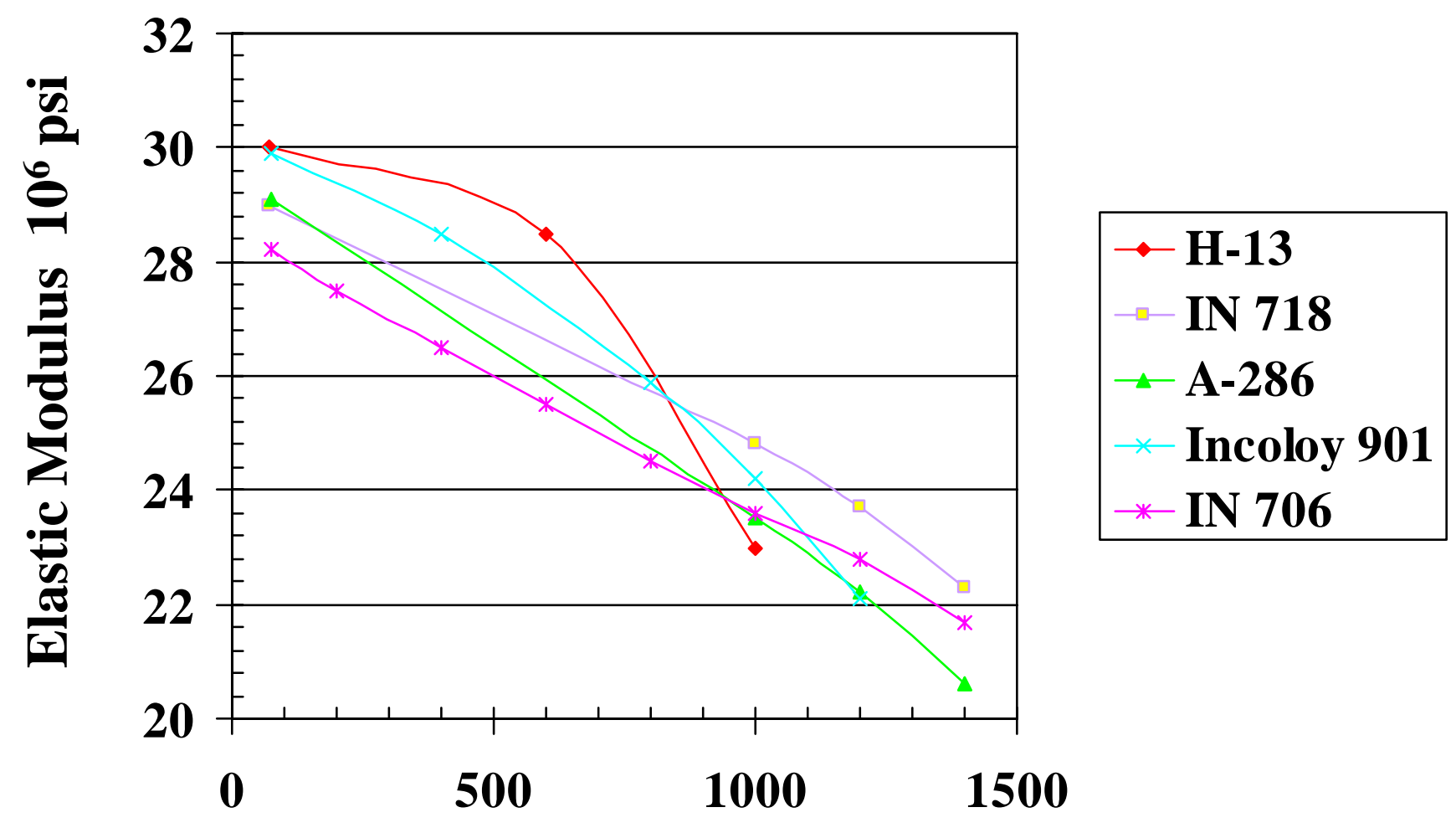

Temperature ${ }^{\circ} \mathbf{F}$ 
Figure 11: Equilibrium amounts of various oxide compounds calculated to form when 1 mole of $\mathrm{H}-13$ alloy is reacted with oxygen at 450 Centigrade

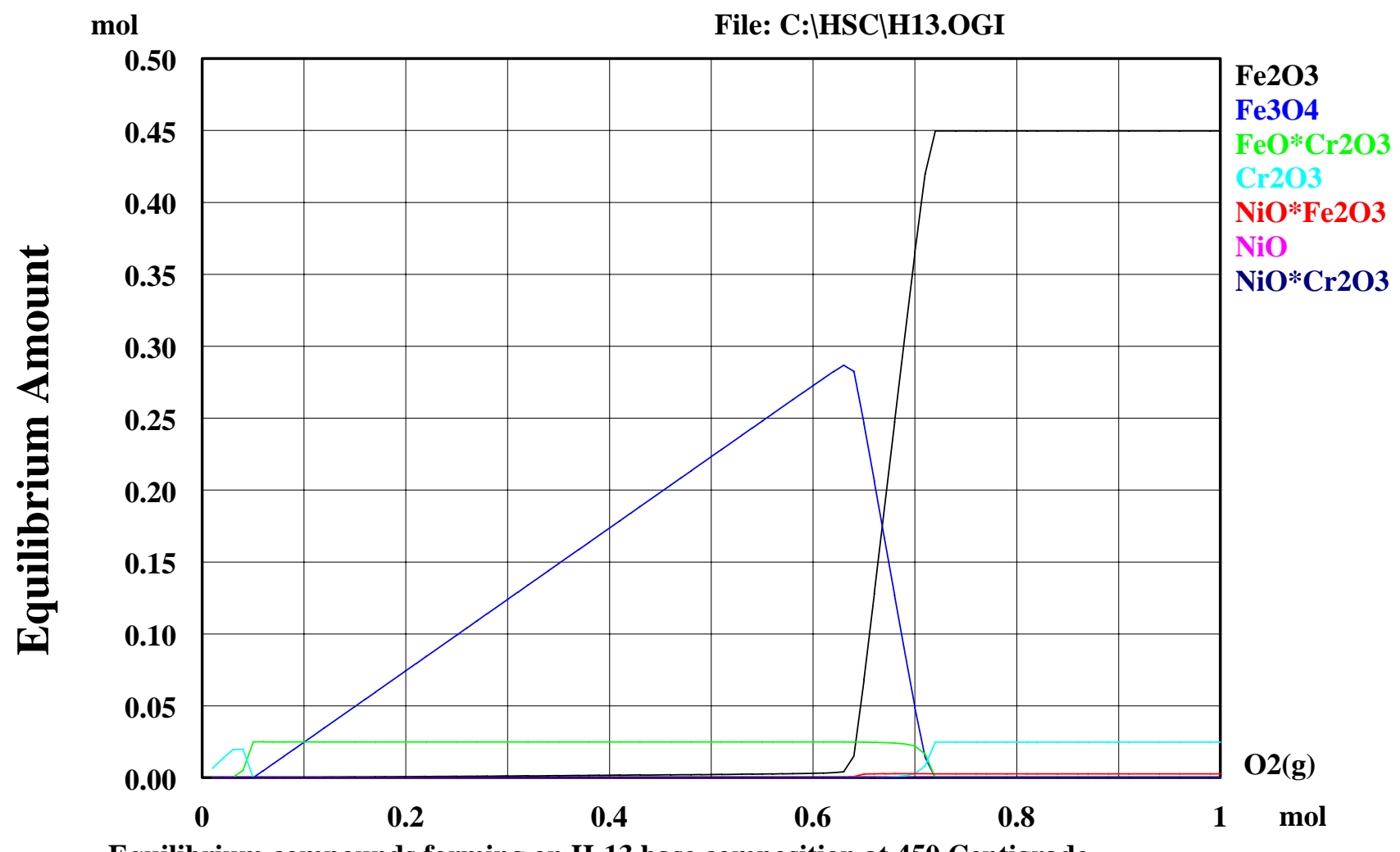

Equilibrium compounds forming on $\mathrm{H}-13$ base composition at 450 Centigrade 
Figure 12: Equilibrium amounts of various oxide compounds calculated to form when 1 mole of IN-718 alloy is reacted with oxygen at 450 Centigrade

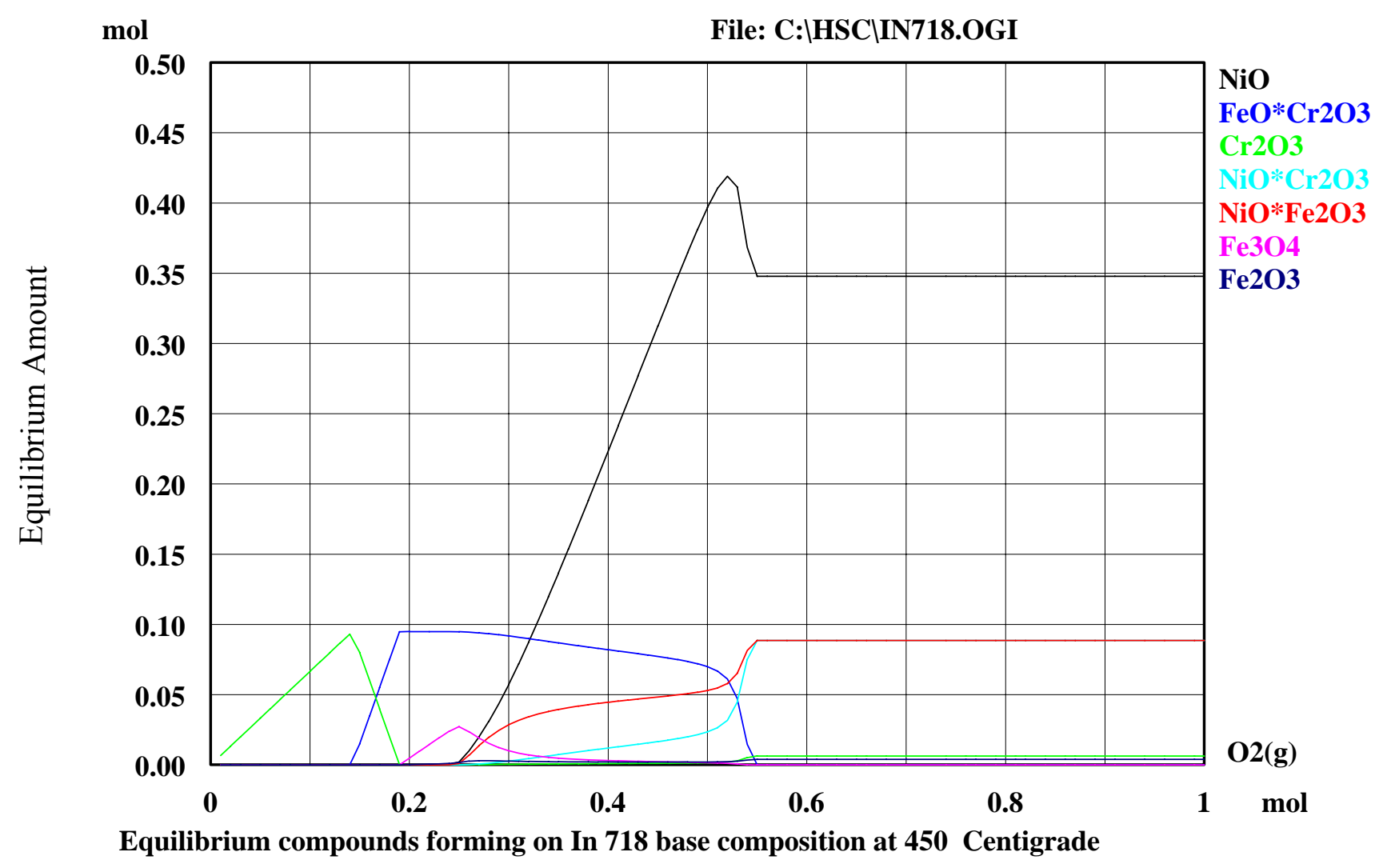


Figure 13: Equilibrium amounts of various oxide compounds calculated to form when 1 mole of IN-718 alloy with $30 \% \mathrm{Cr}$ is reacted with oxygen at 450 Centigrade

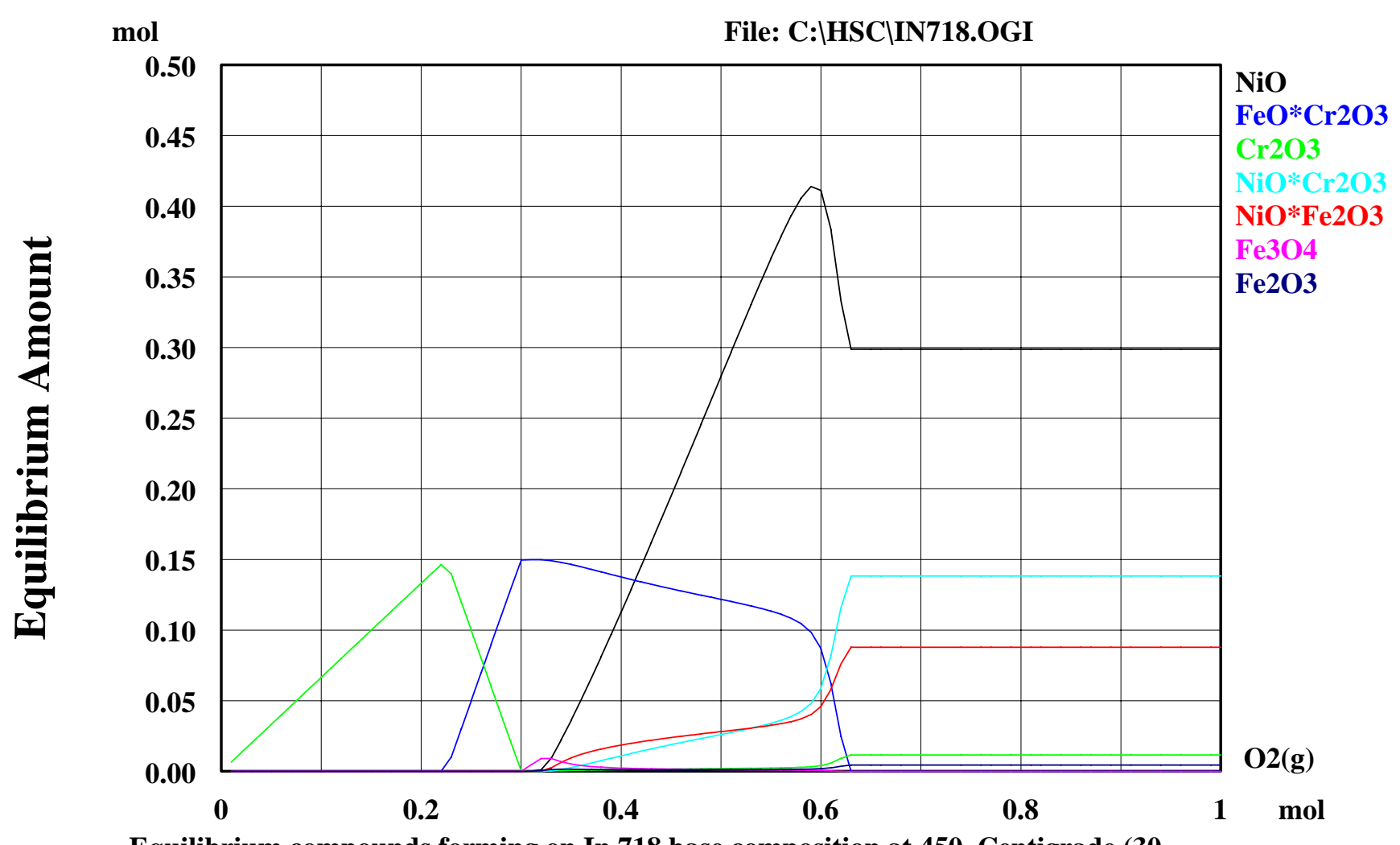

Equilibrium compounds forming on In 718 base composition at 450 Centigrade (30 
Figure 14: Equilibrium amounts of various oxide compounds calculated to form when 1 mole of IN-706 alloy is reacted with oxygen at 450 Centigrade

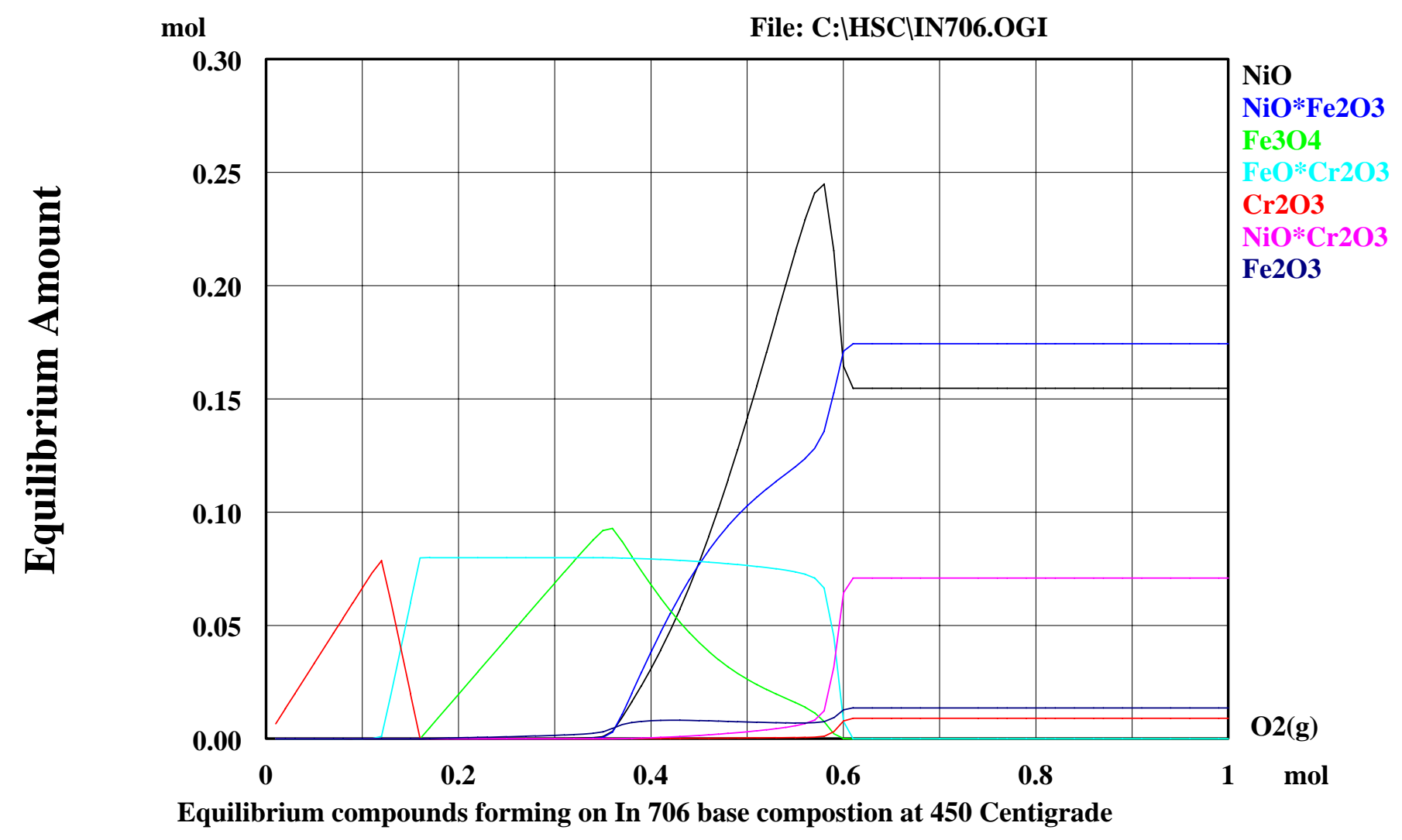


Figure 15: Equilibrium amounts of various oxide compounds calculated to form when 1 mole of Incoloy 901 alloy is reacted with oxygen at 450 Centigrade

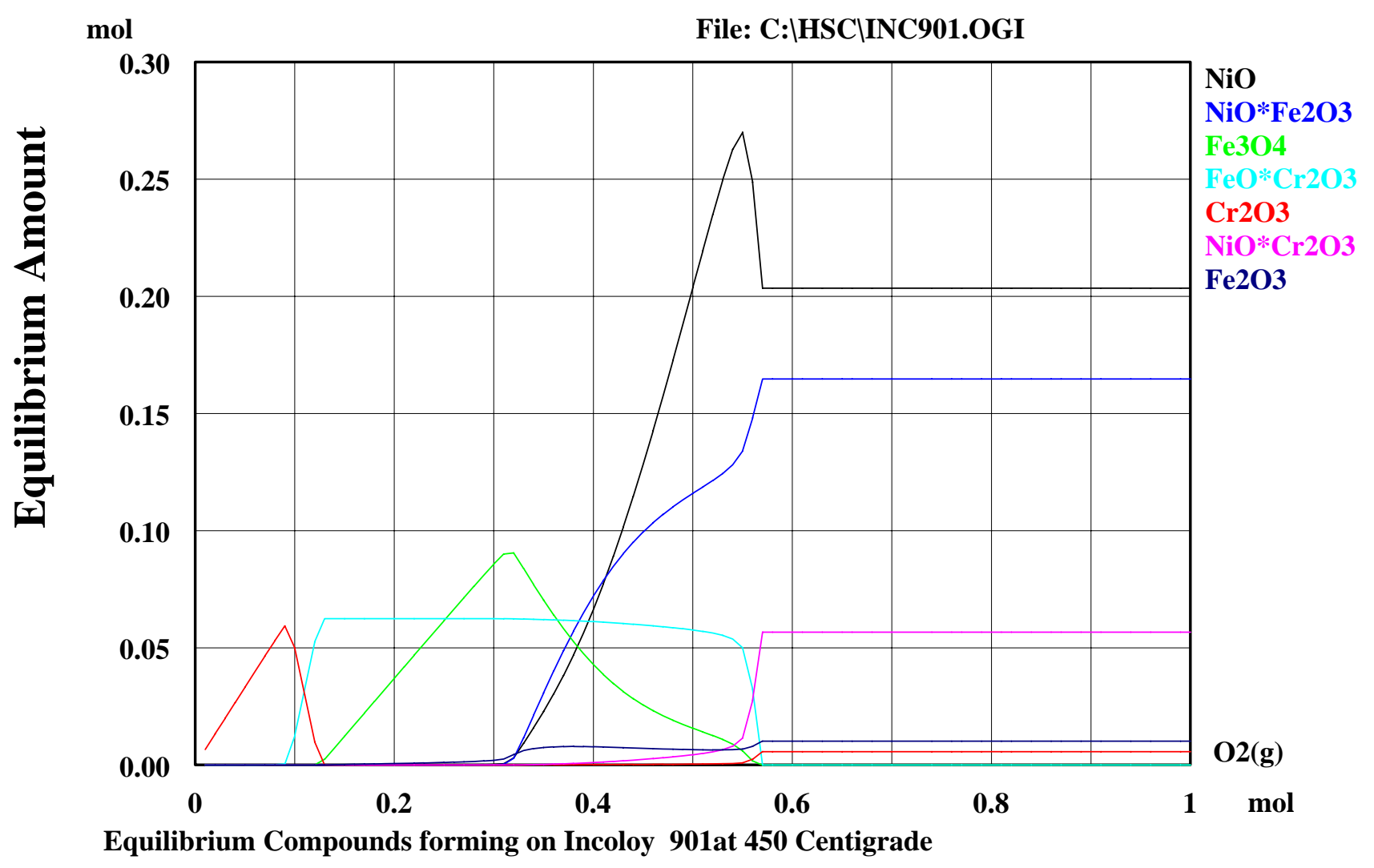


Figure 16: Equilibrium amounts of various oxide compounds calculated to form when 1 mole of Incoloy 909 alloy is reacted with oxygen at 450

\section{Centigrade}

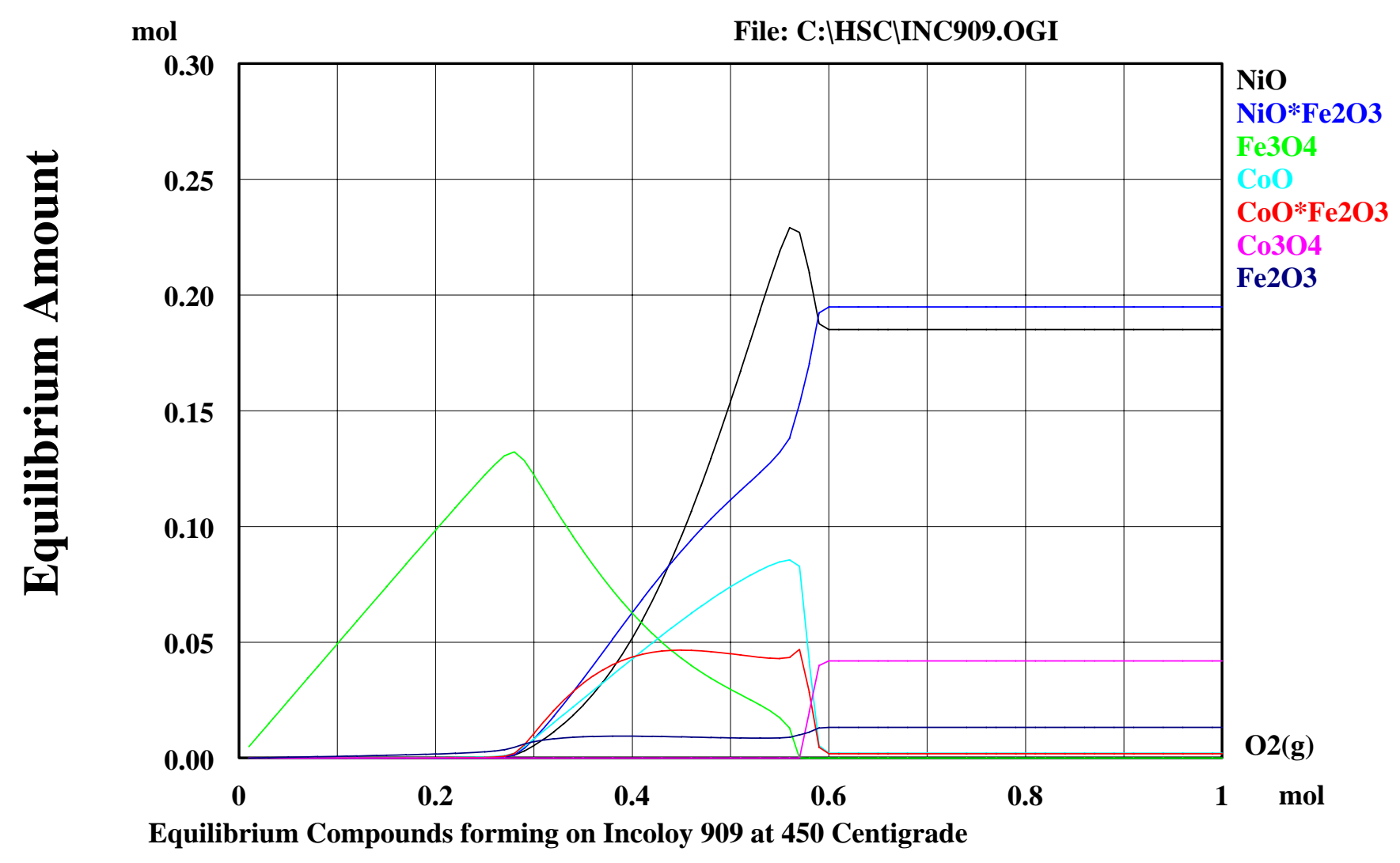


Figure 17: Equilibrium amounts of various oxide compounds calculated to form when 1 mole of $\mathrm{H}-13$ alloy is reacted with oxygen at 565 Centigrade showing the formation of FeO.

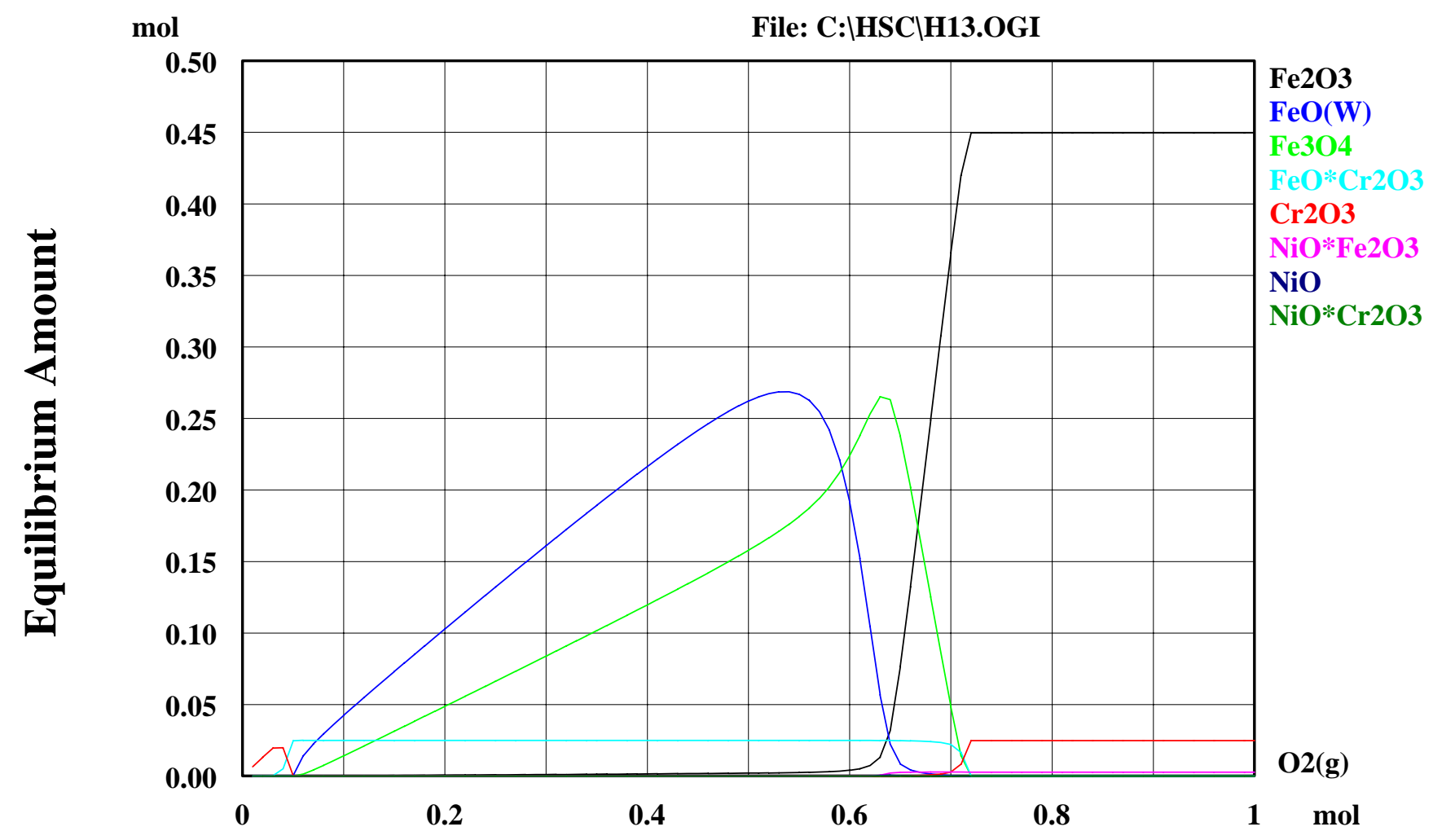

Equilibrium compounds forming on $\mathrm{H}-13$ base composition at 450 Centigrade 


\section{Figure 18: Broken Test Pins}

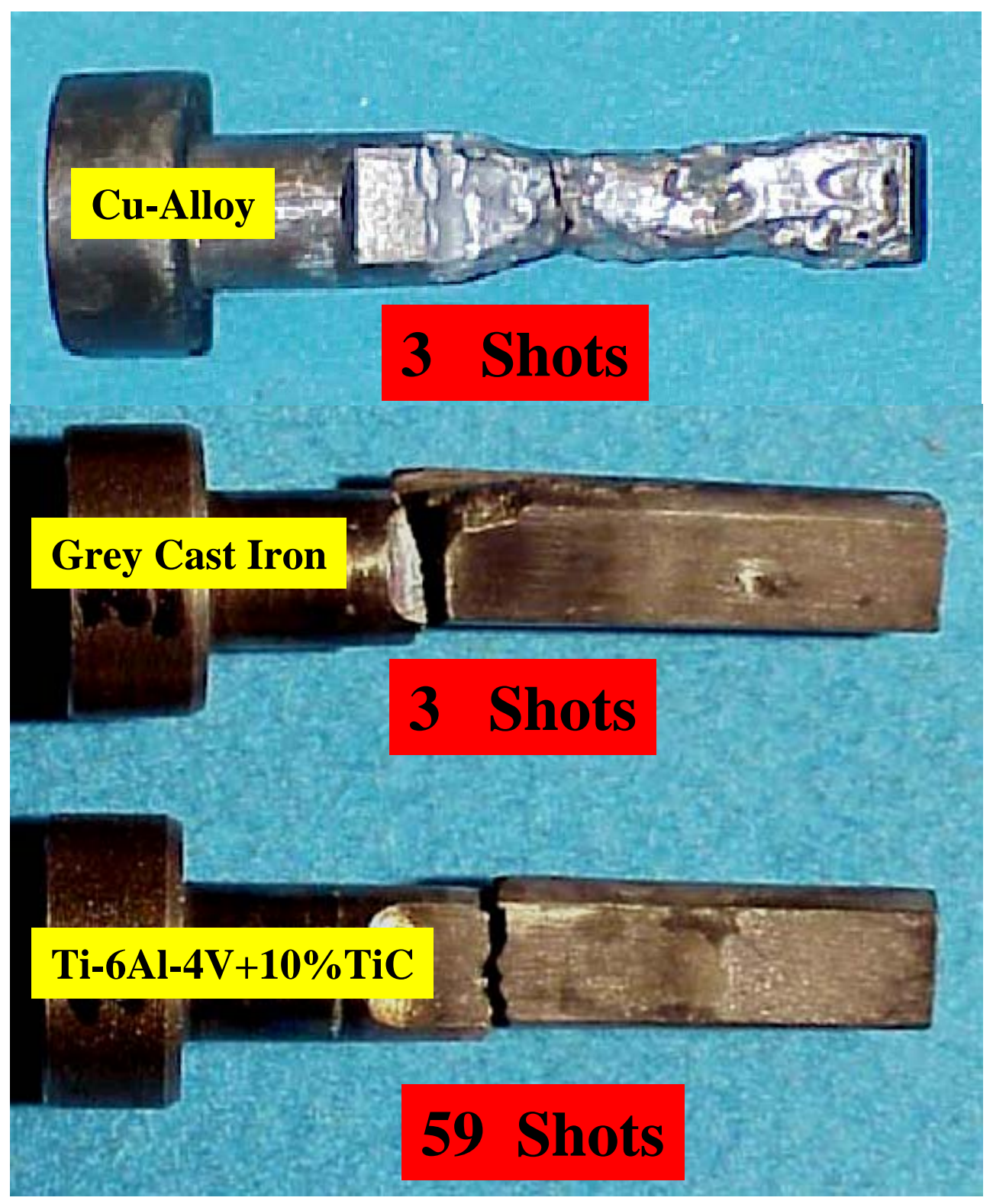




\section{Figure 19: Appearance of Pins after 50 Shots (with Soldered Al Dissolved in $\mathrm{NaOH}$ )}

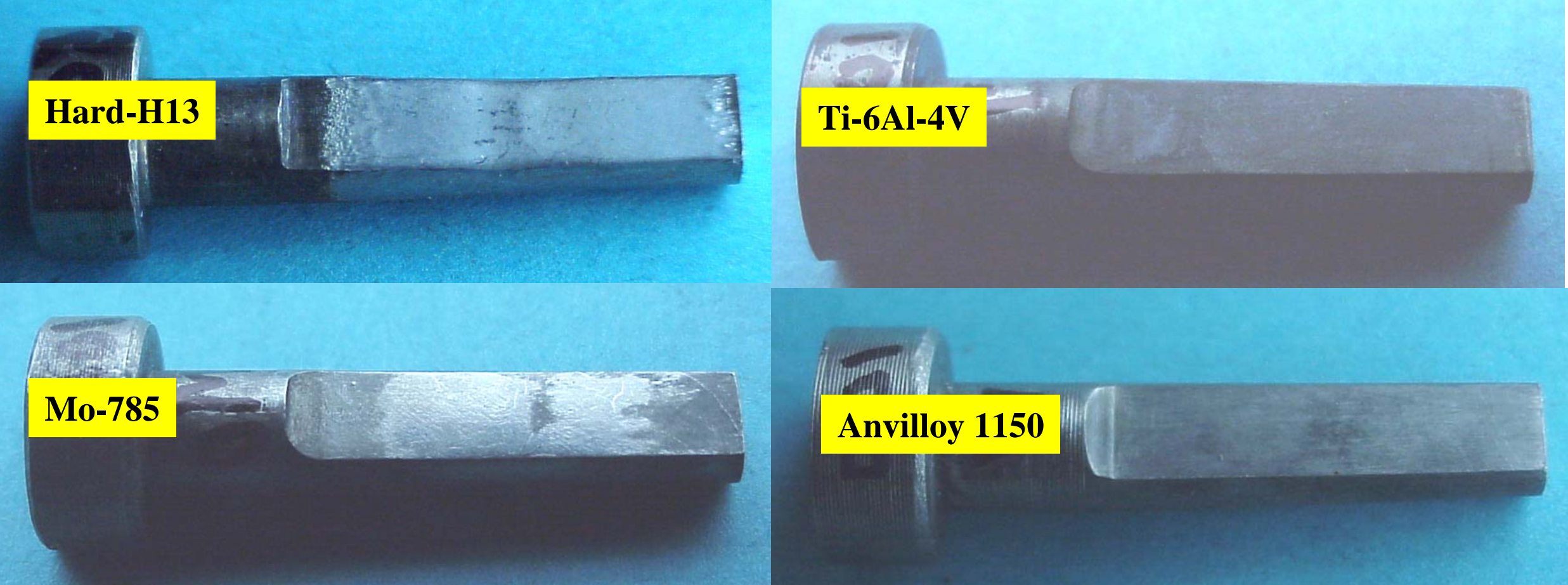




\section{Figure 20: Effect of Pin Material on Soldering}

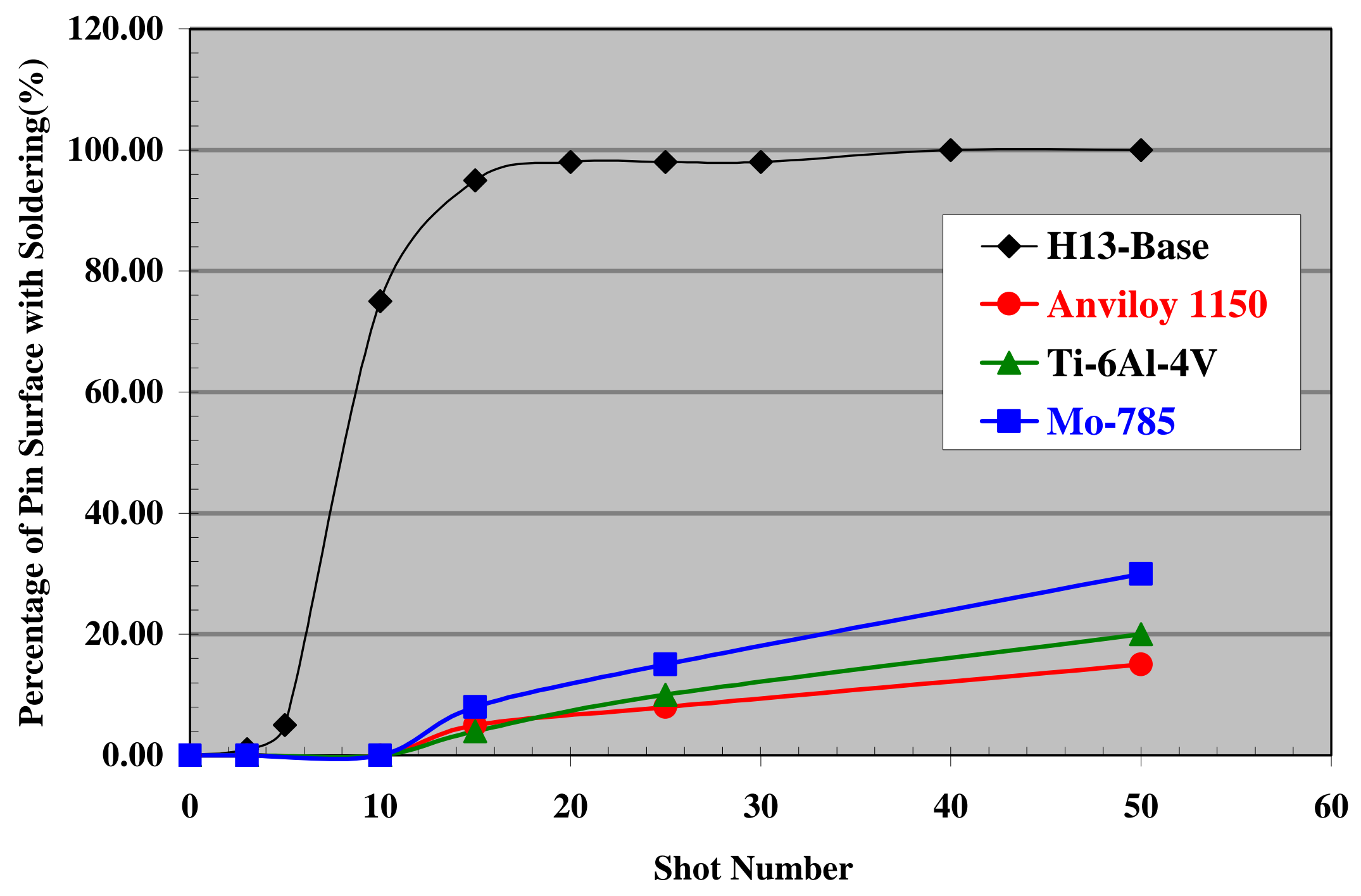


Figure 21: Effects of Pin Material \& Number of Shots on

\section{Percentage Area Covered with Soldering}

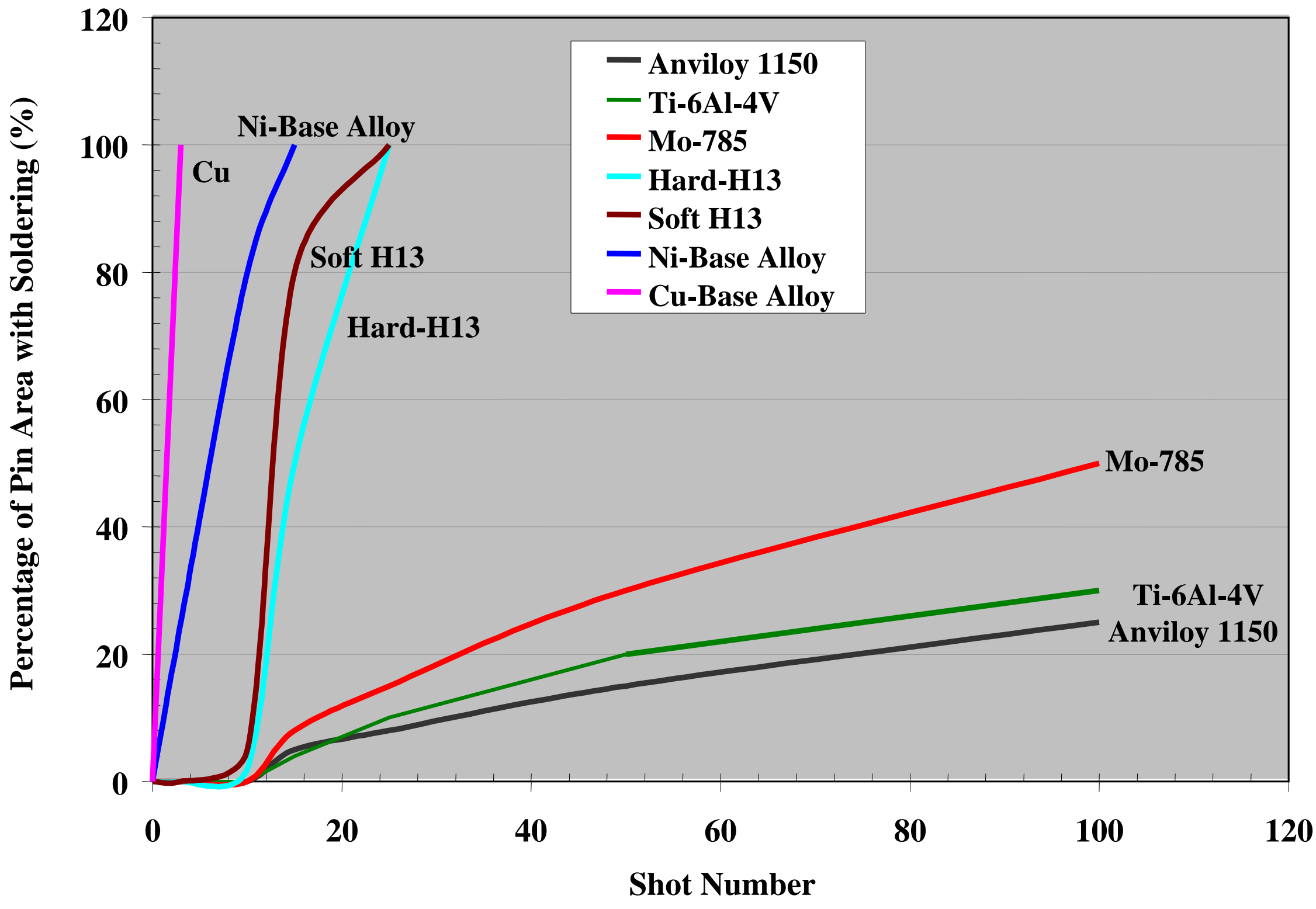


Figure 22: Effects of the Pin Material on Soldering

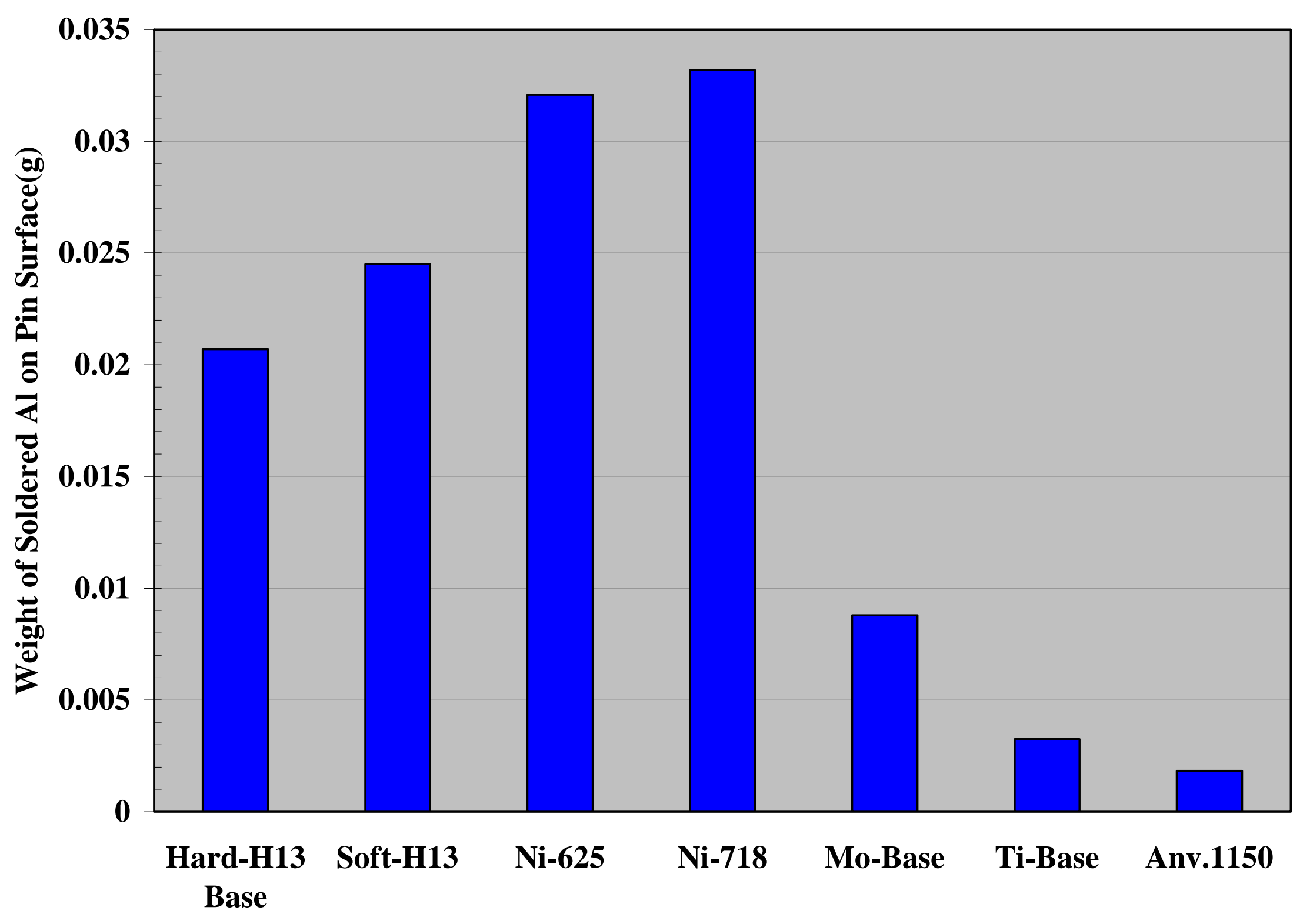


Figure 23: Washout in the Hard H13 Pin Impinged Directly by the $\mathrm{Al}$ (50 shots)

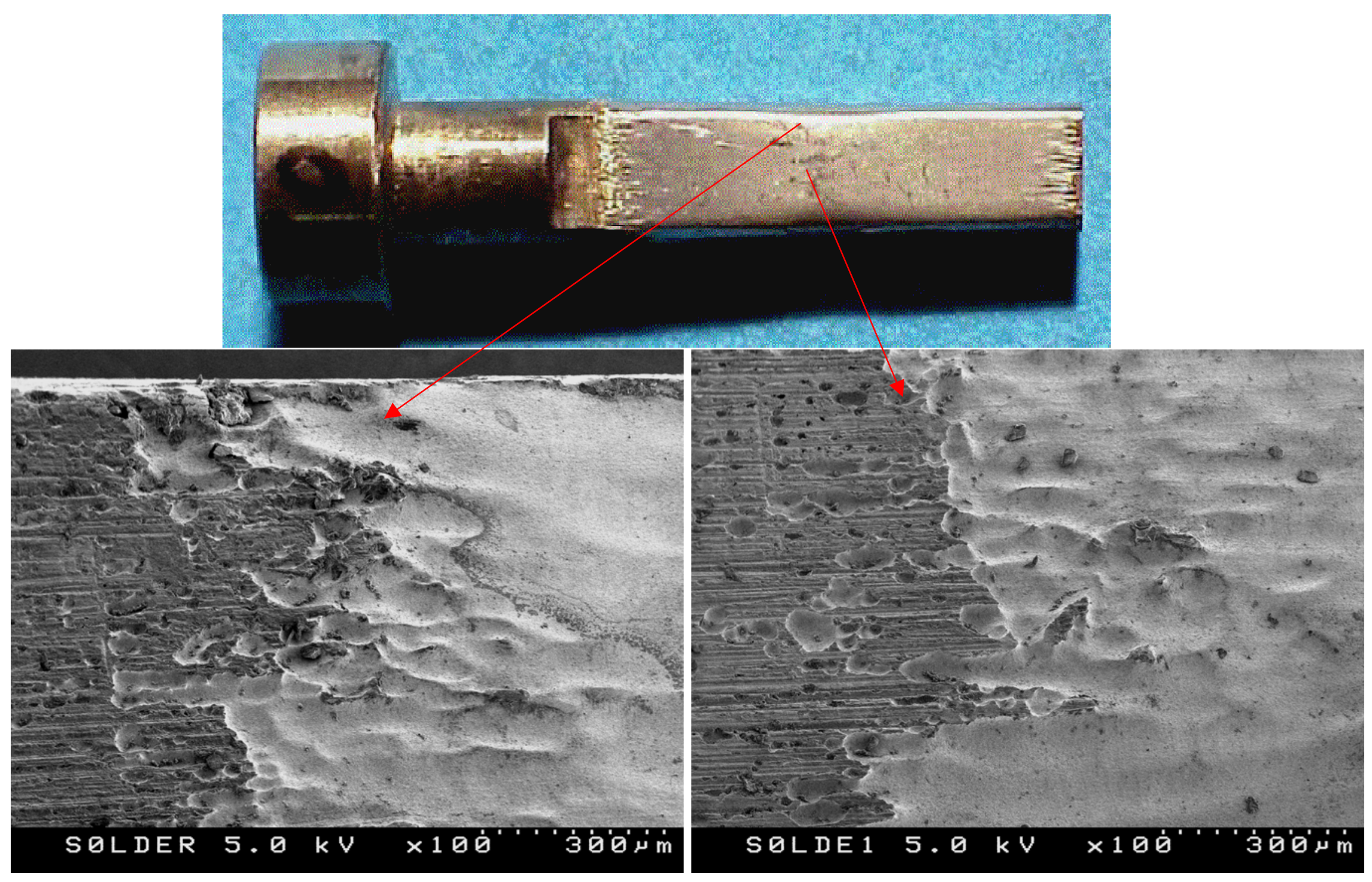


Figure 24: Effects of Pin Material on Washout

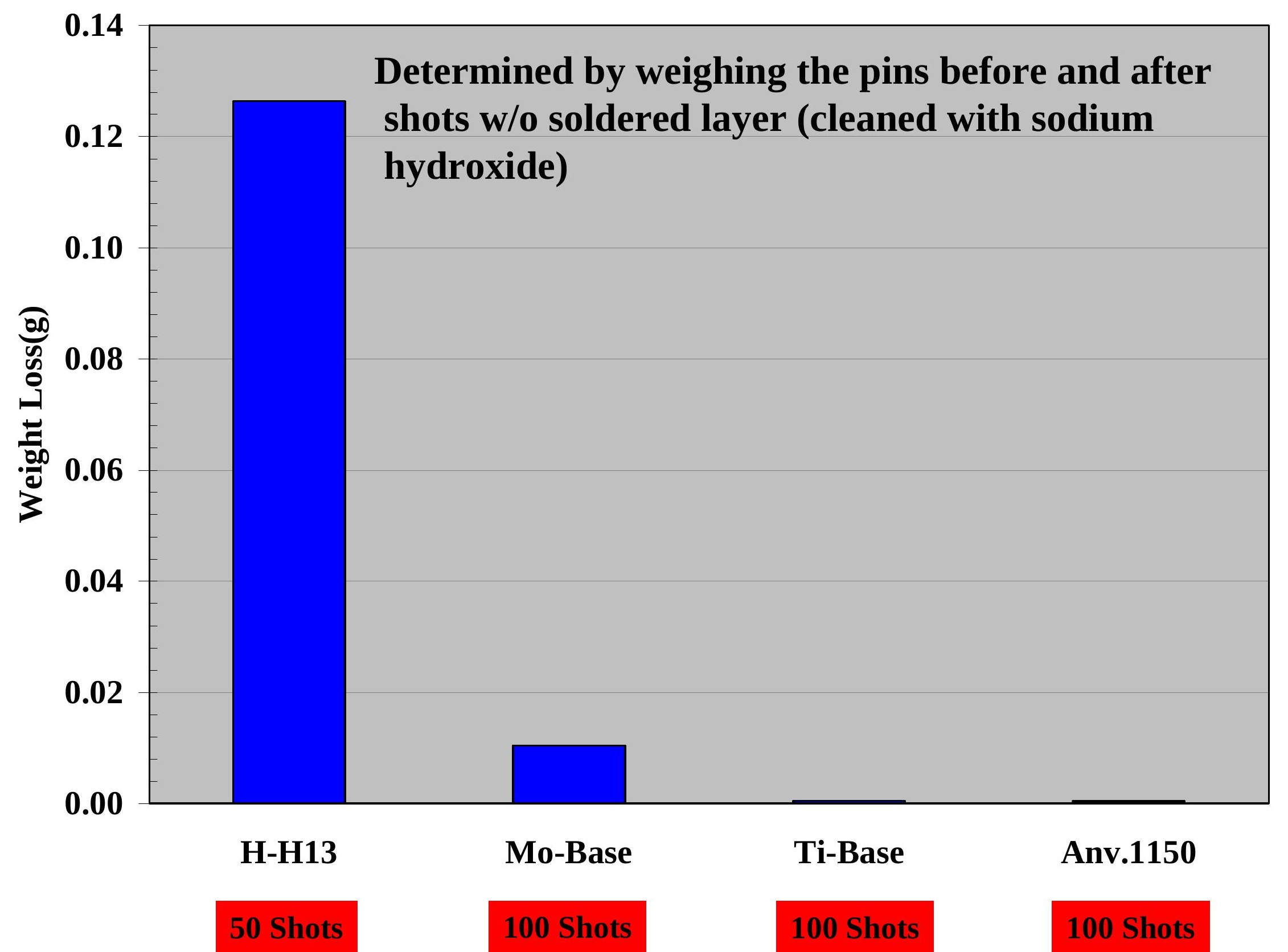




\section{Figure 25: Washout Induced Weight Loss}

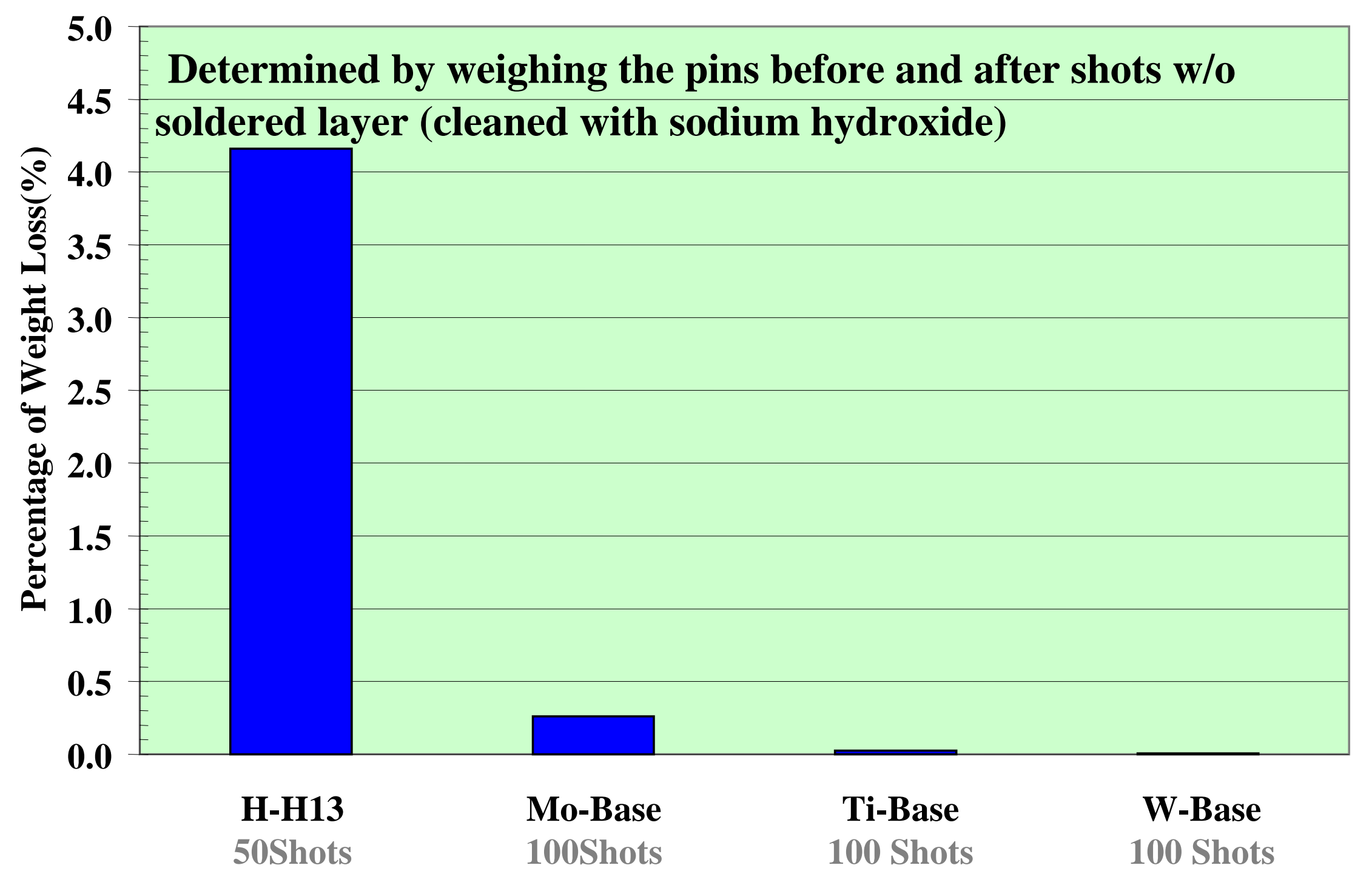




\section{Figure 26: Percentage of Weight Loss}

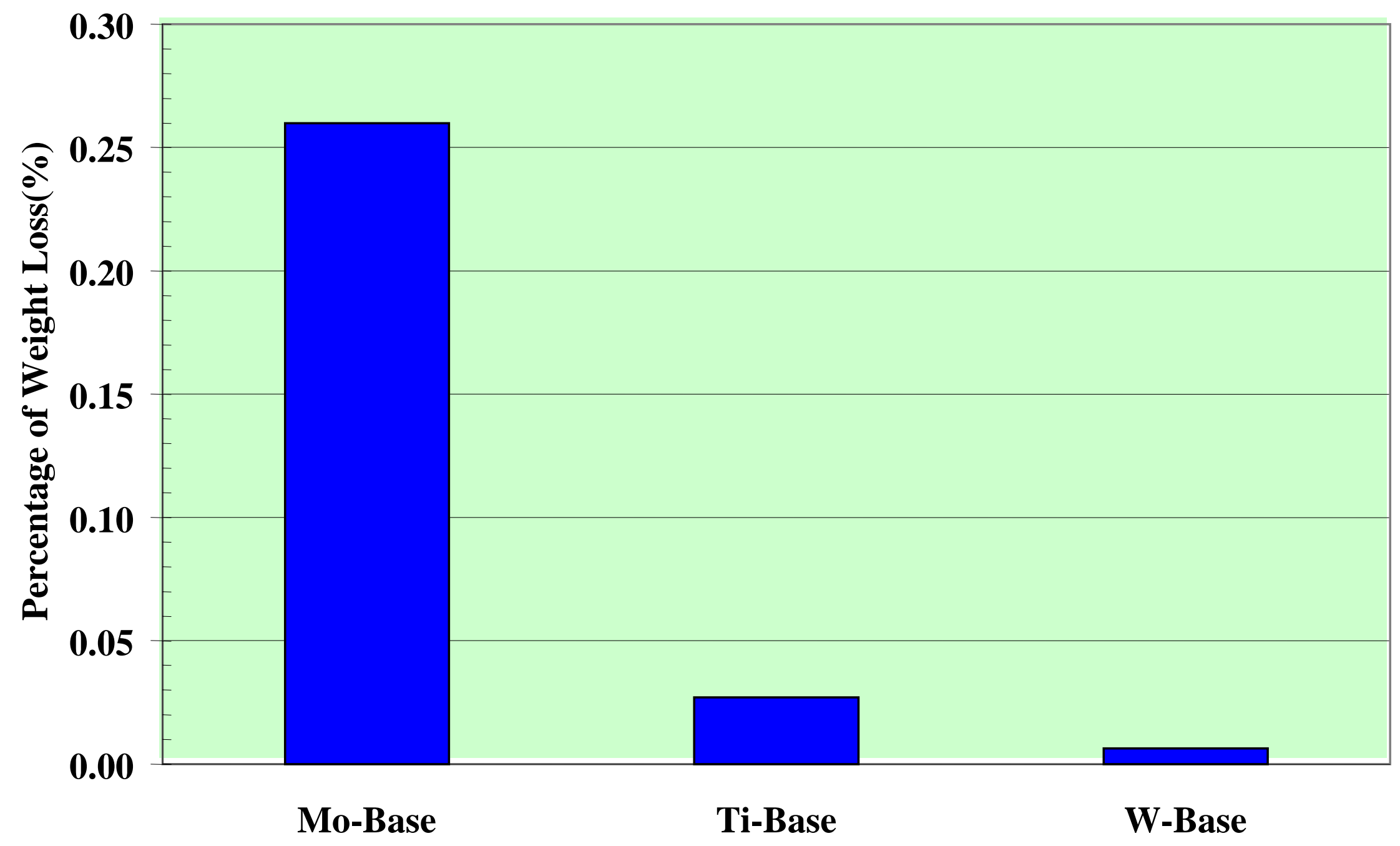

Determined by weighing the pins before and after shots w/o the soldered layer (cleaned with sodium hydroxide) 
Figure 27: Soldering-Washout \& Thermal Fatigue Ranking

\section{0-Best 1-Worst}

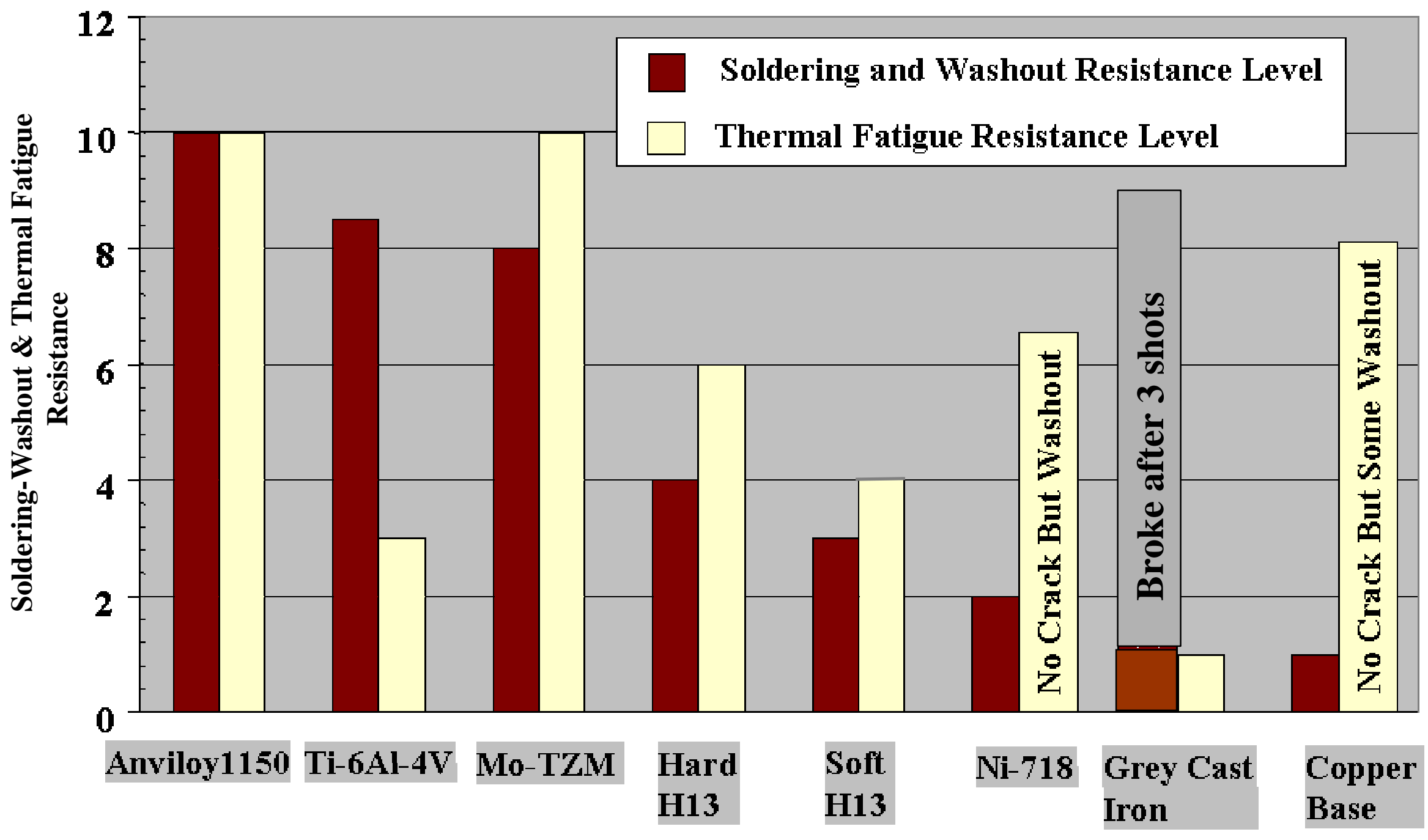




\section{Figure 28: Hardness Distribution in Nitro-Carburized Diffusion Layers}
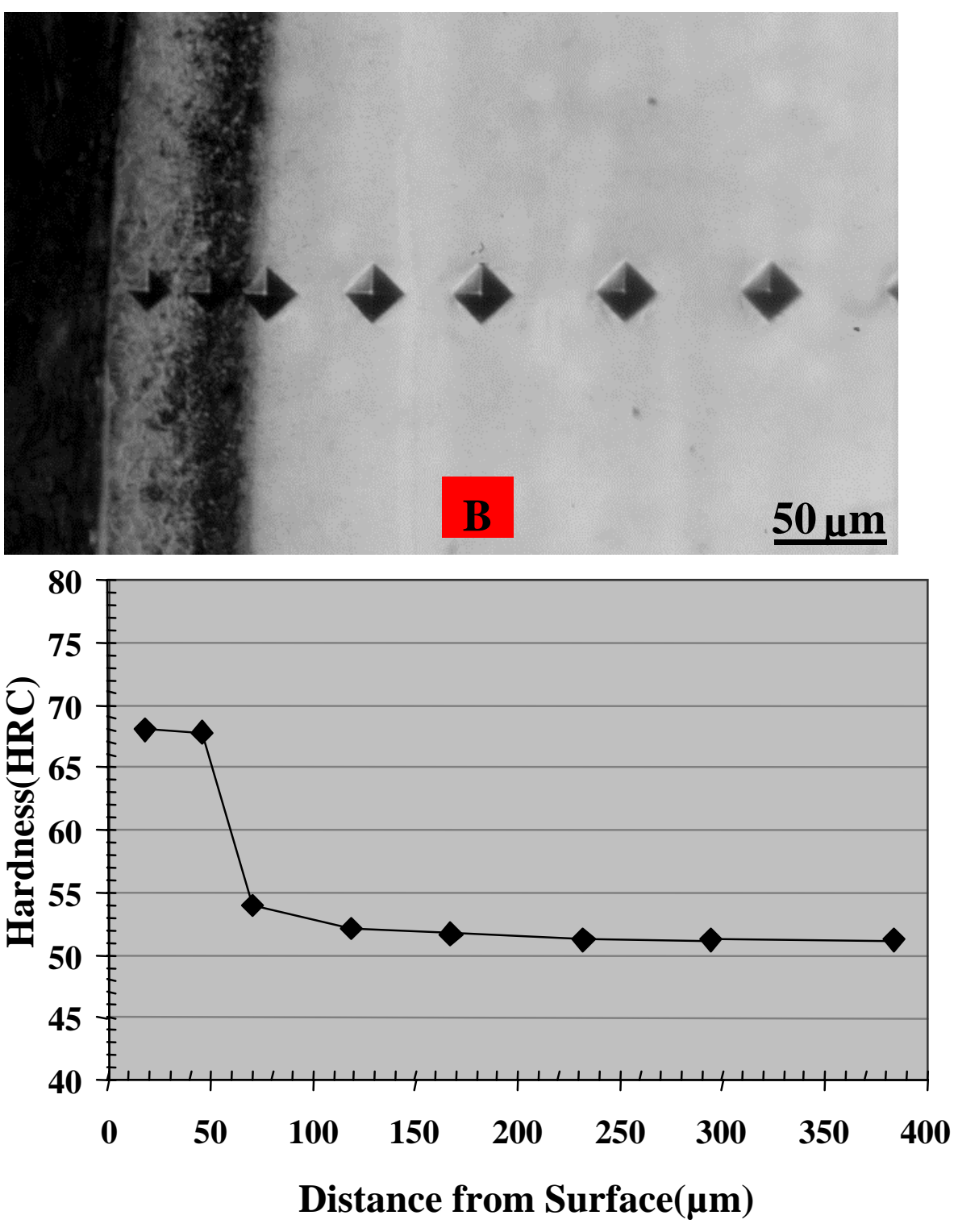
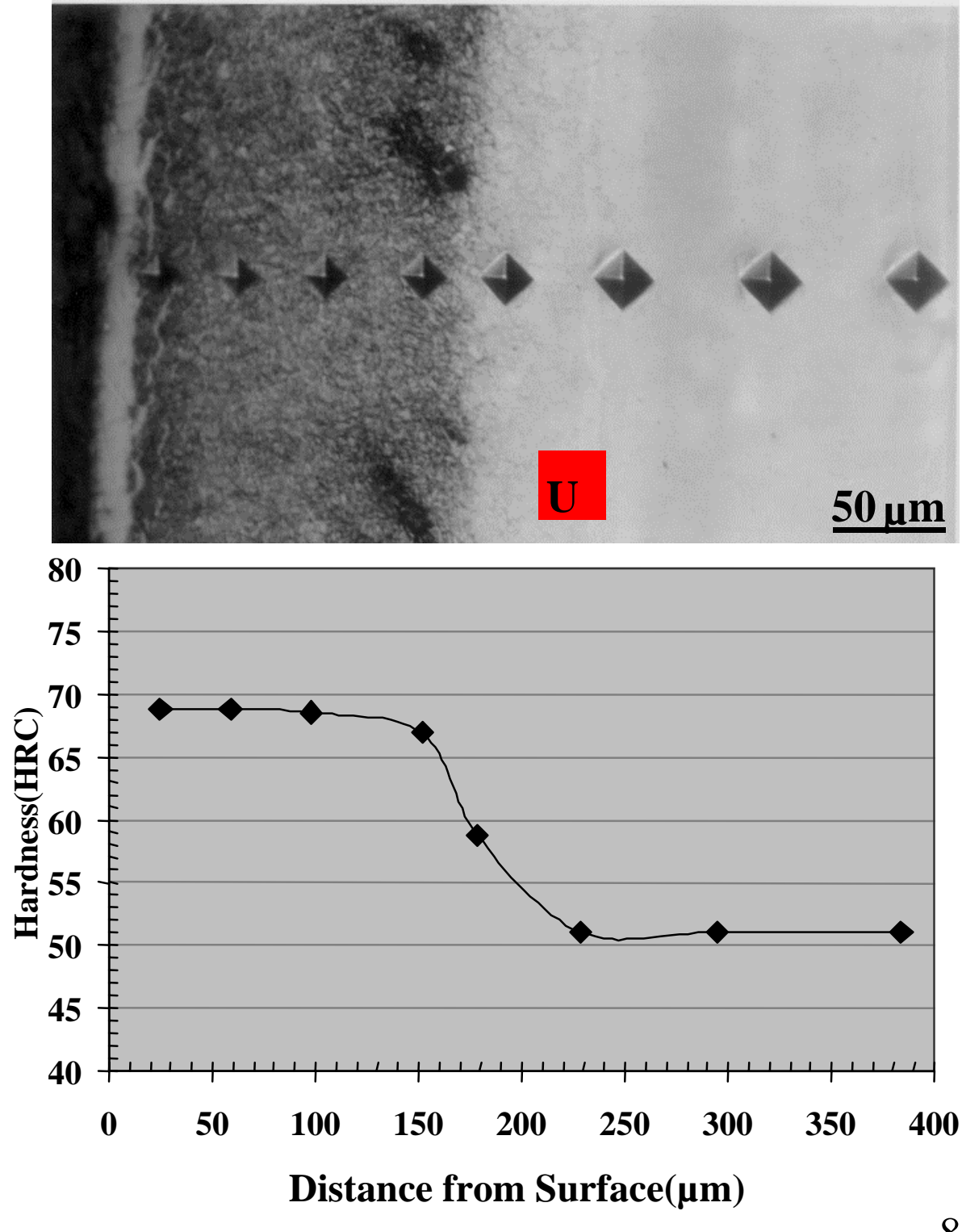
Figure 29: Hardness Distribution in Nitro-Carburized Diffusion Layers
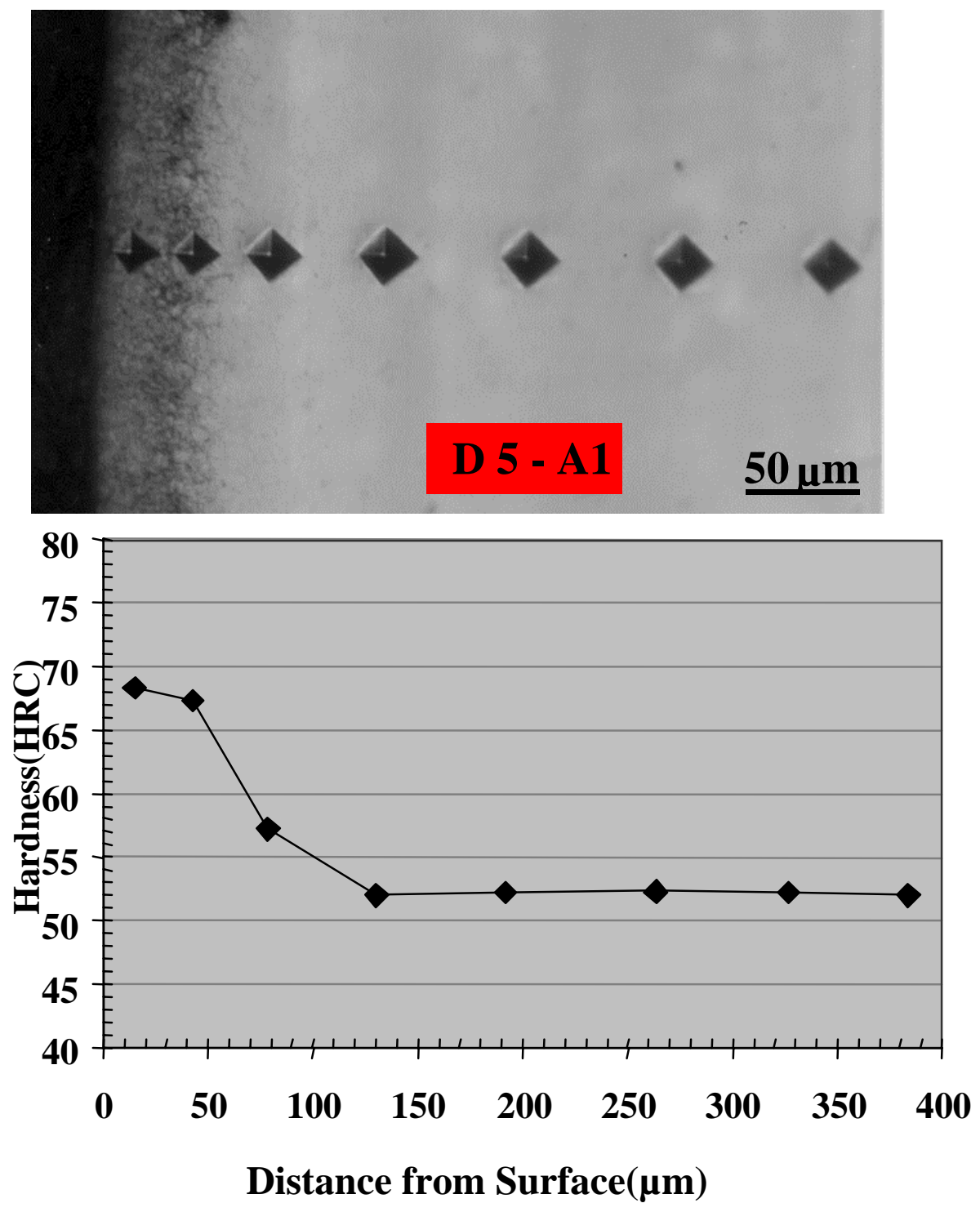
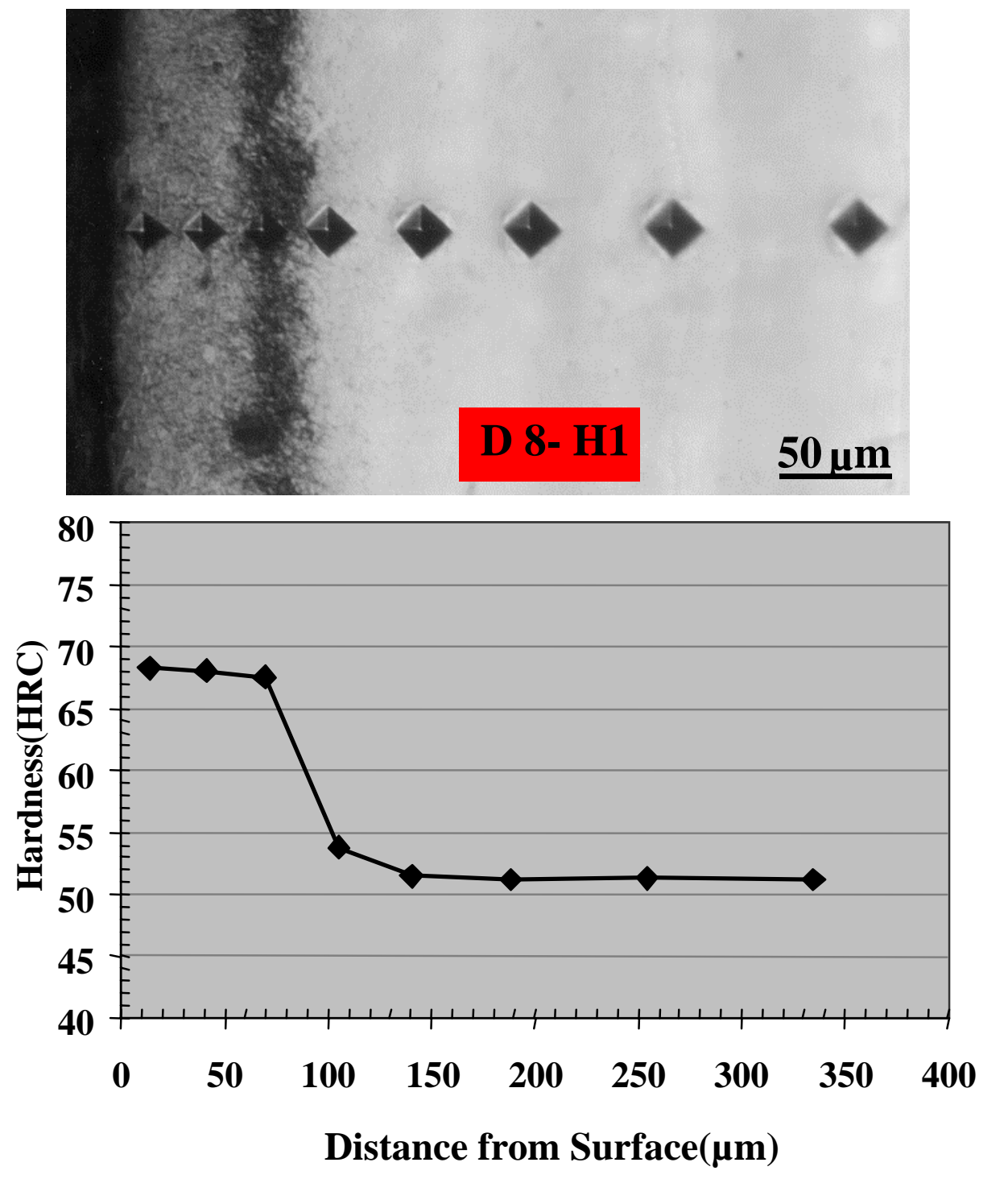


\section{Figure 31: Effect of the Nitro-Carburizing Treatment on Soldering}

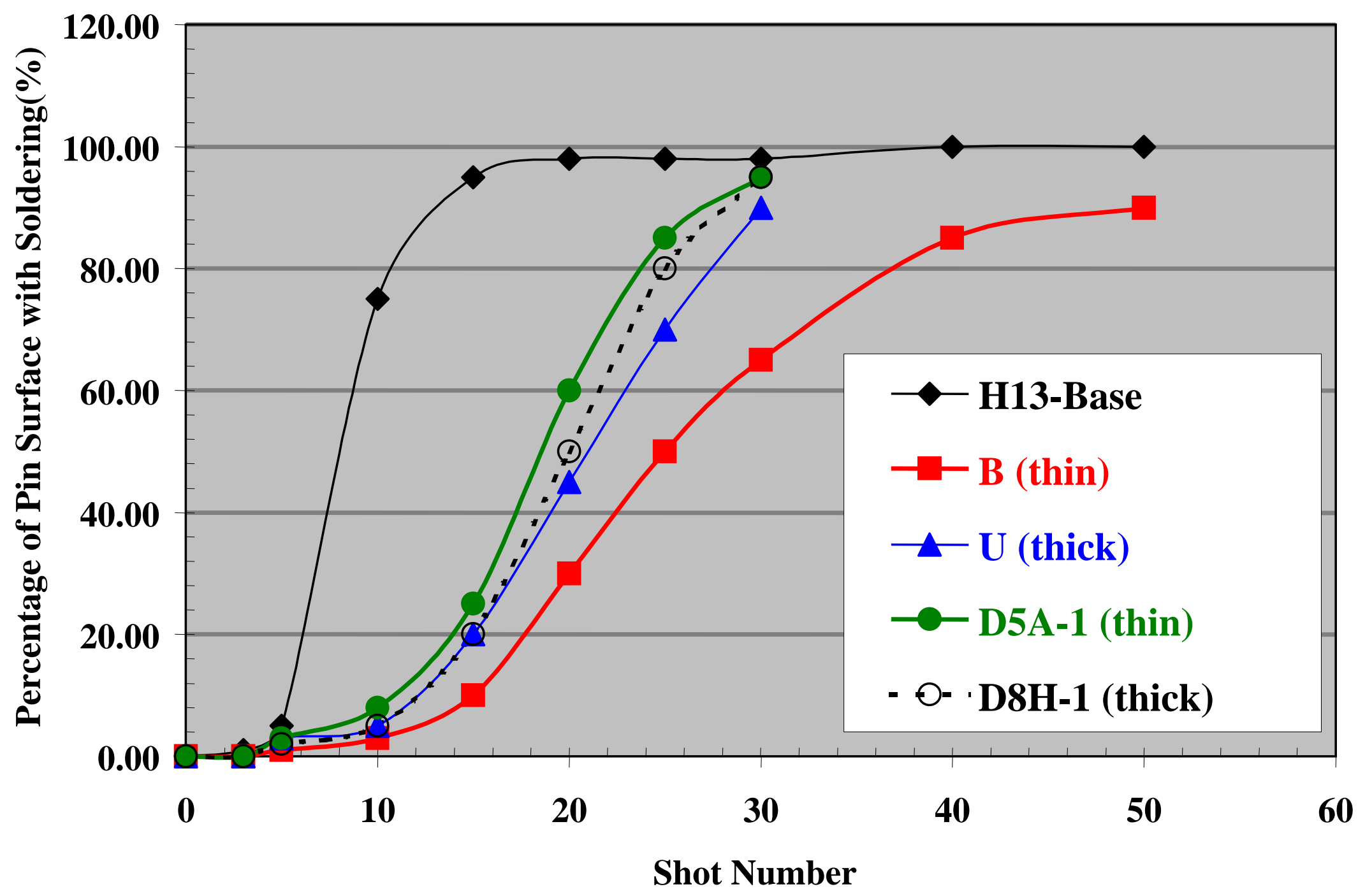




\section{Figure 32: Effect of Nitro-carburizing on Soldering After 50 Shots}

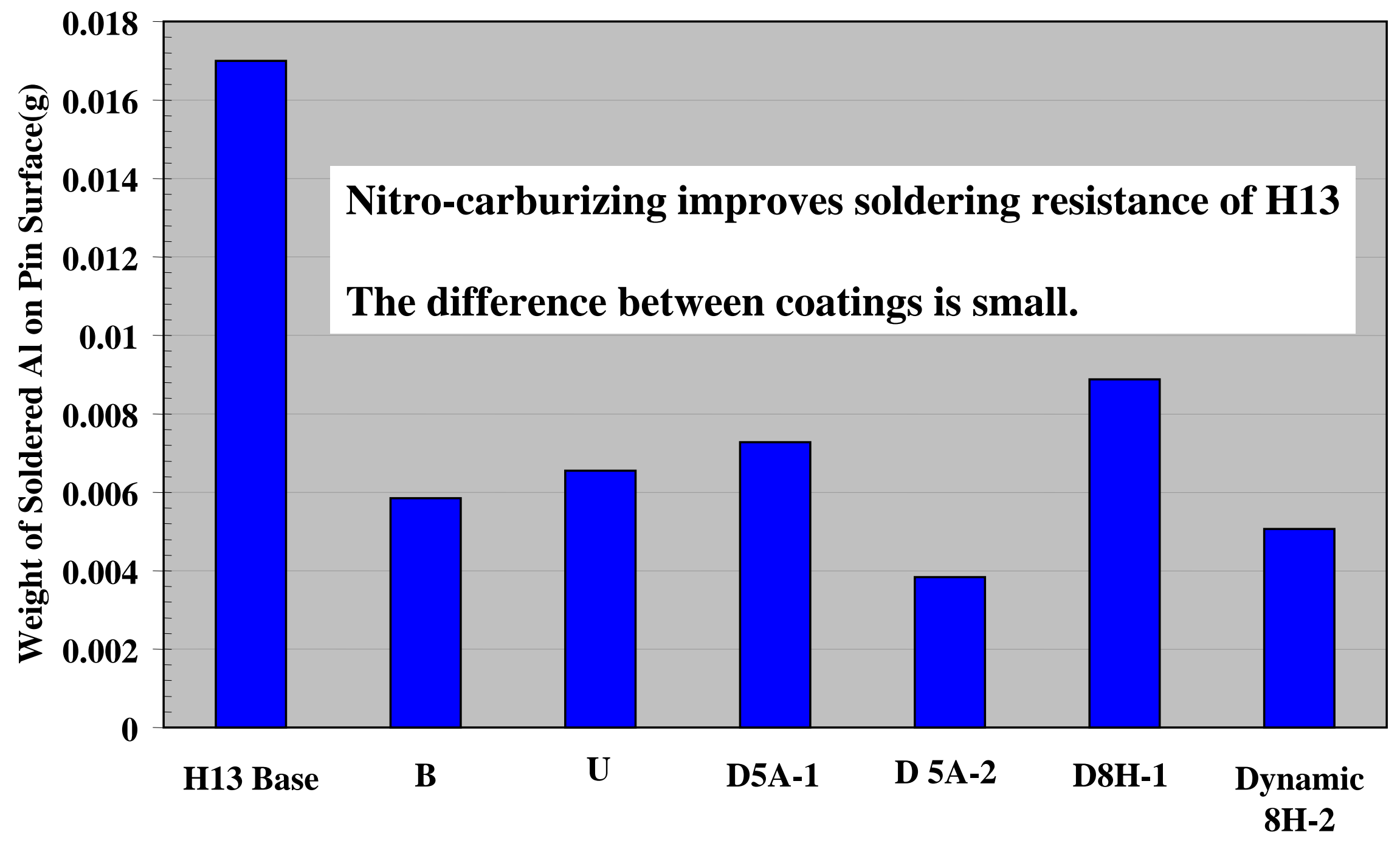


Figure 33: Appearance of $\mathrm{H13}$ and Nitro-Carburized Pins after 30 Shots

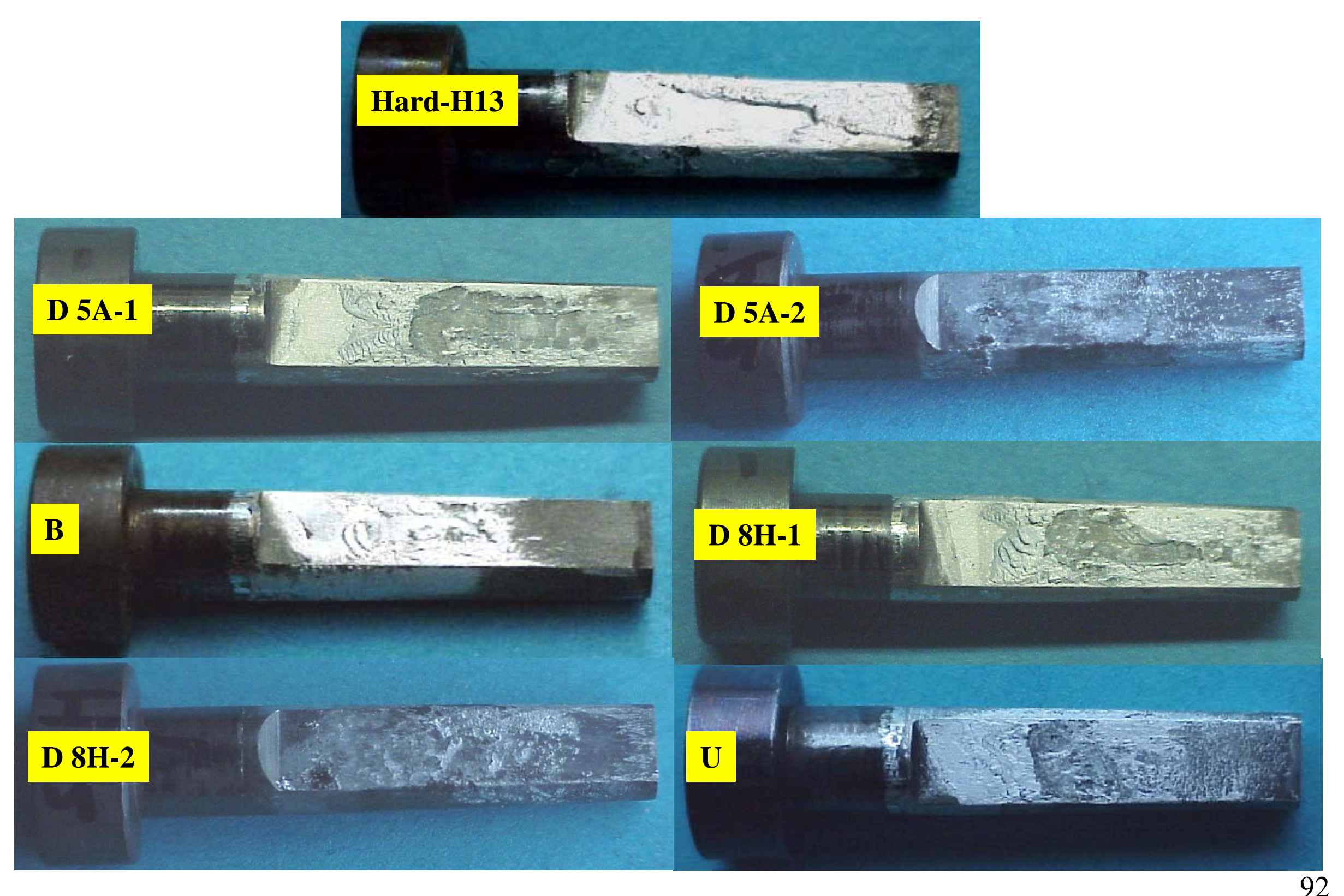




\section{Figure 34: Appearance of $\mathrm{H13}$ and Nitro-Carburized Pins after the Test (Soldered Al Dissolved in NaOH)}

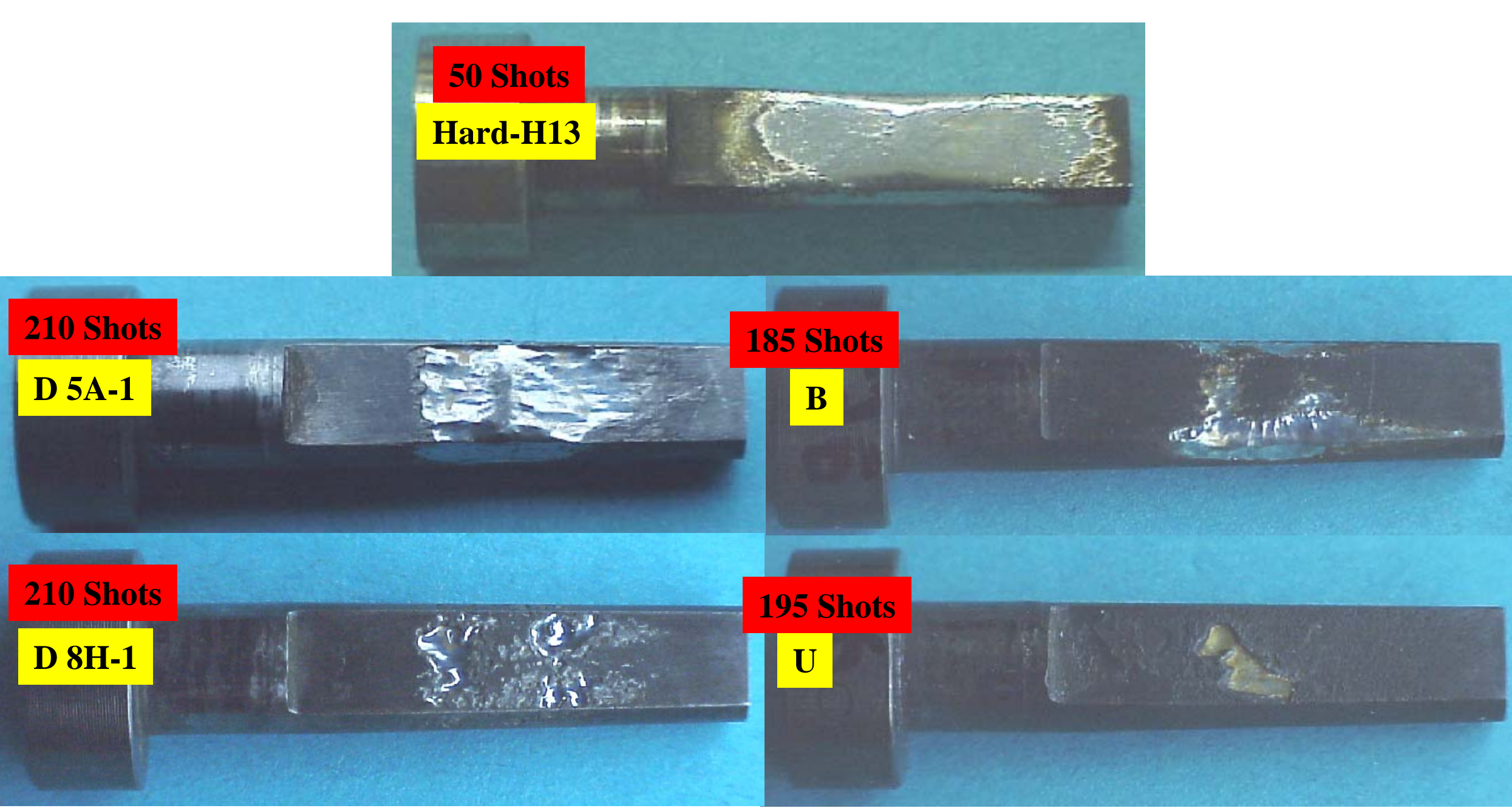


Figure 35: Effect of Nitro-Carburizing on Washout

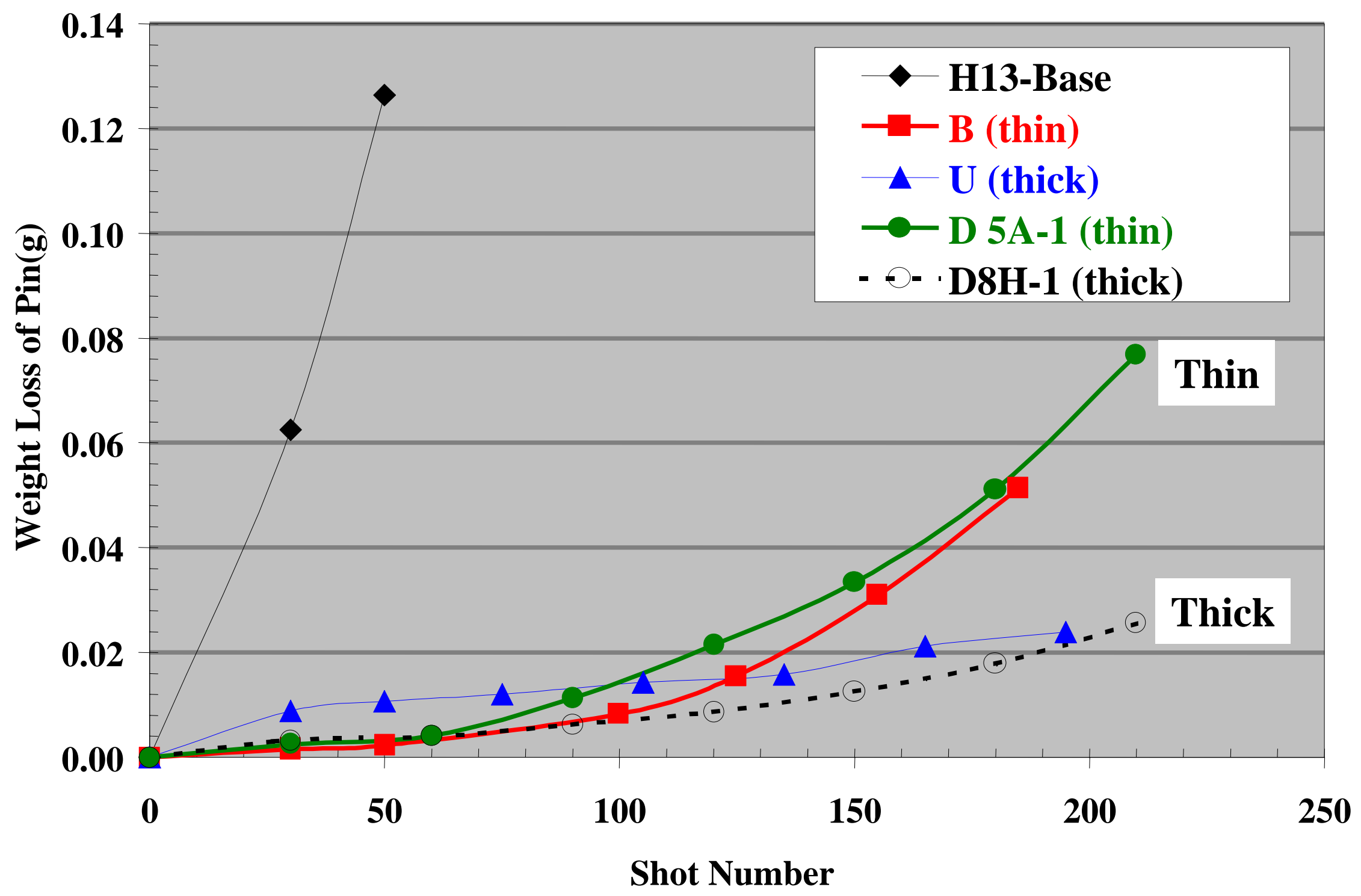

Thick nitro-carburized layers are better for washout than thin layers 94 
Figure 36: Impingement Surface of Thin Nitro-Carburized layer in "B" Pin (after 50 Shots - Soldered Al Dissolved in $\mathrm{NaOH}$ )

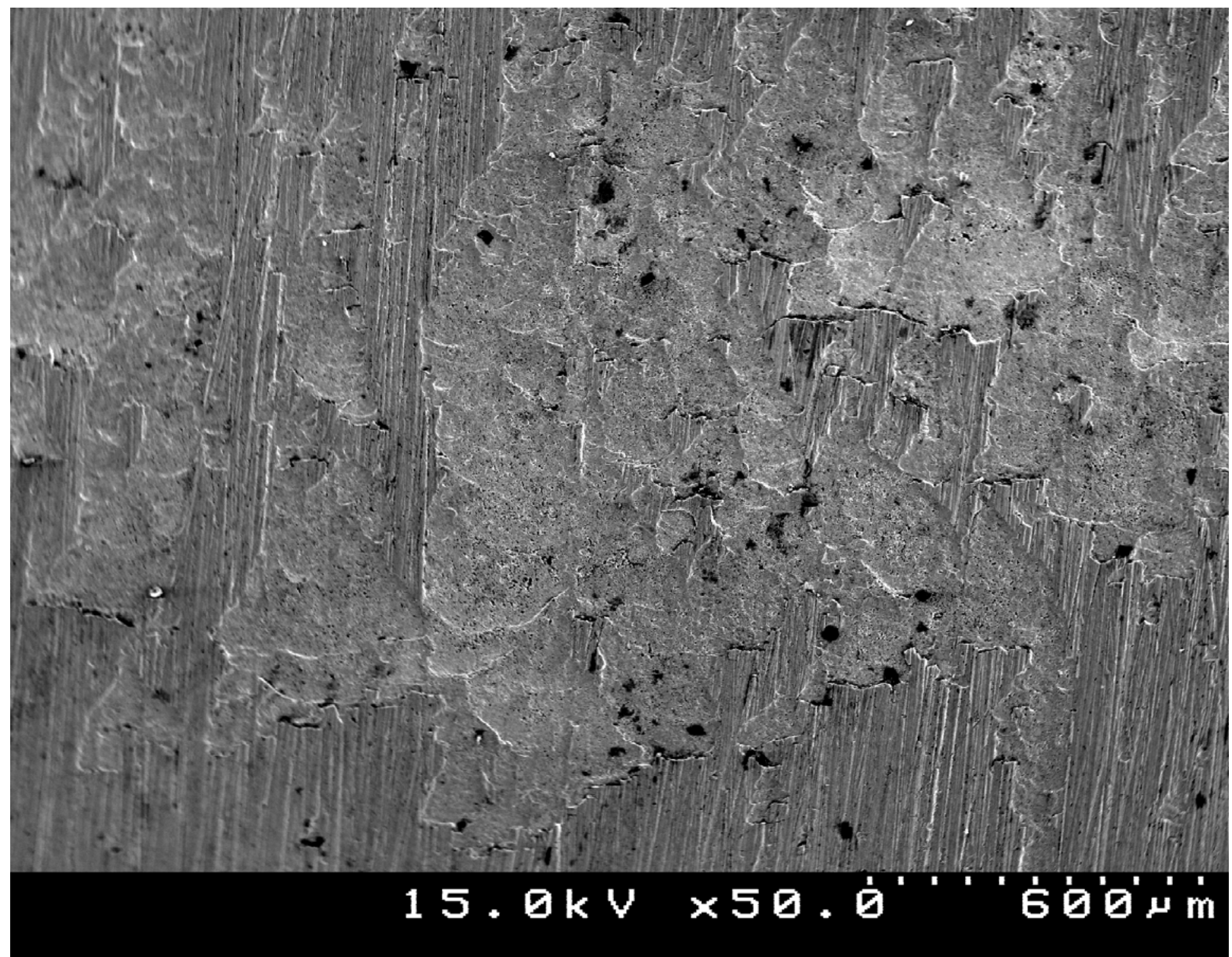


Figure 37: Impingement Surface of Thin Nitro-Carburized layer in " $B$ " Pin (after 150 Shots-Soldered Al Dissolved in $\mathrm{NaOH}$ )

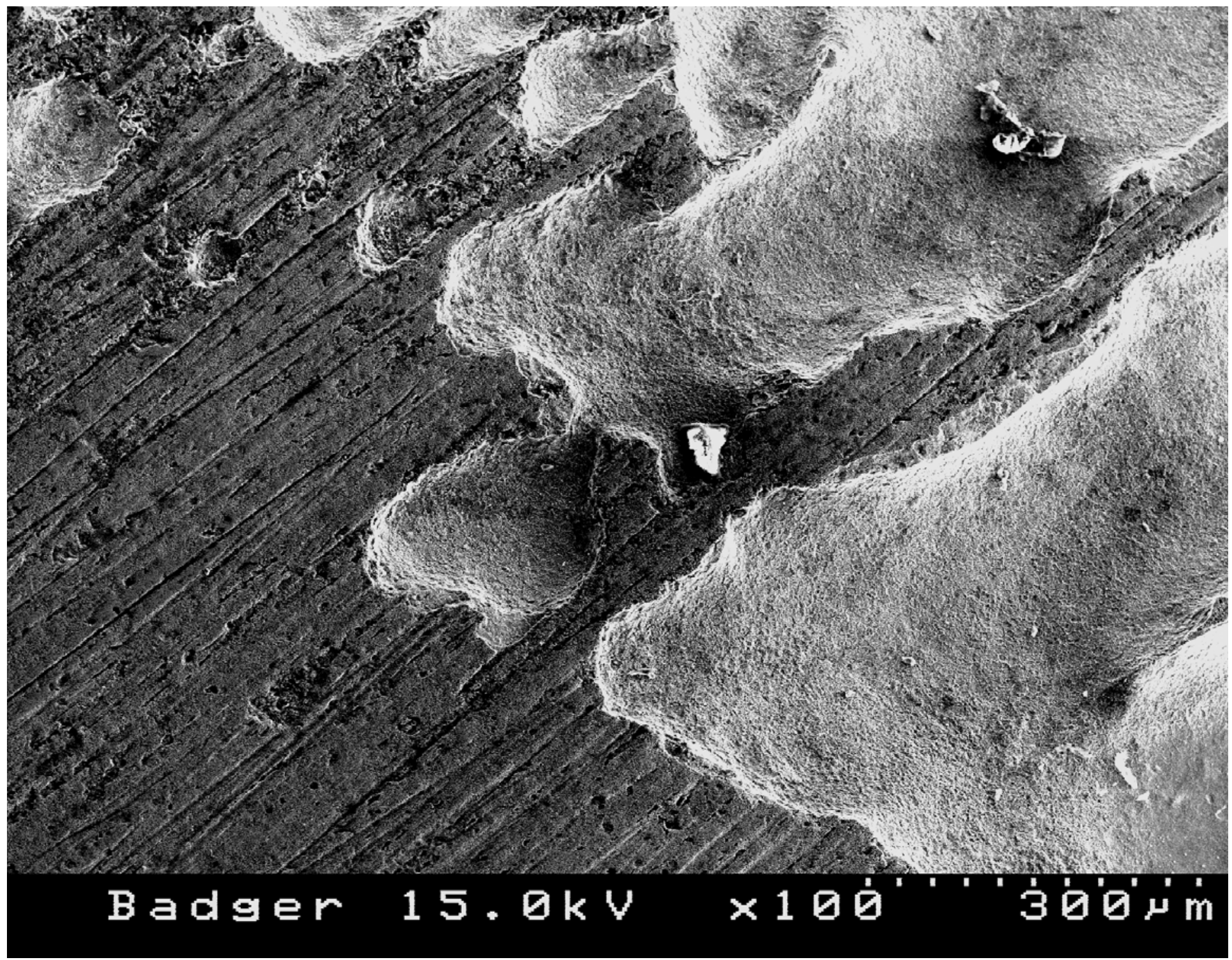


Figure 38: Impingement Surface of Thick Nitro-Carburized Layer in "U" Pin (after 150 Shots and Soldered Al Dissolved in $\mathrm{NaOH}$ )

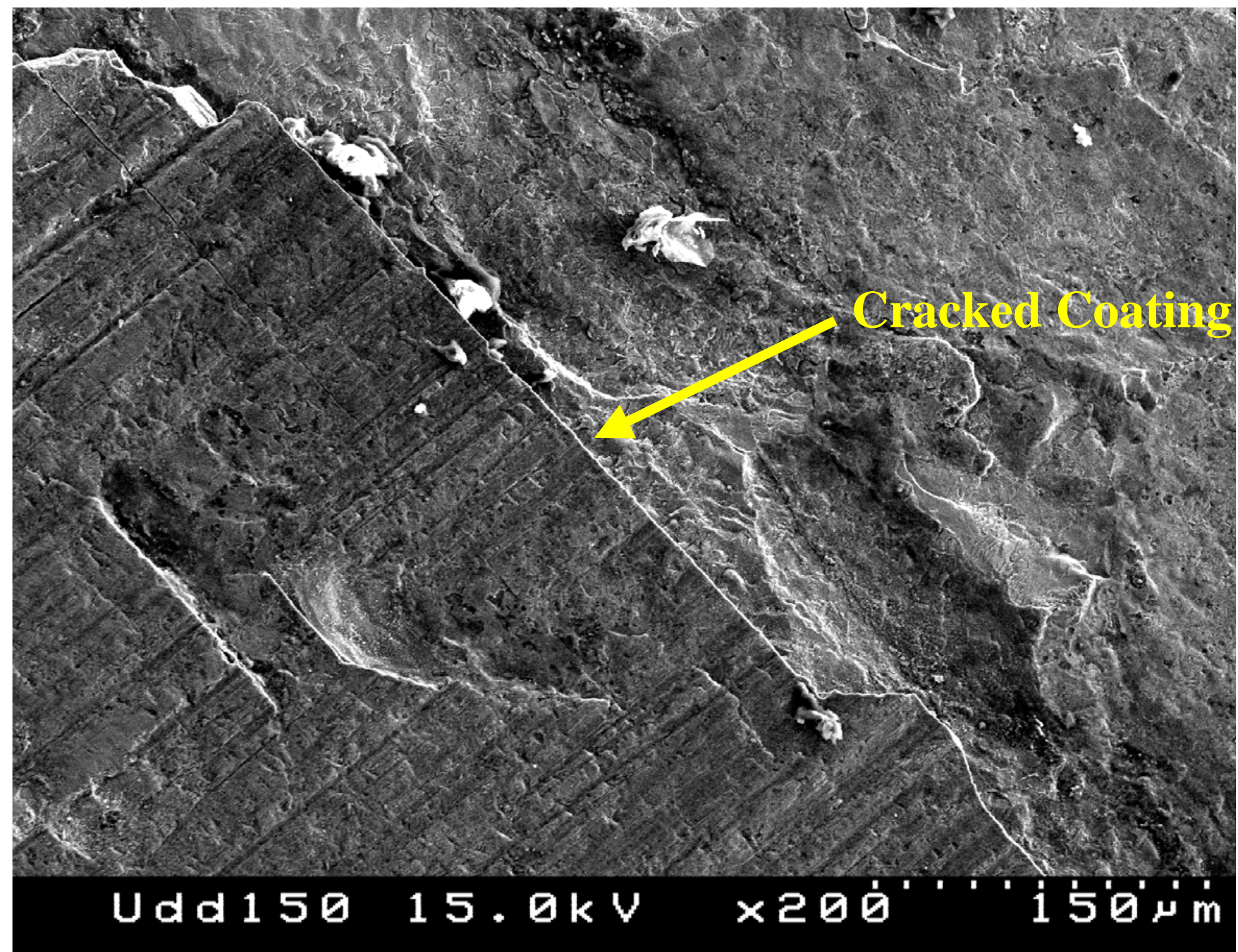


Figure 40: Average Max Crack Length of Nitrocarburized H13

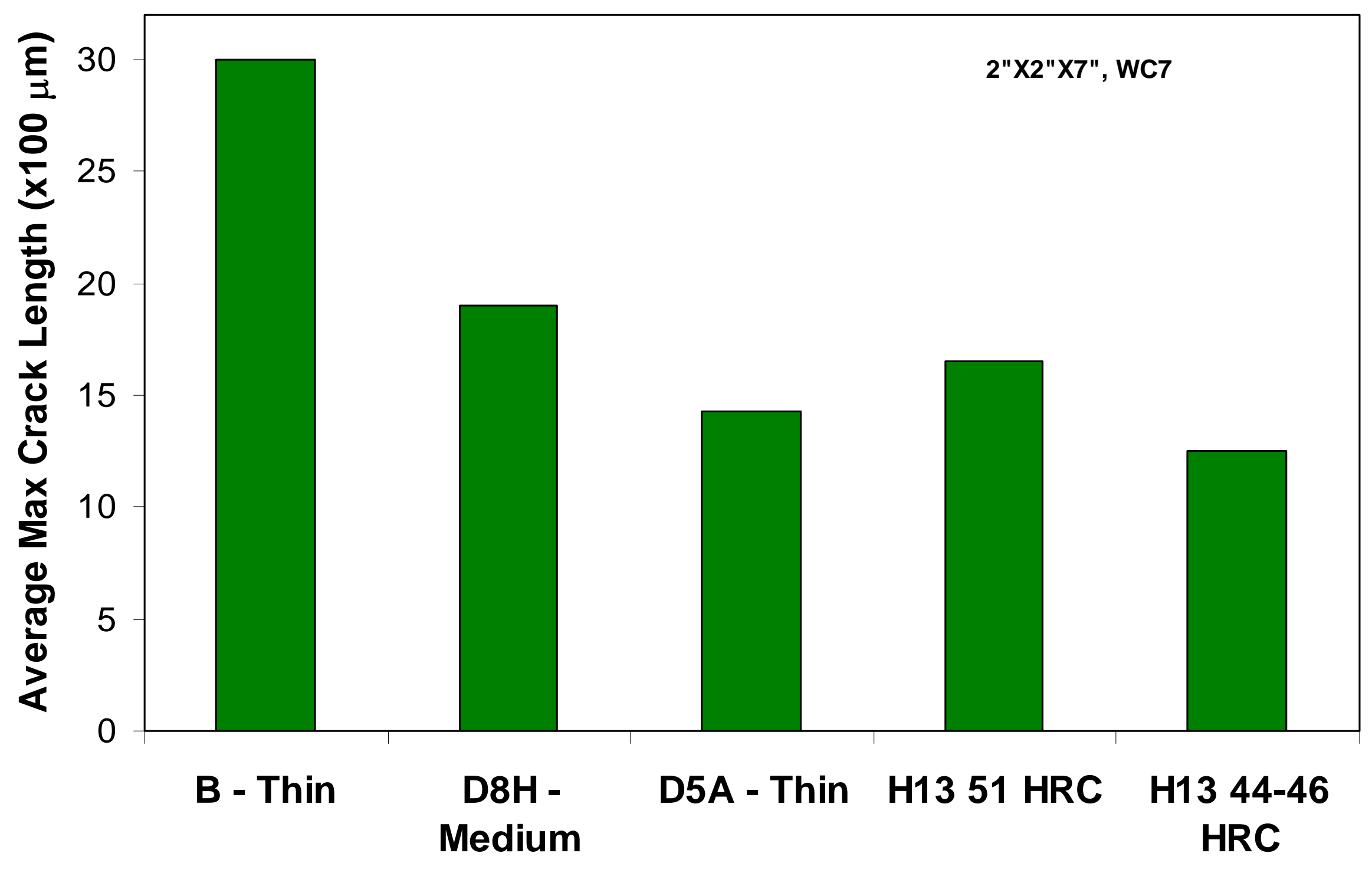


Figure 41: Total Crack Area of Nitrocarburized H13

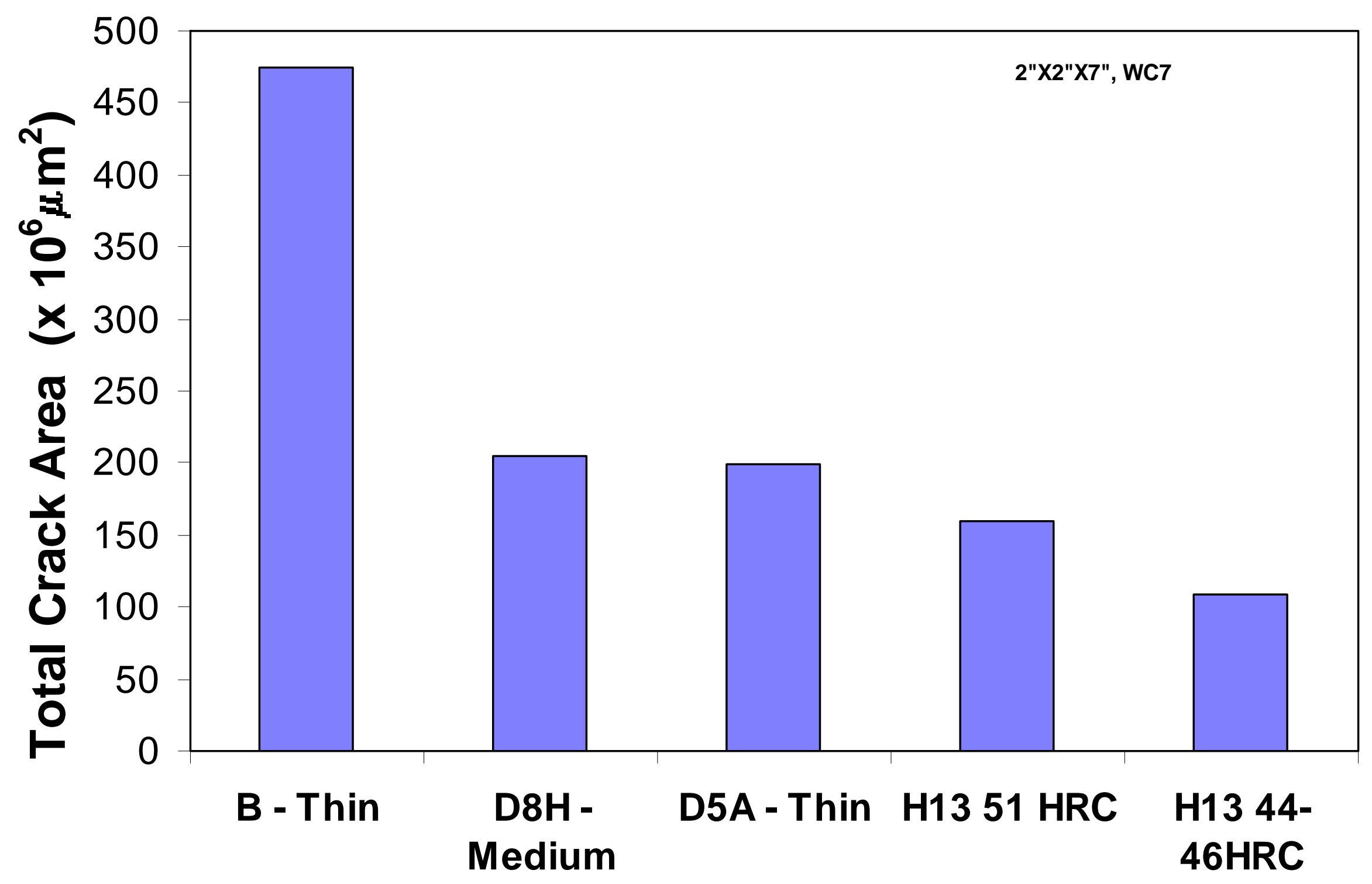




\section{Table 6: Characteristics of PVD Coatings}

\begin{tabular}{|c|c|c|c|c|}
\hline Coating & Coating Process & $\begin{array}{c}\text { Thickness* } \\
(\mu \mathrm{m})\end{array}$ & $\begin{array}{c}\text { Hardness** } \\
\left(\mathbf{H v}-\mathbf{k g} / \mathbf{m m}^{2}\right)\end{array}$ & $\begin{array}{c}\text { Oxidation } \\
\text { Temperature } \\
(\mathbf{F}) * *\end{array}$ \\
\hline CrN+W (I) & PVD & 3.5 & $2500 \pm 400$ & 2,278 \\
\hline CrN (P) & PVD & 5.0 & $2500 \pm 400$ & 2,278 \\
\hline (TiAl)N (B) & PVD & 2.0 & $2600 \pm 400$ & $2,278-2,368$ \\
\hline CrC (B) & PVD & 6.25 & $1850 \pm 200$ & 2,278 \\
\hline
\end{tabular}

* Measured

** Literature 


\section{Figure 42: Cross- Section of PVD Coatings and Pin Substrates}
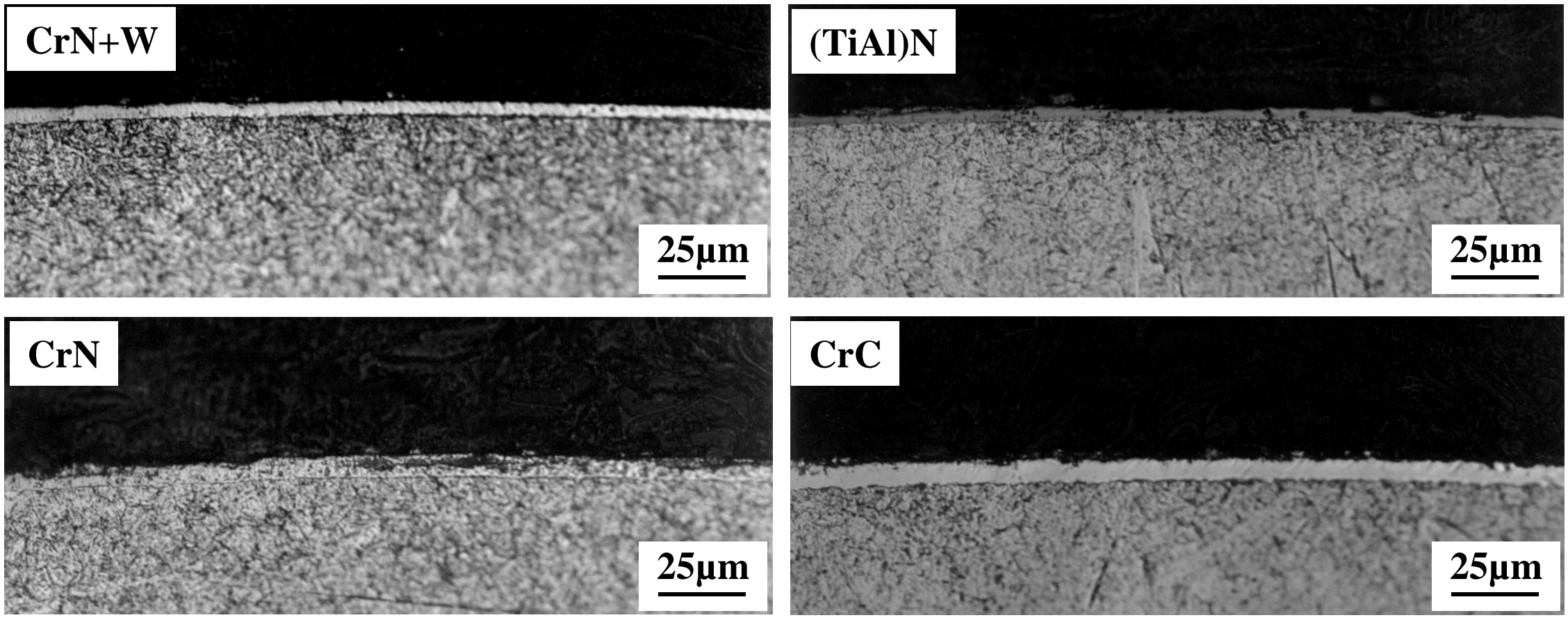
Figure 43: Appearance of PVD Coated Pins before Testing \& after 30 Shots

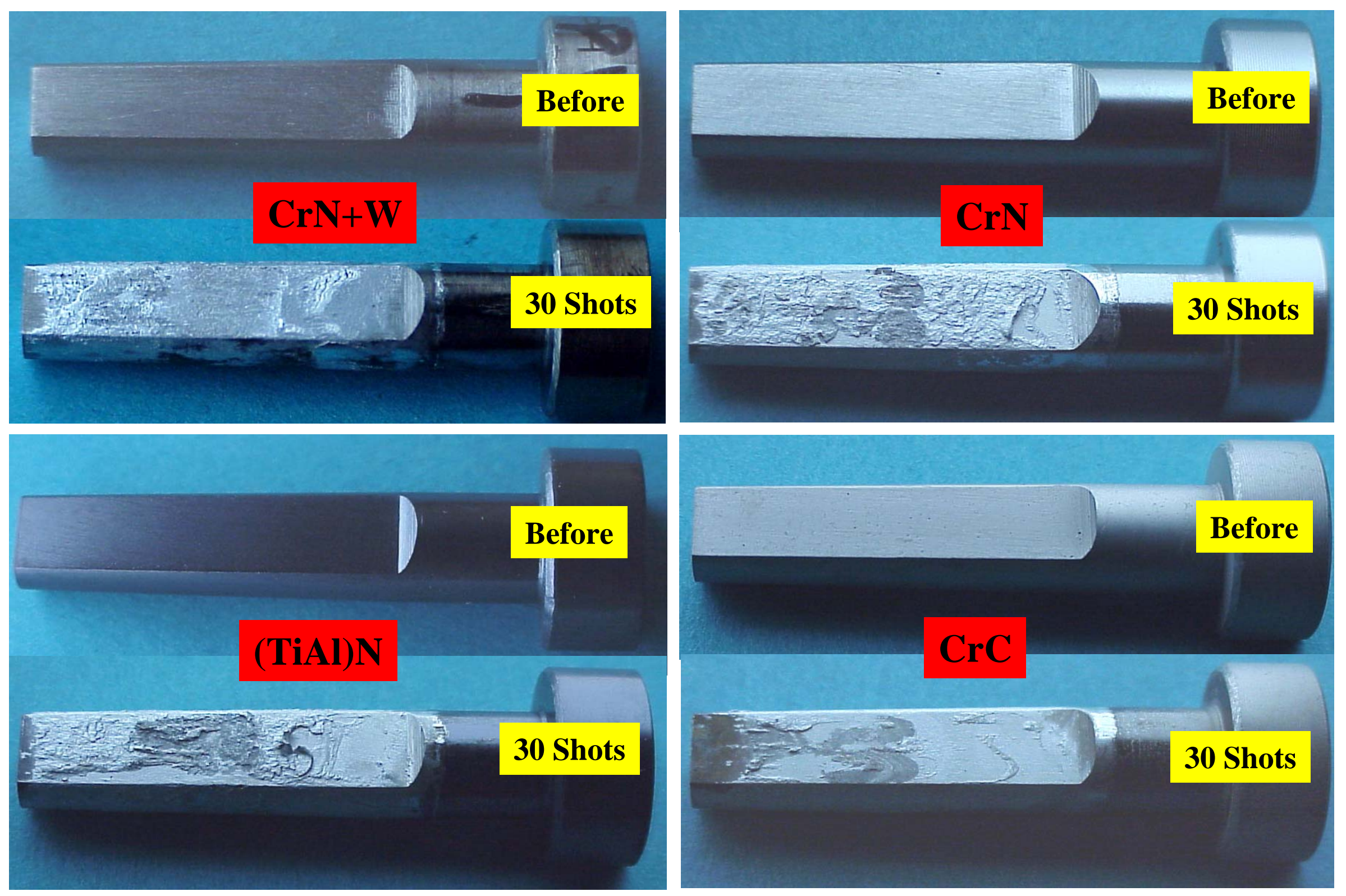


Figure 44: Soldering Appearance of H13 Pin with CrN+W PVD Coating

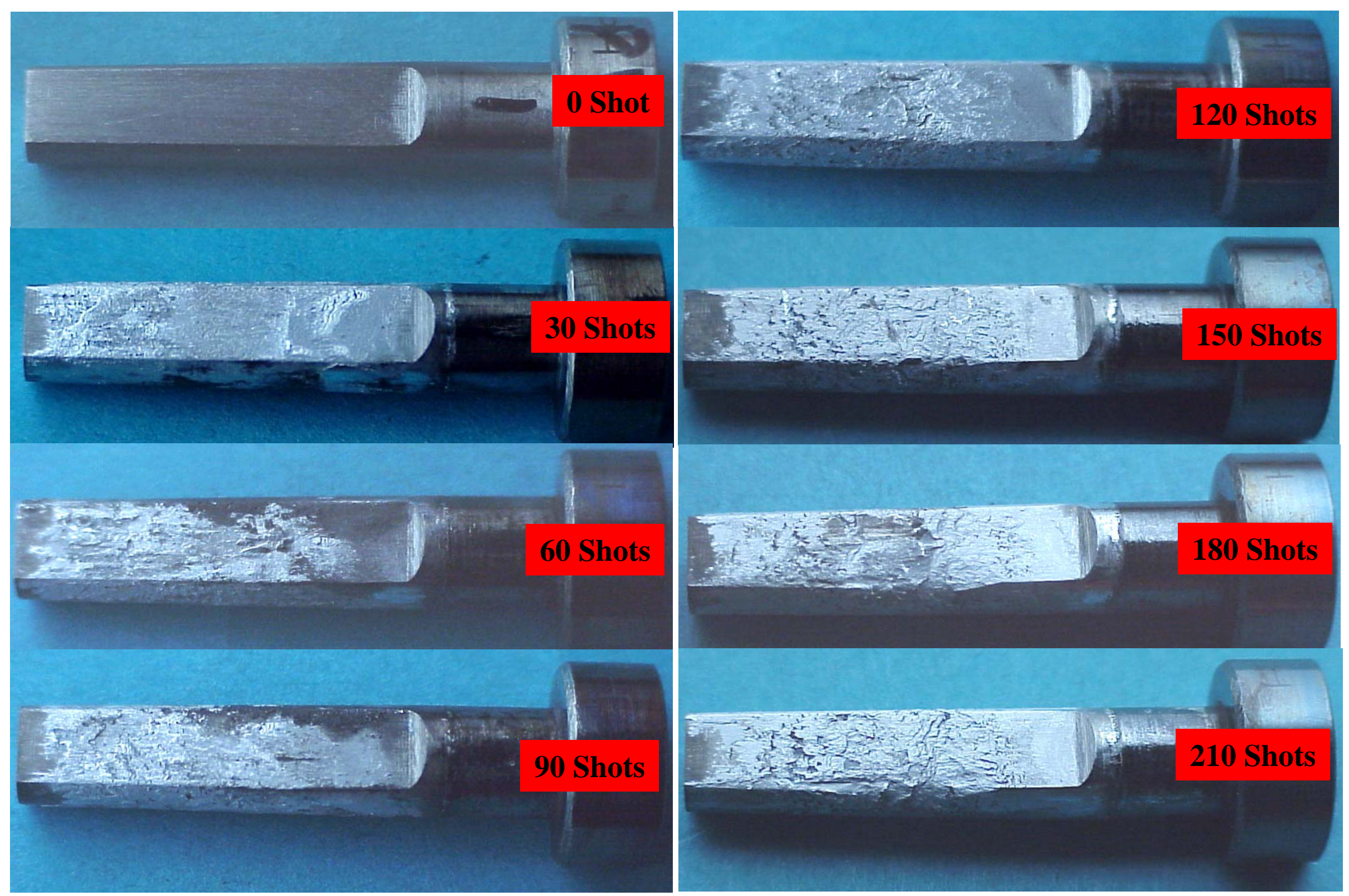




\section{Figure 45: Soldering Appearance of H13 Pin with CrN PVD Coating}
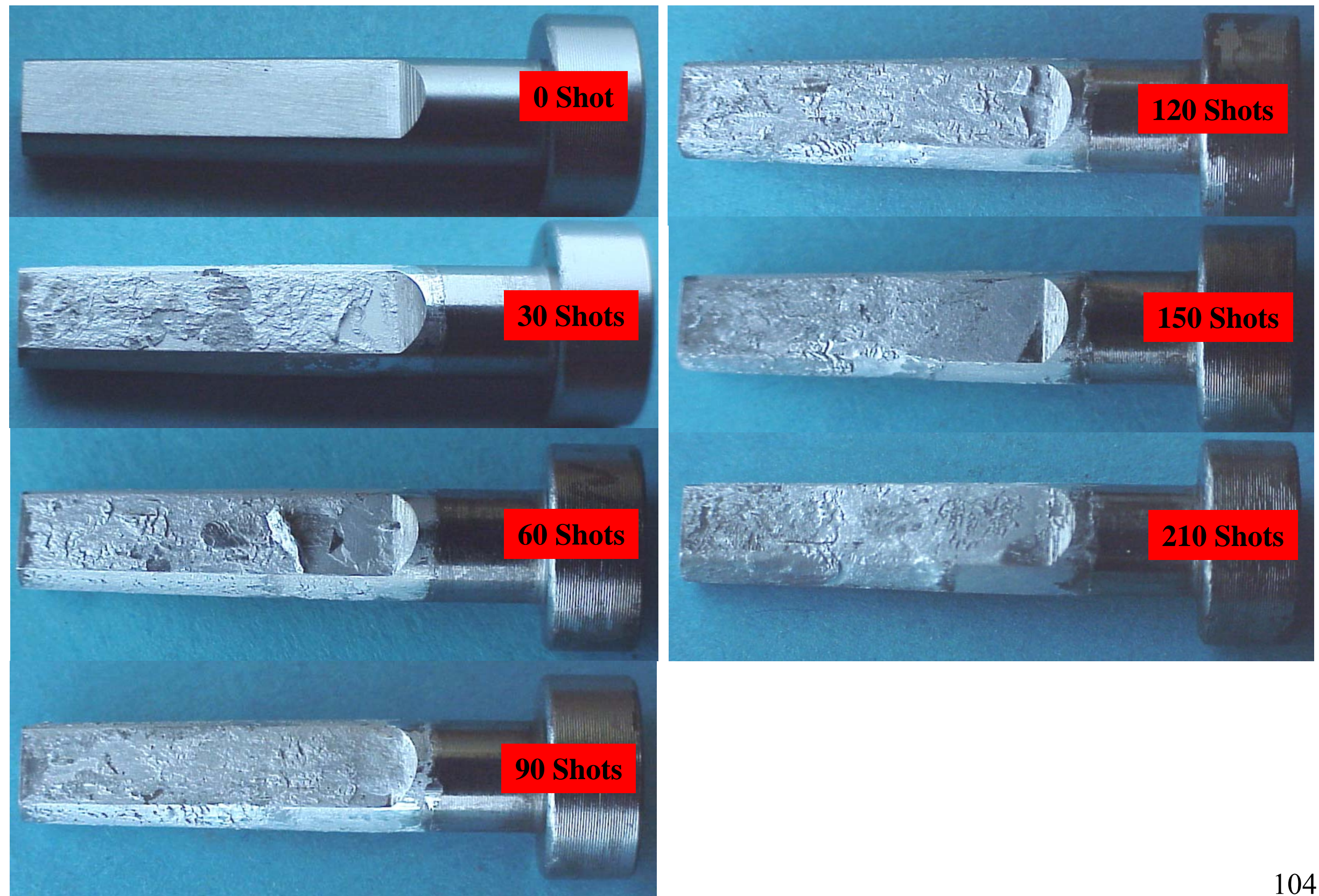
Figure 46: Soldering Appearance of H13 Pin with (TiAl)N PVD Coating

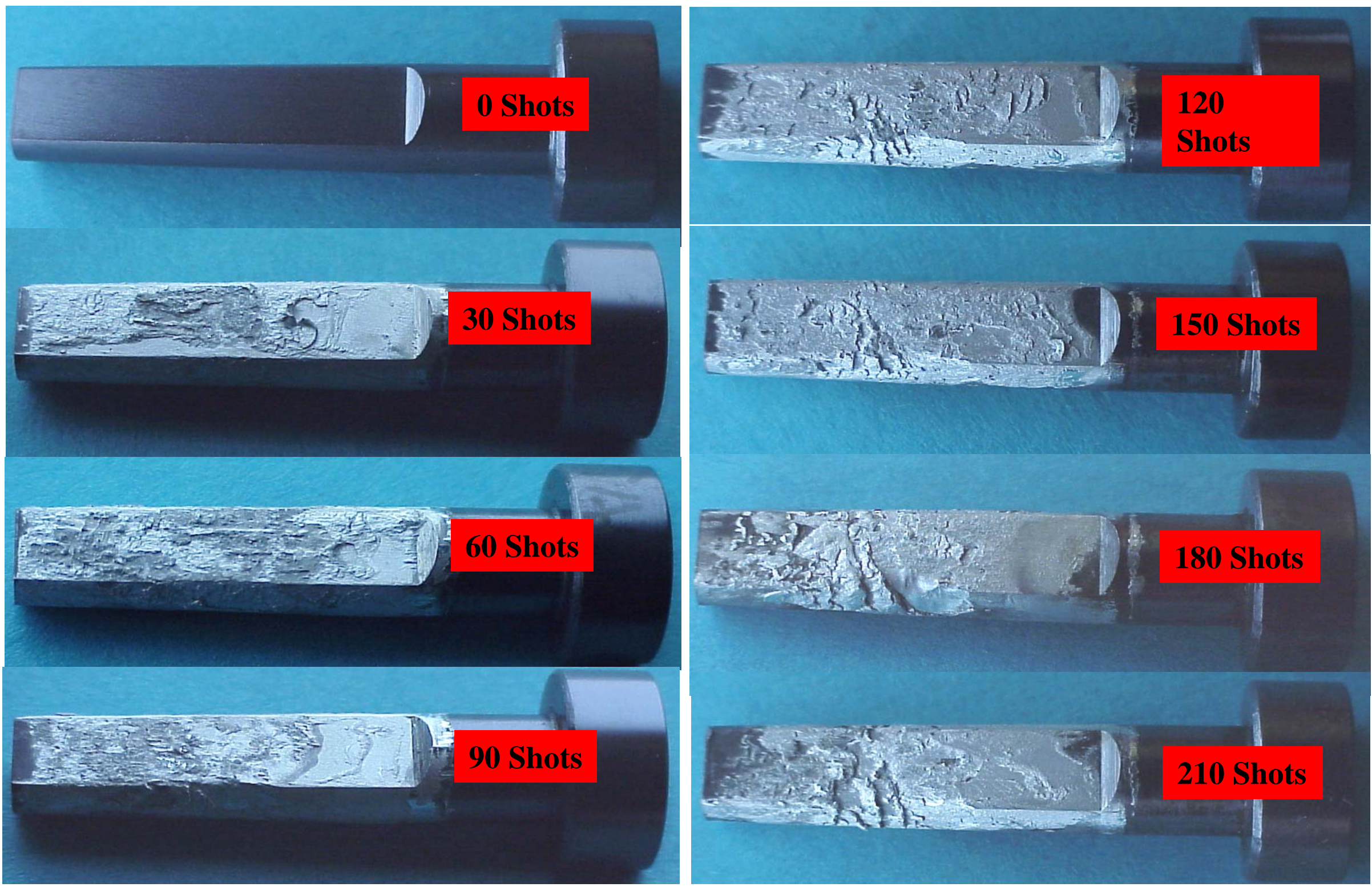


Figure 47: Soldering Appearance of H13 Pin with CrC PVD Coating

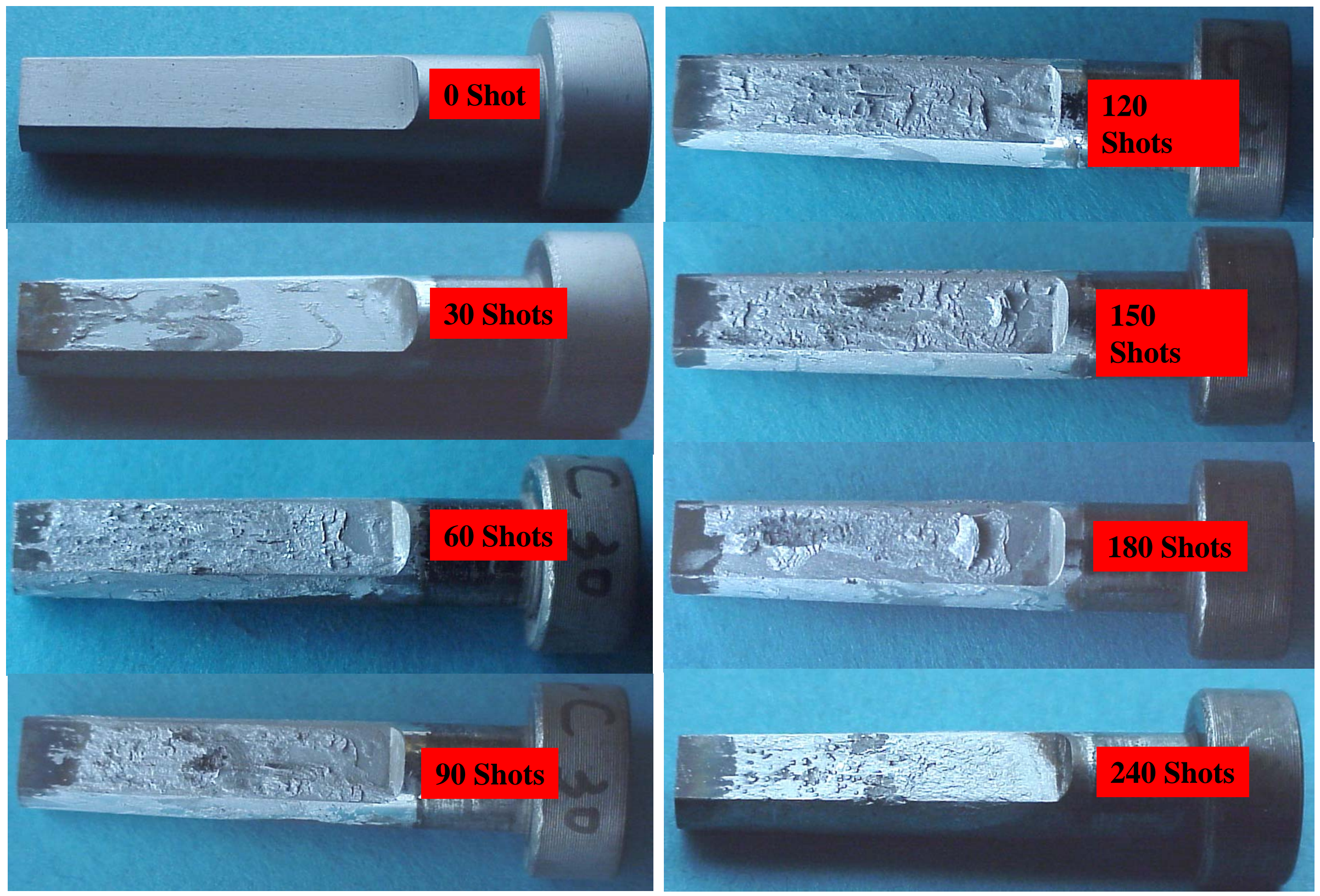


Figure 48: Effect of PVD Coating on Soldering

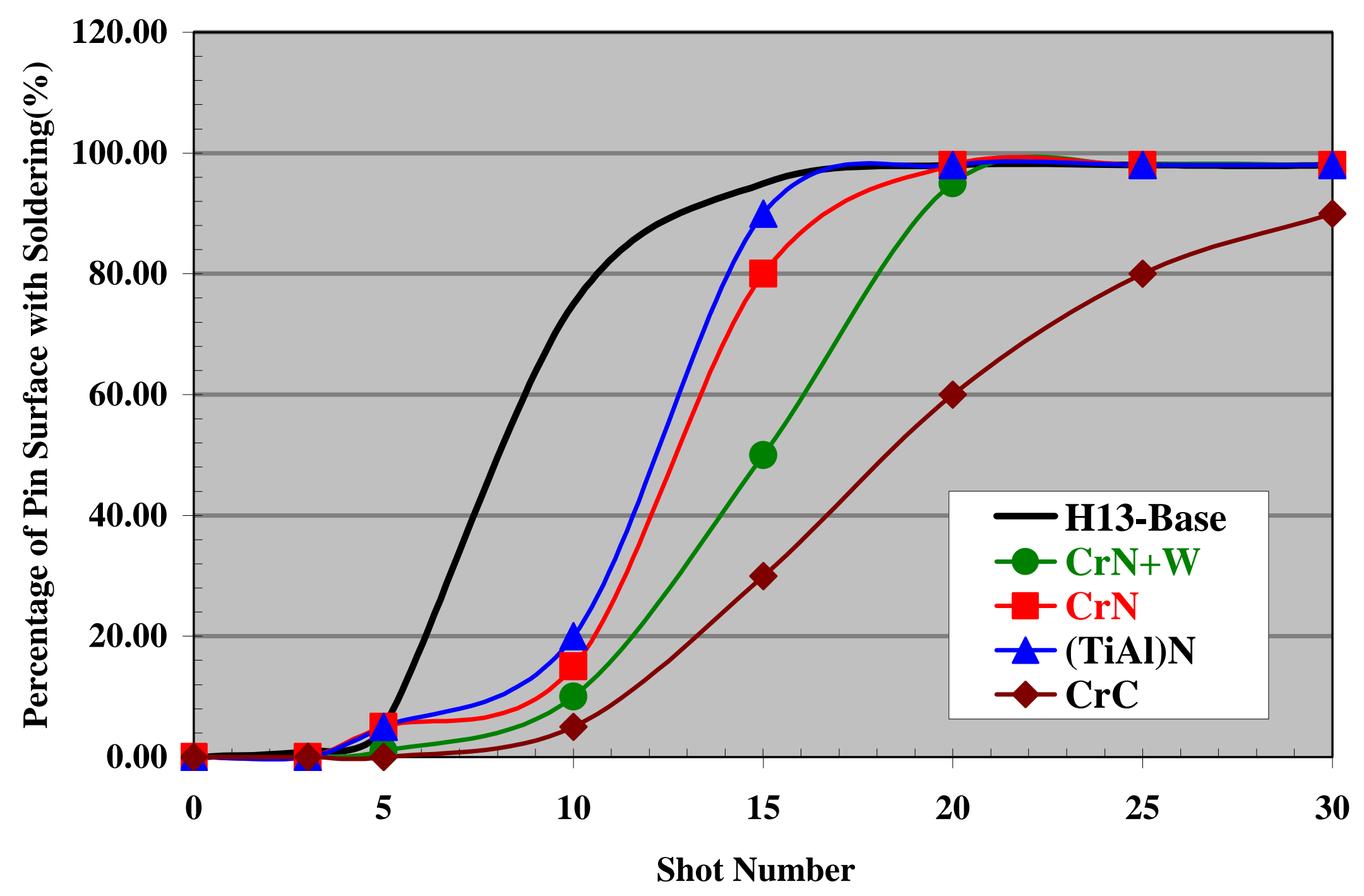


Figure 49: Effect of PVD Coating Materials on Soldering (after 30 shots)

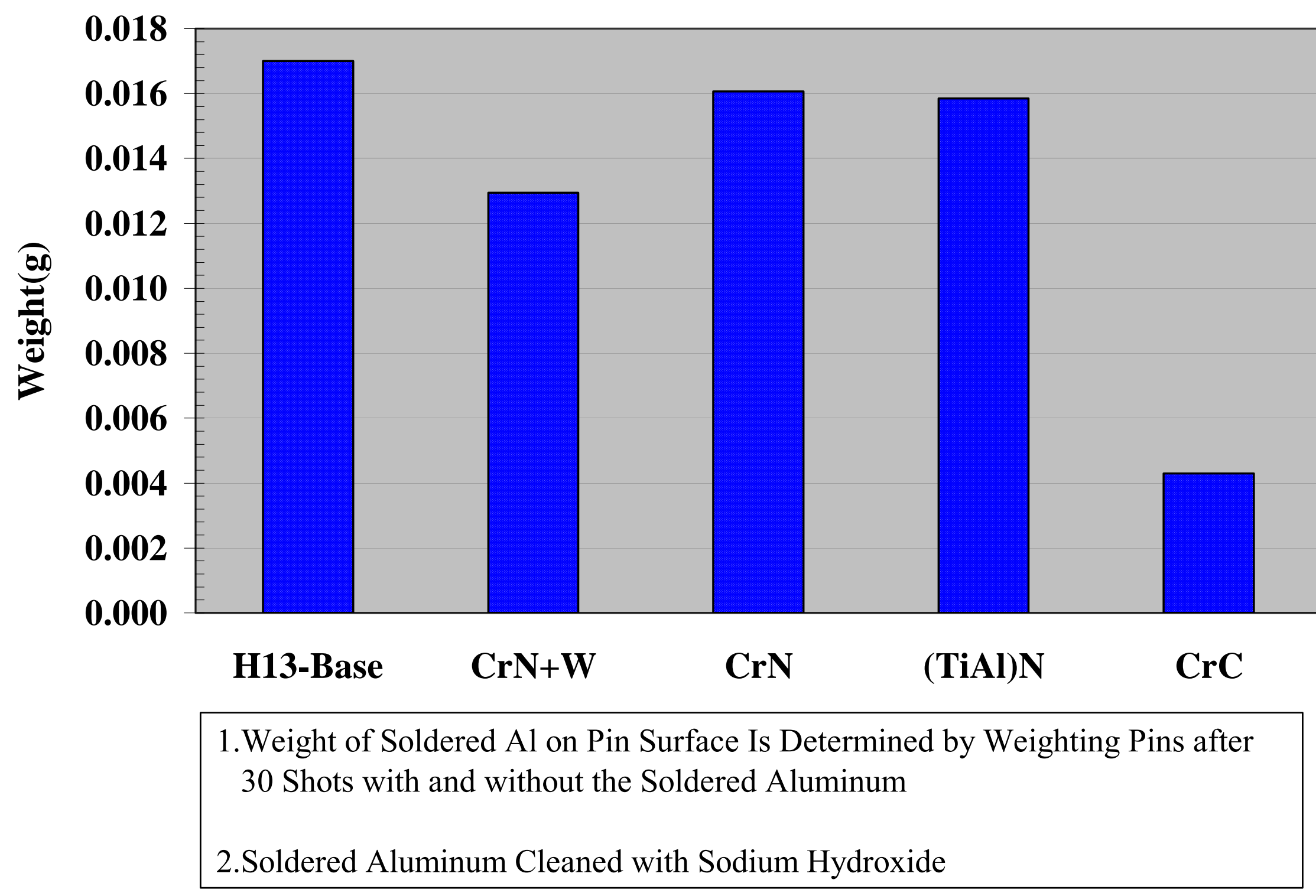


Figure 50: Effect of PVD Coatings on Washout Resistance

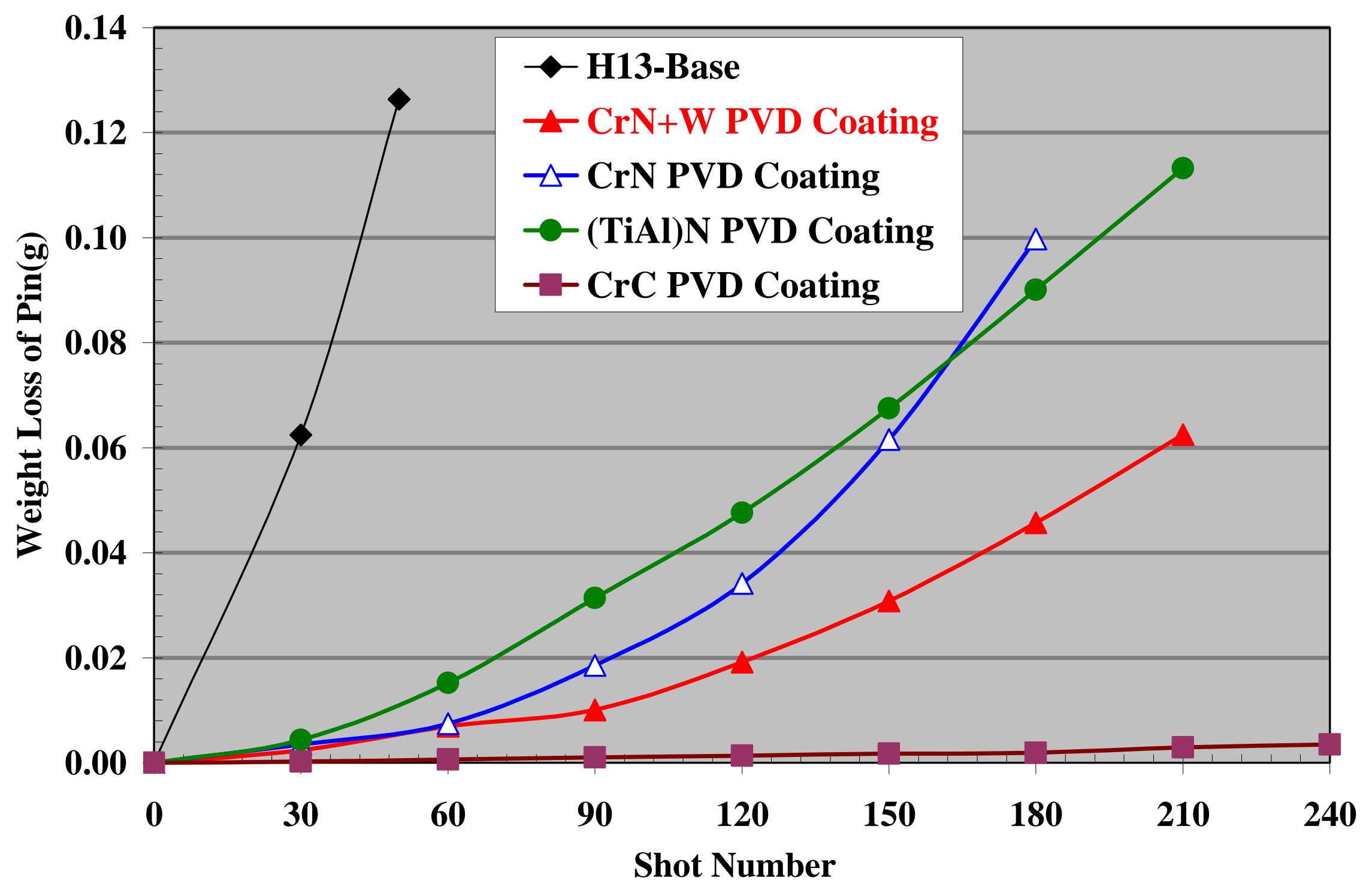


Figure 51: Washout Comparison of PVD Coatings and Nitrocarburizing

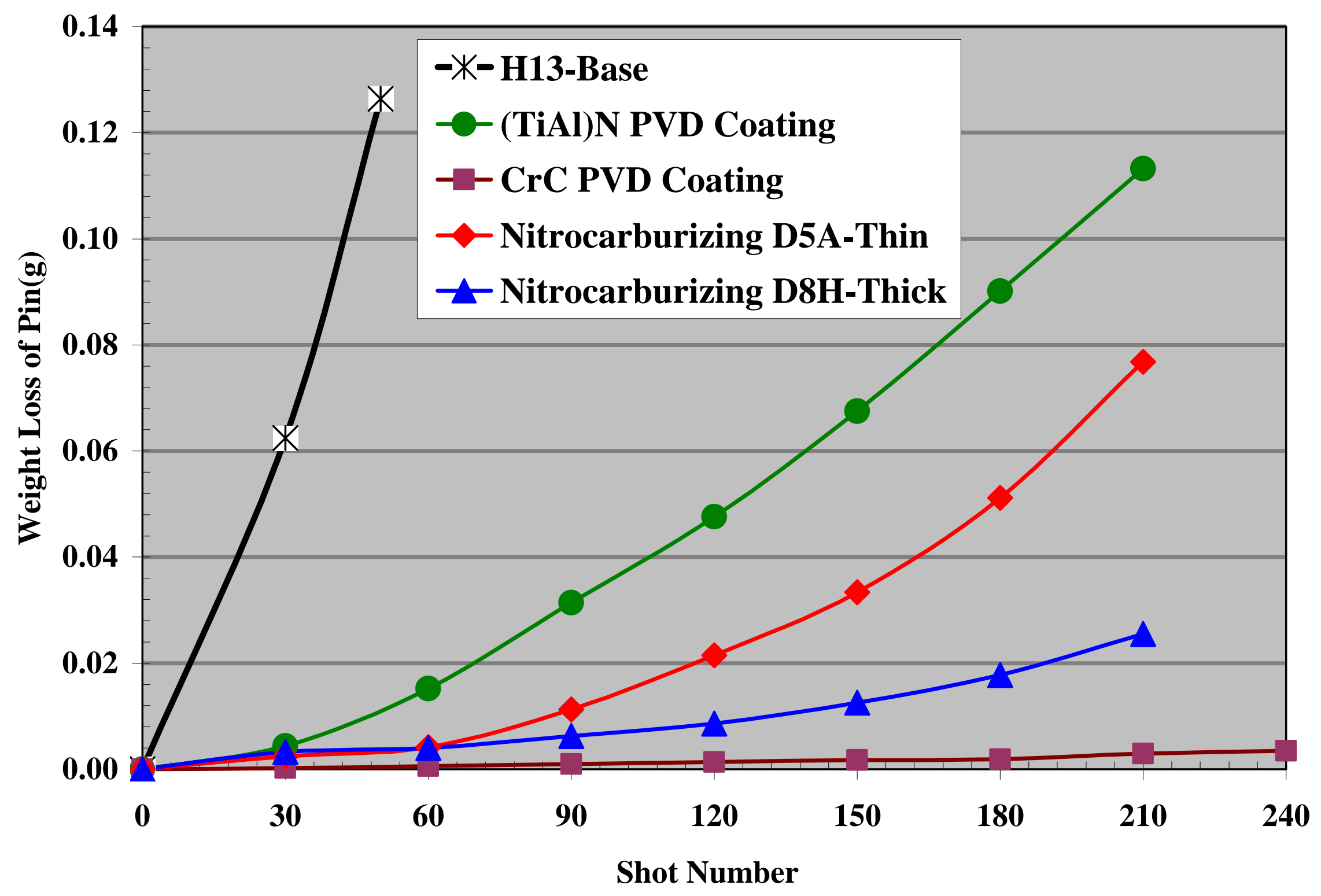


Figure 52: Degradation of H13 Pin with CrN+W PVD Coating

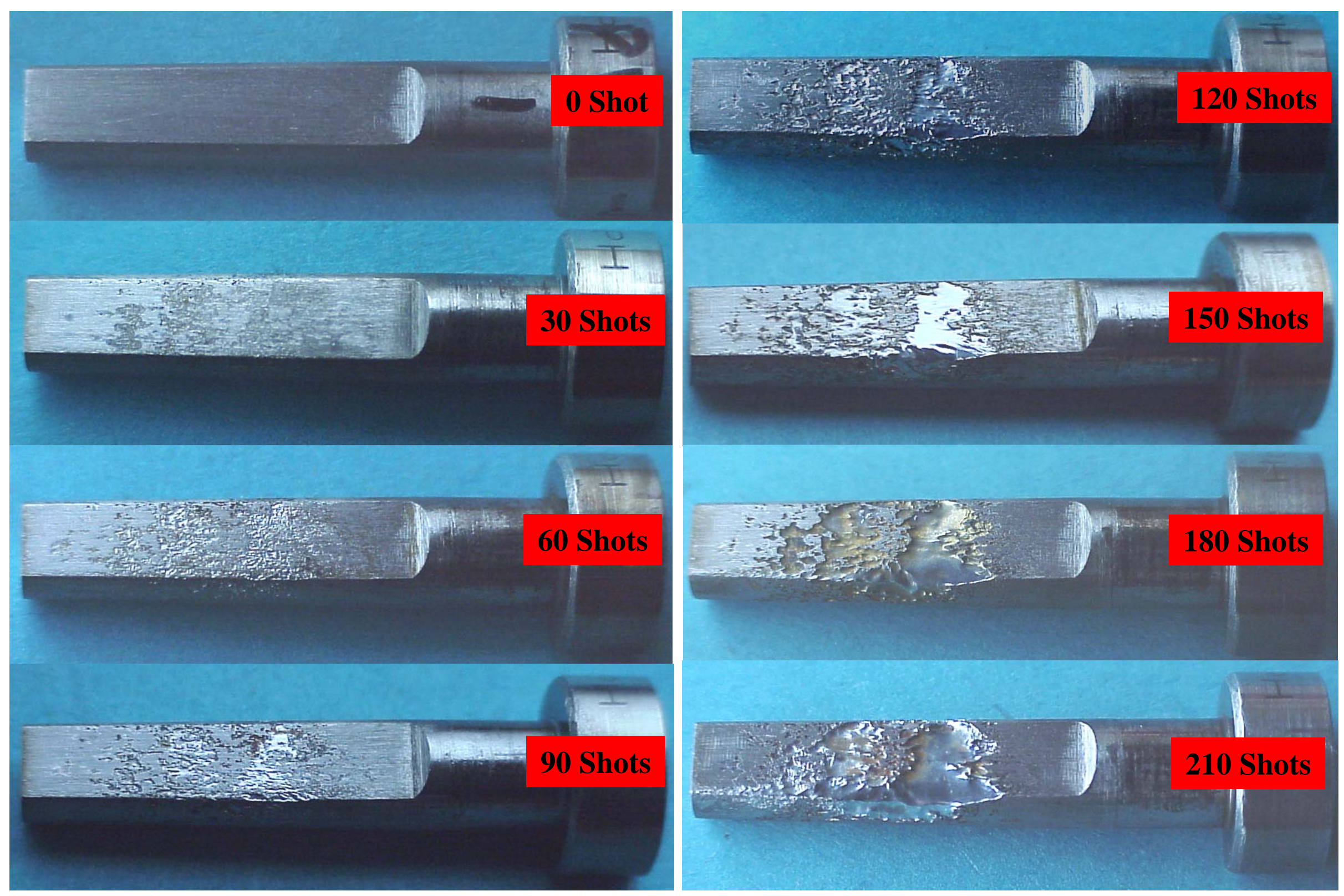




\section{Figure 53: Degradation of H13 Pin with CrN+W PVD Coating (magnified)}

\section{Shot}

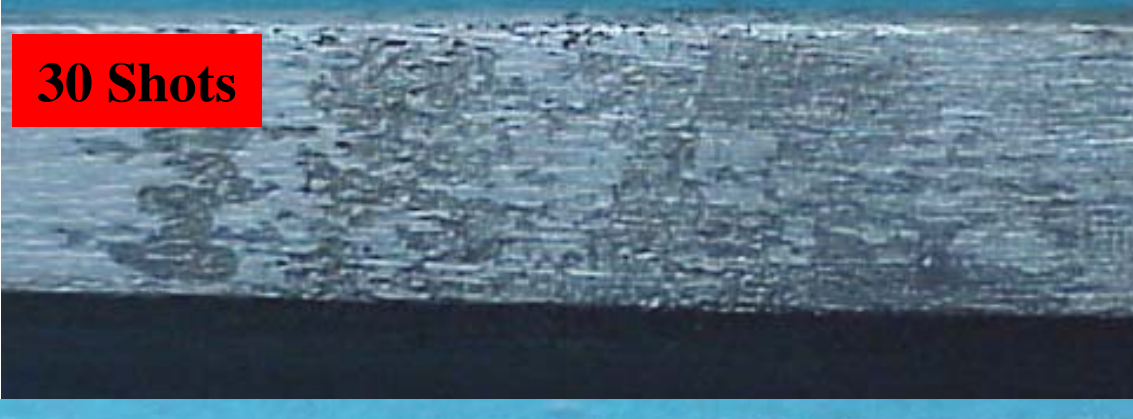

\section{Shots}
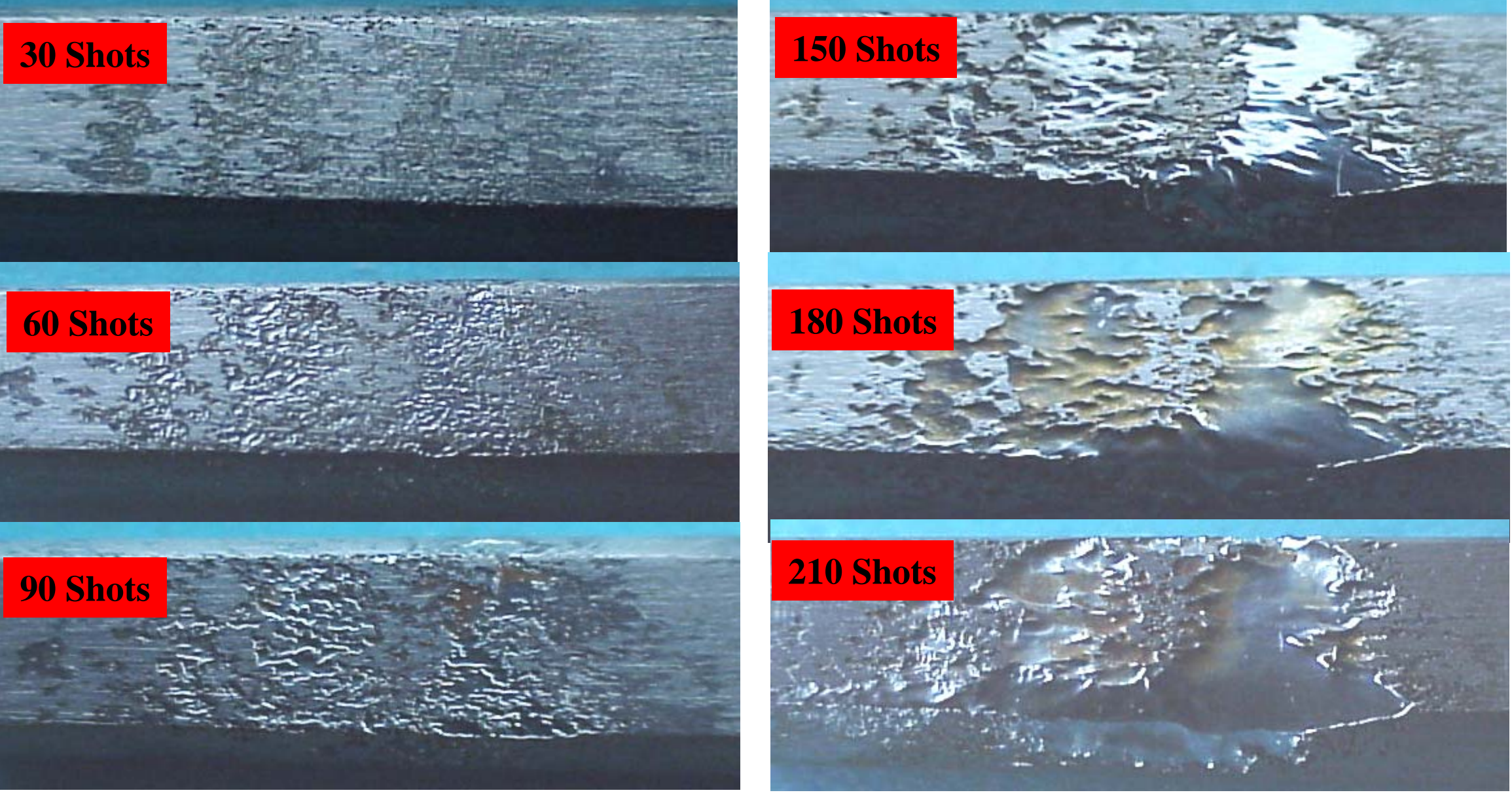


\section{Figure 54: Degradation of H13 Pin with CrN PVD Coating}
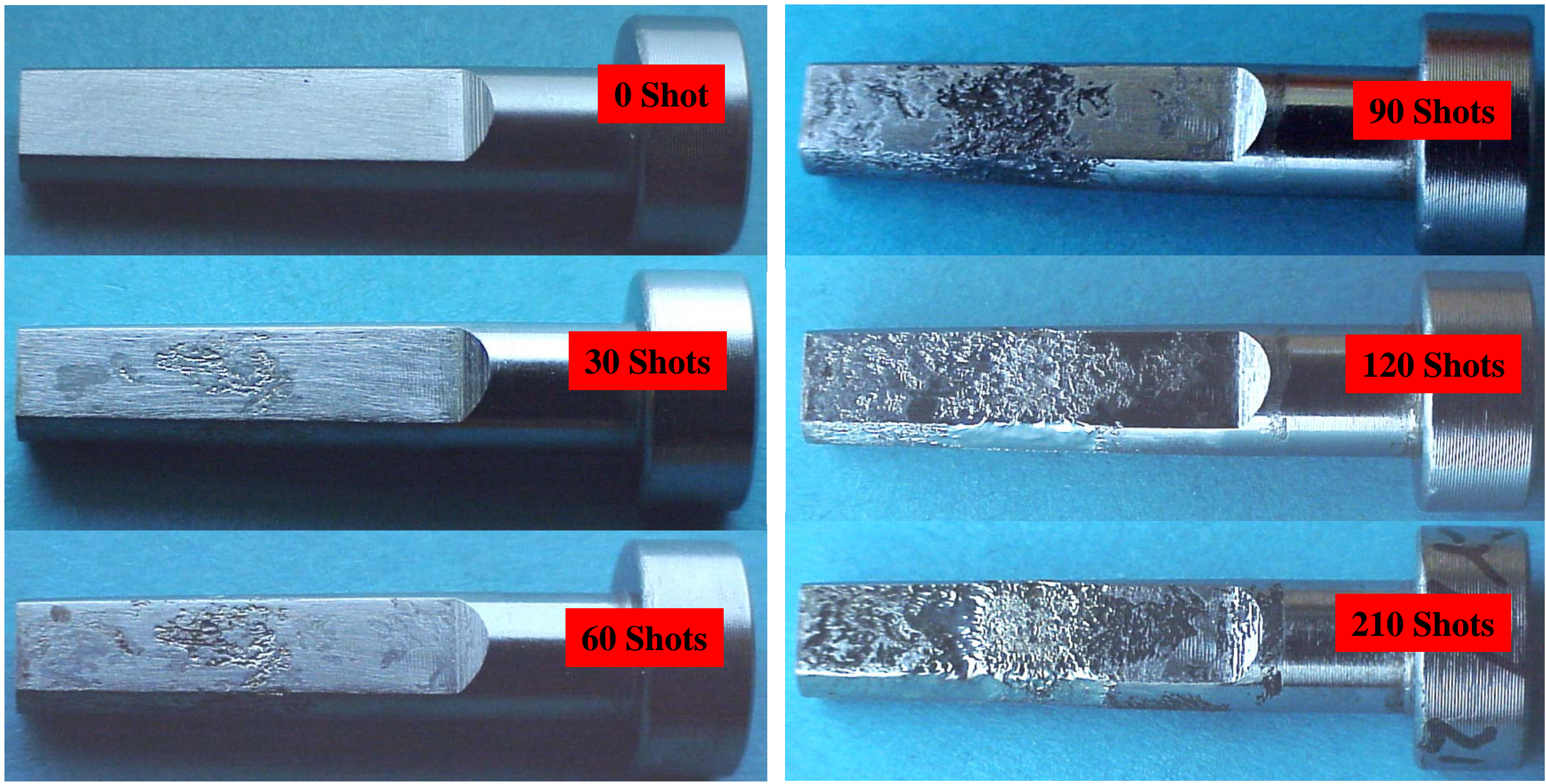
Figure 55: Degradation of H13 Pin with CrN PVD Coating (magnified)
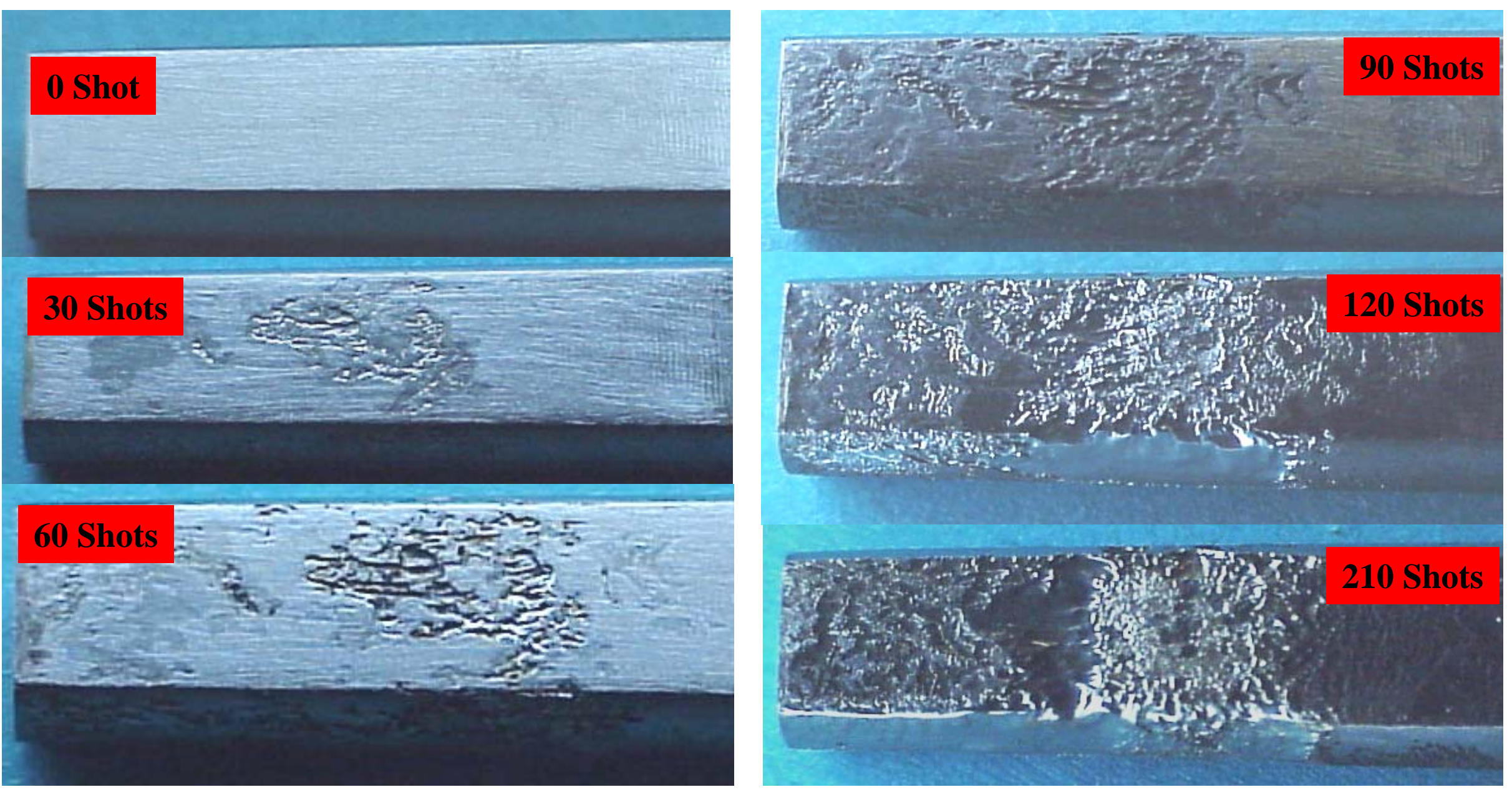


\section{Figure 56: Degradation of H13 Pin with (TiAl)N PVD Coating}

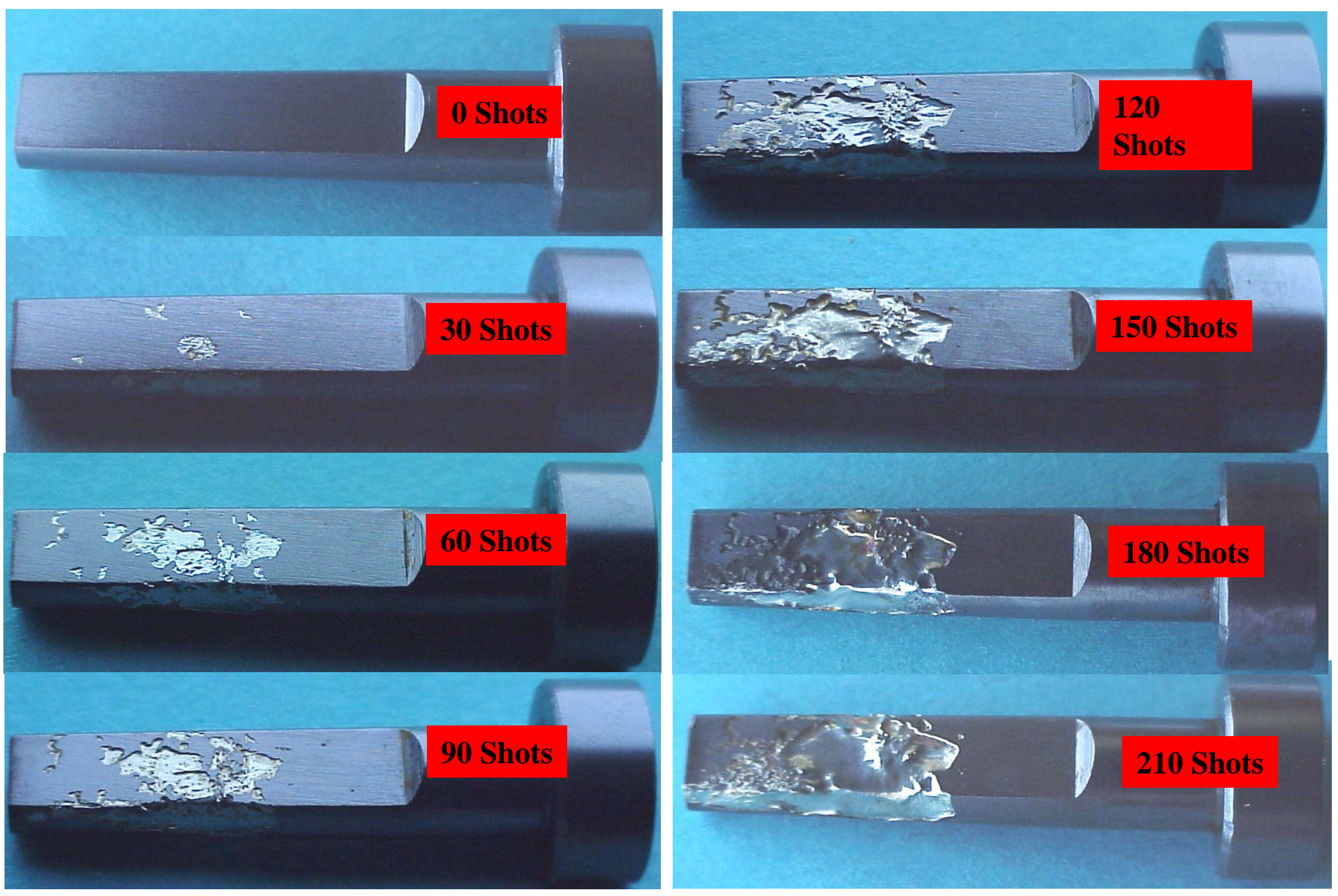


Figure 57: Degradation of H13 Pin with (TiAl)N PVD Coating (magnified)
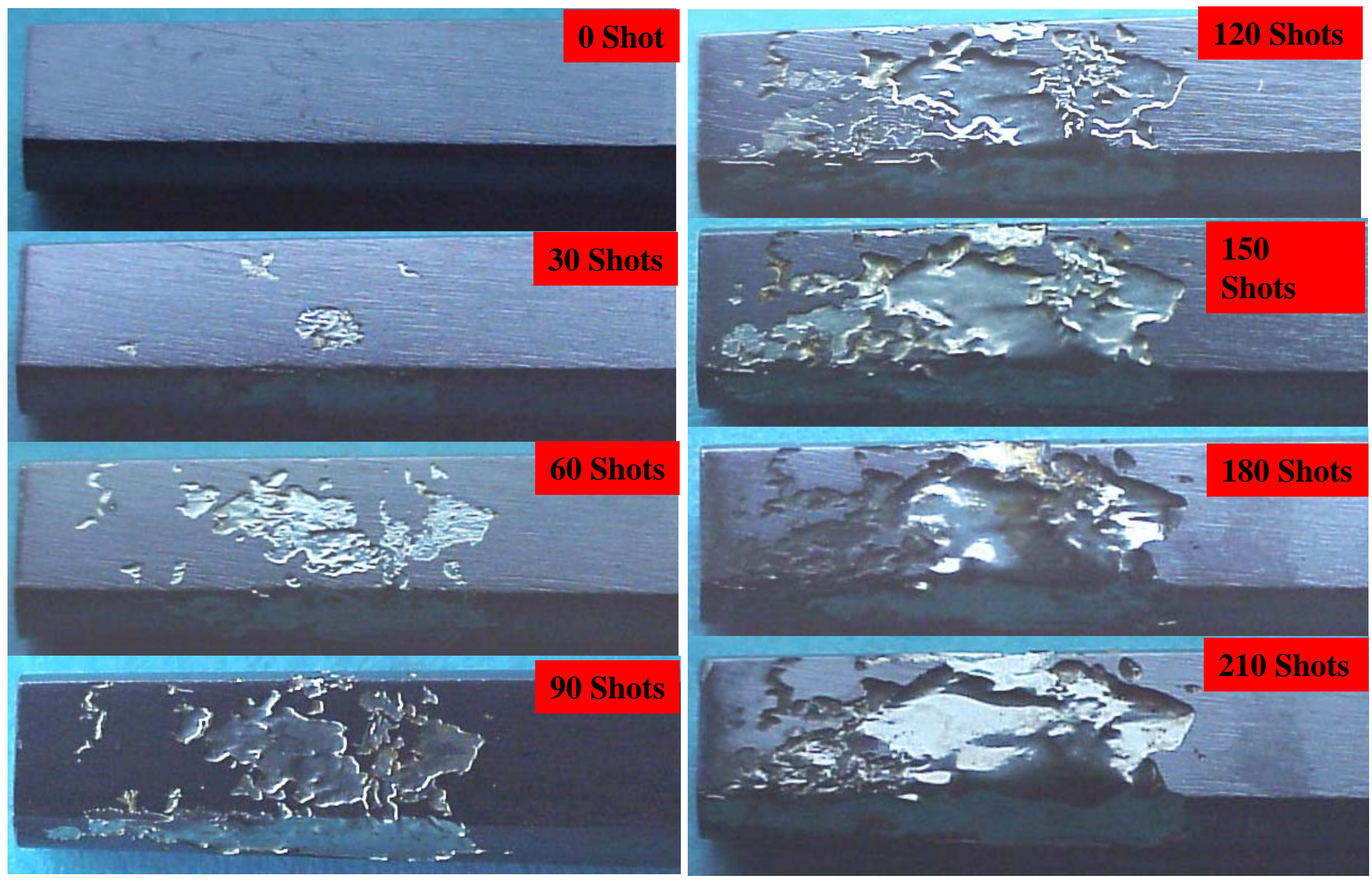


\section{Figure 58: Degradation of H13 Pin with CrC PVD Coating}

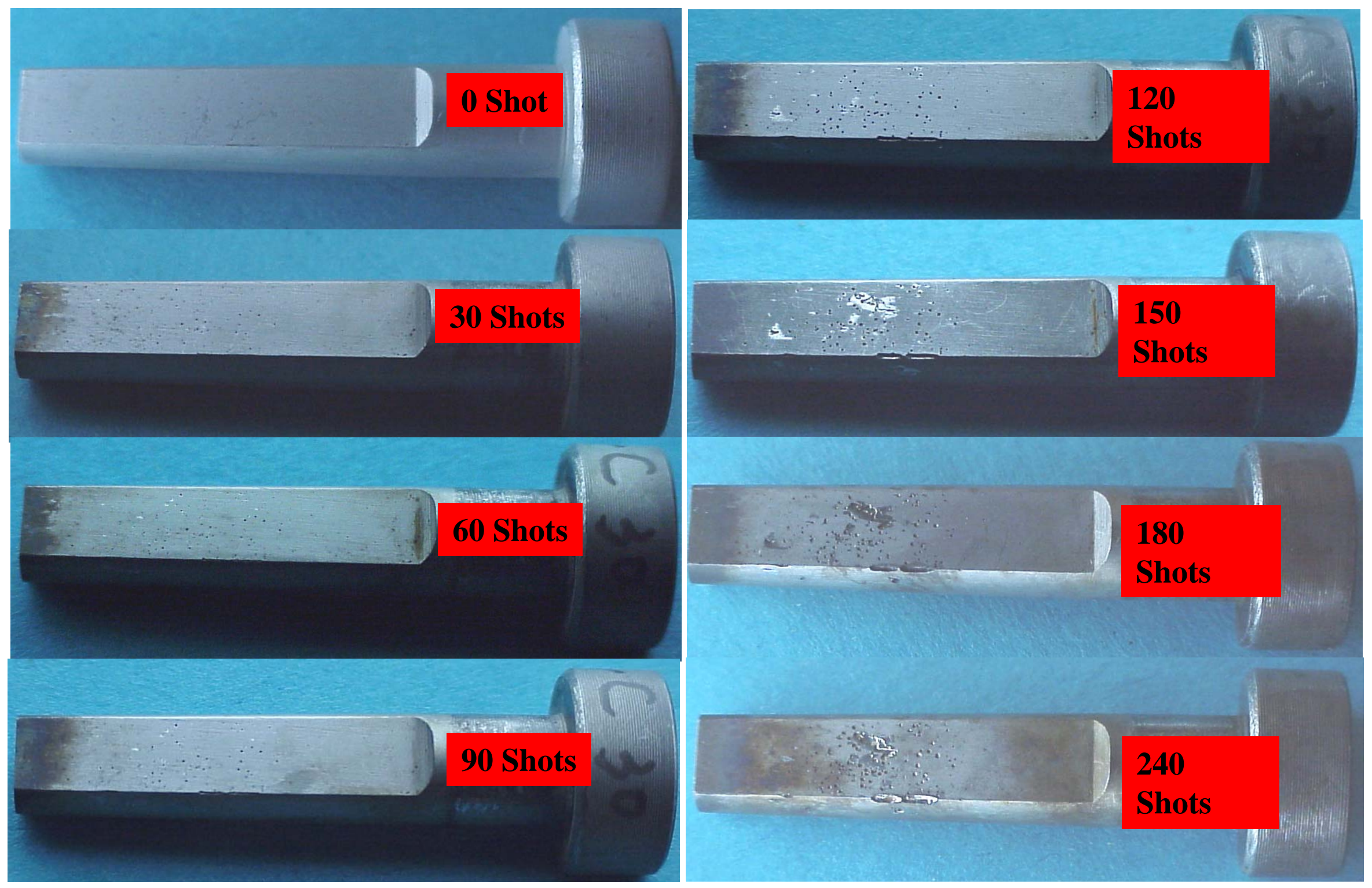


Figure 59: Degradation of H13 Pin with CrC PVD Coating (magnified)

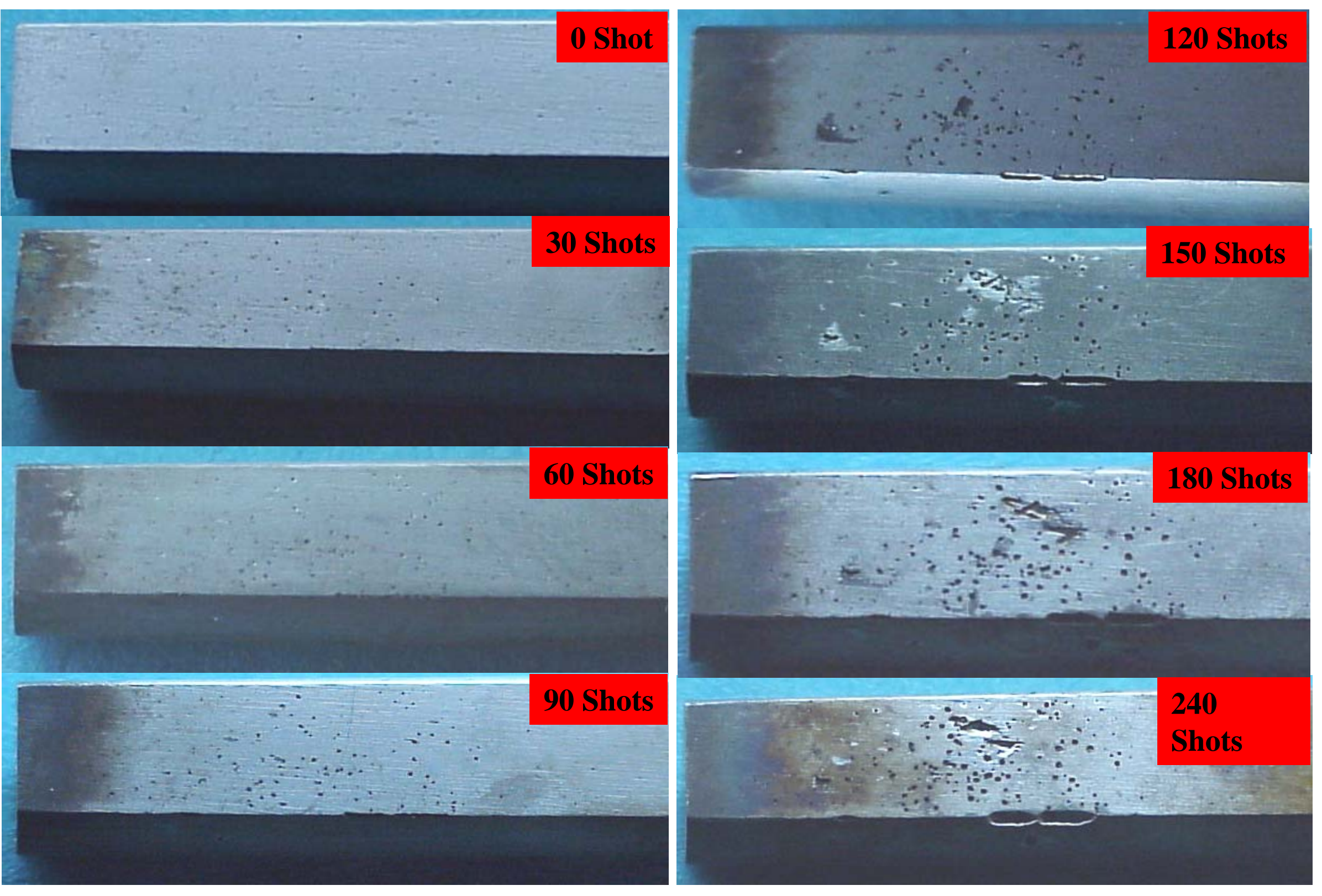


Fig. 60: Degradation of H13 Pin with CrN+W PVD Coating (Pin Holes and Worn off)
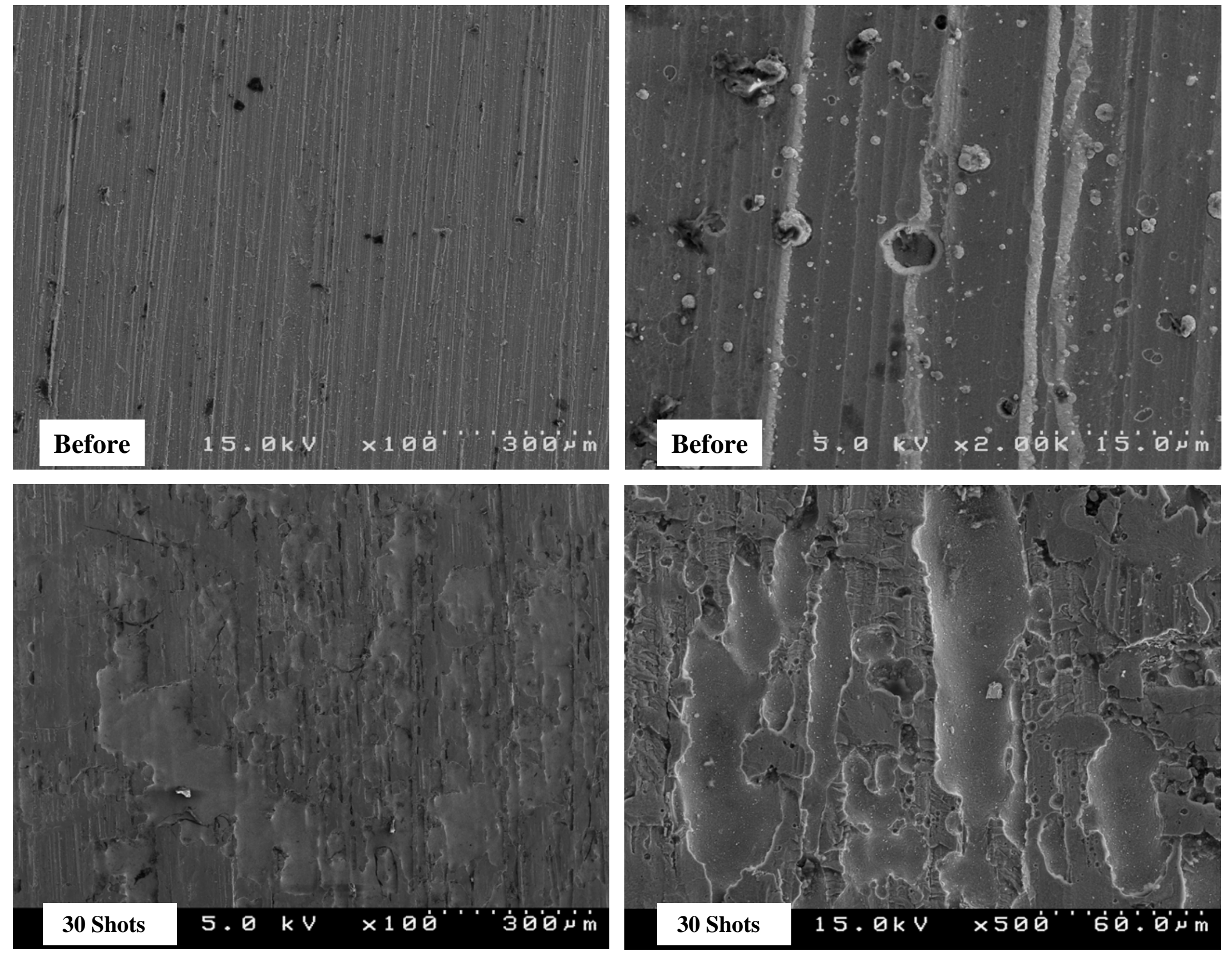
Figure 61: Degradation of H13 Pin with CrN+W PVD Coating after 210 Shots (Pin Holes and Worn off) 
Figure 62: Degradation of H13 Pin with (TiAl)N PVD Coating (Pin Holes and Worn off)

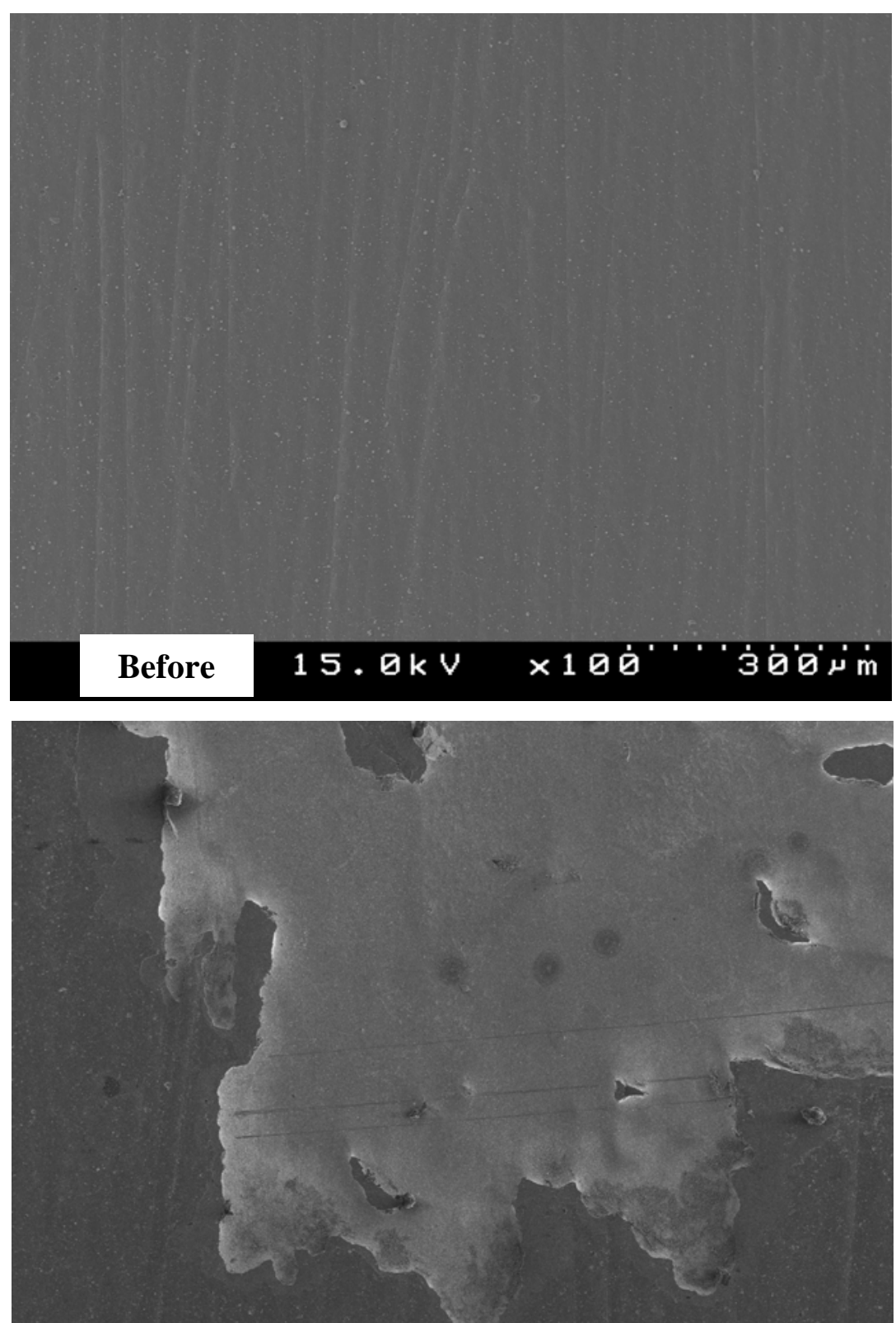


Figure 63: Degradation of H13 Pin with (TiAl)N PVD Coating after 210 Shots (Pin Holes and Worn off)

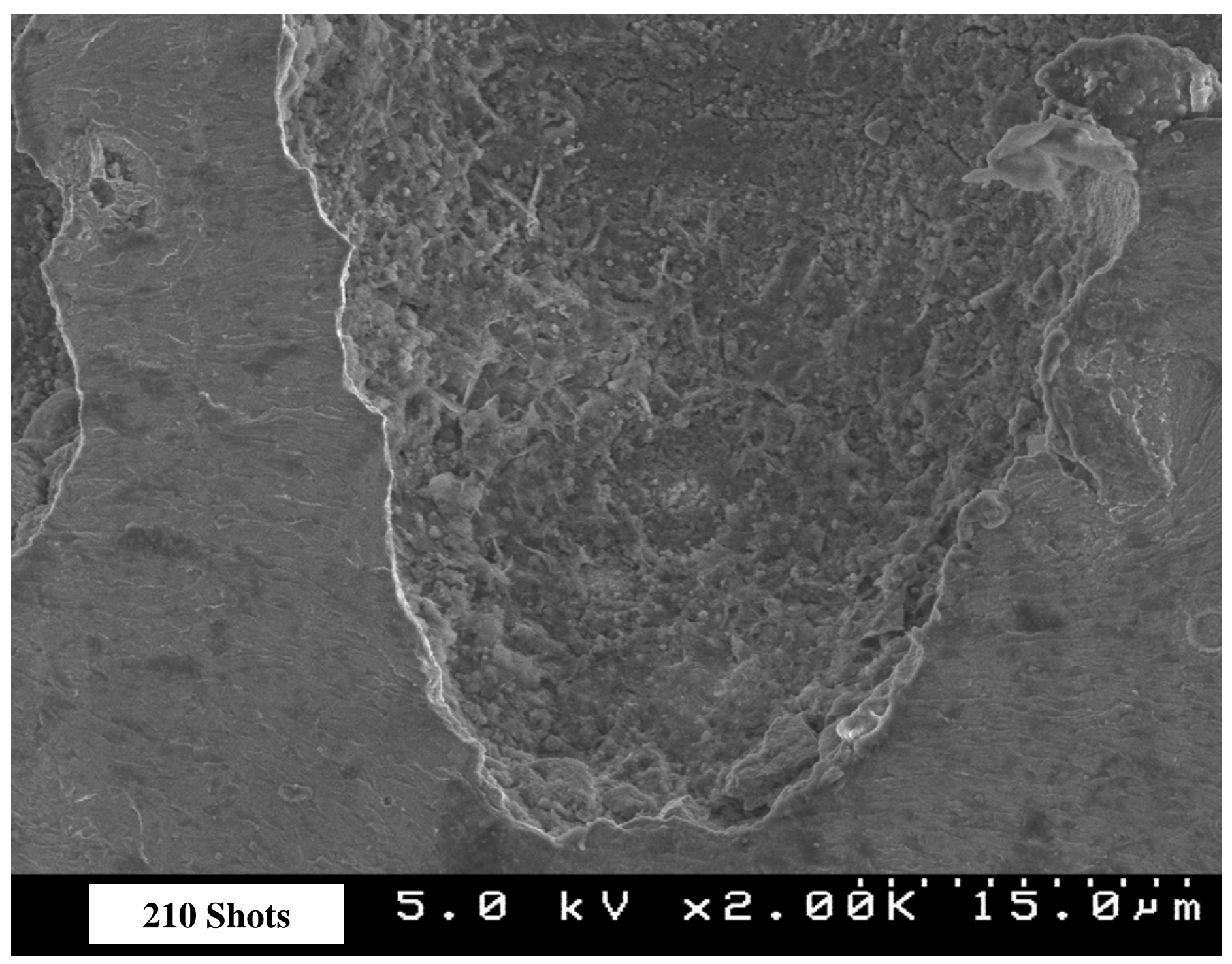




\section{Figure 64: Degradation of H13 Pin with CrC PVD Coating(Only Pin Holes)}
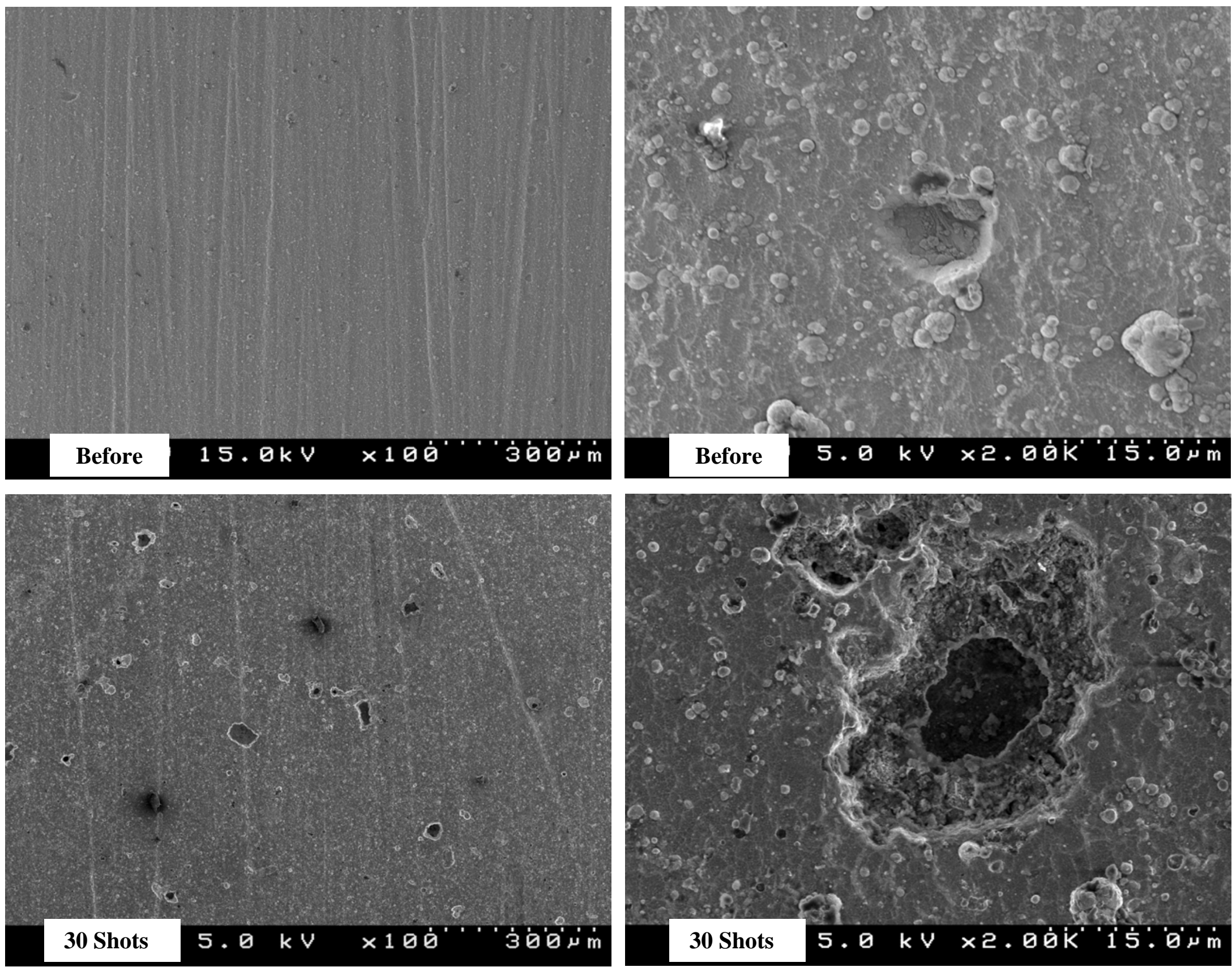
Figure 65: Degradation of H13 Pin with CrC PVD Coating after 240 Shots (Only Pin Holes)
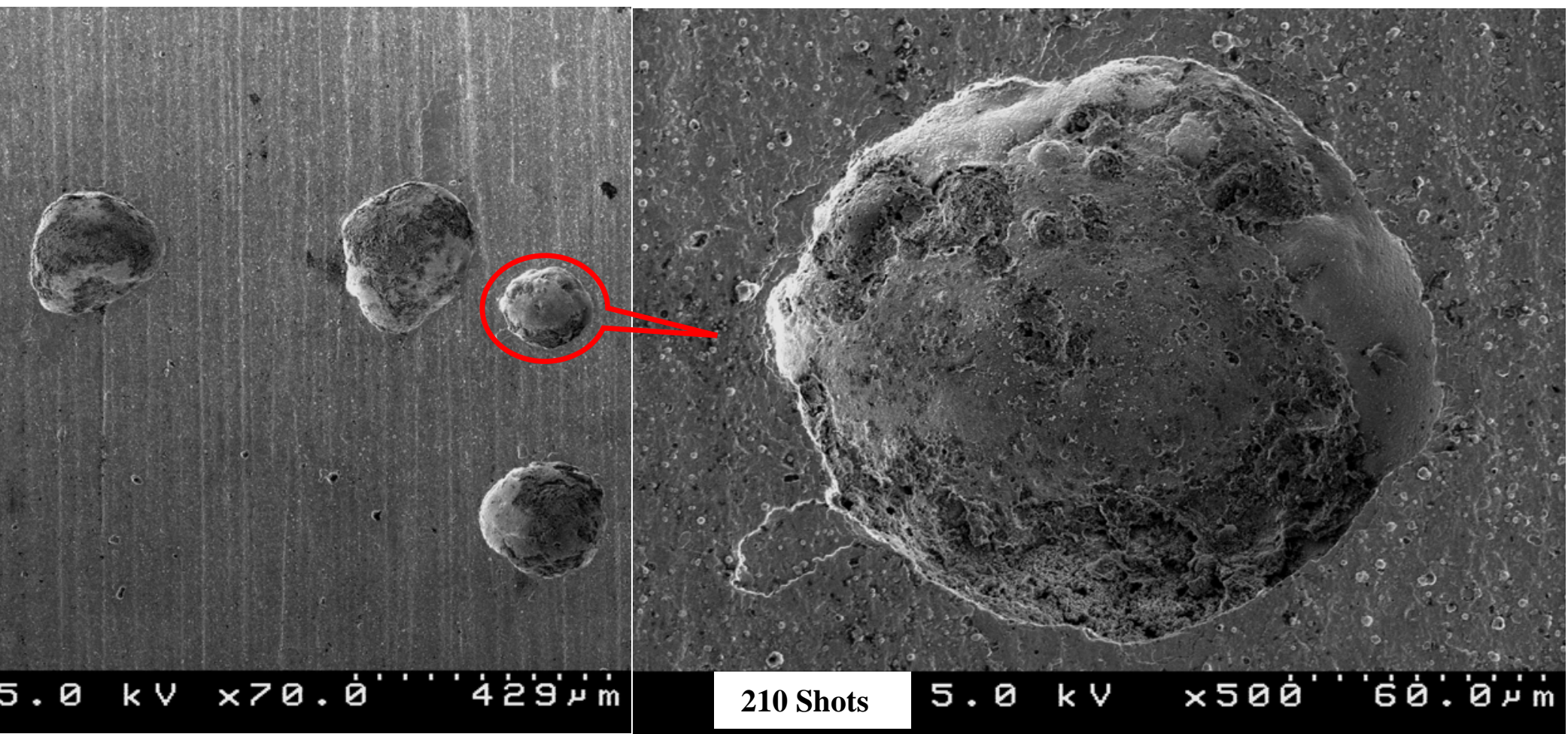
Figure 66: Cross Section View \& Failure Mode of CrN+W PVD Coated H13 Pin after 120 Shots

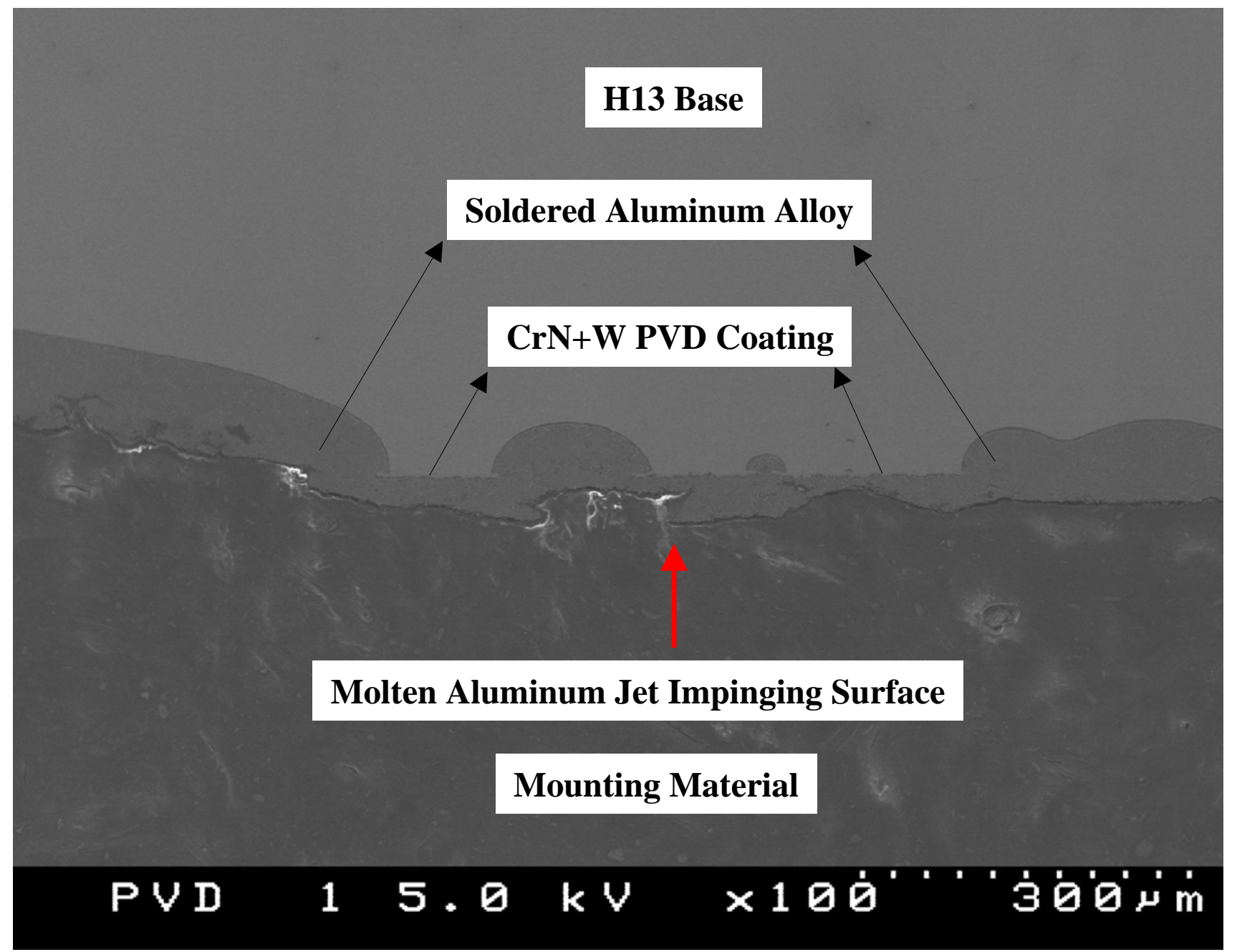


Figure 67: Cross Section View \& Failure Mode of CrN+W PVD Coated H13 Pin after 120 Shots

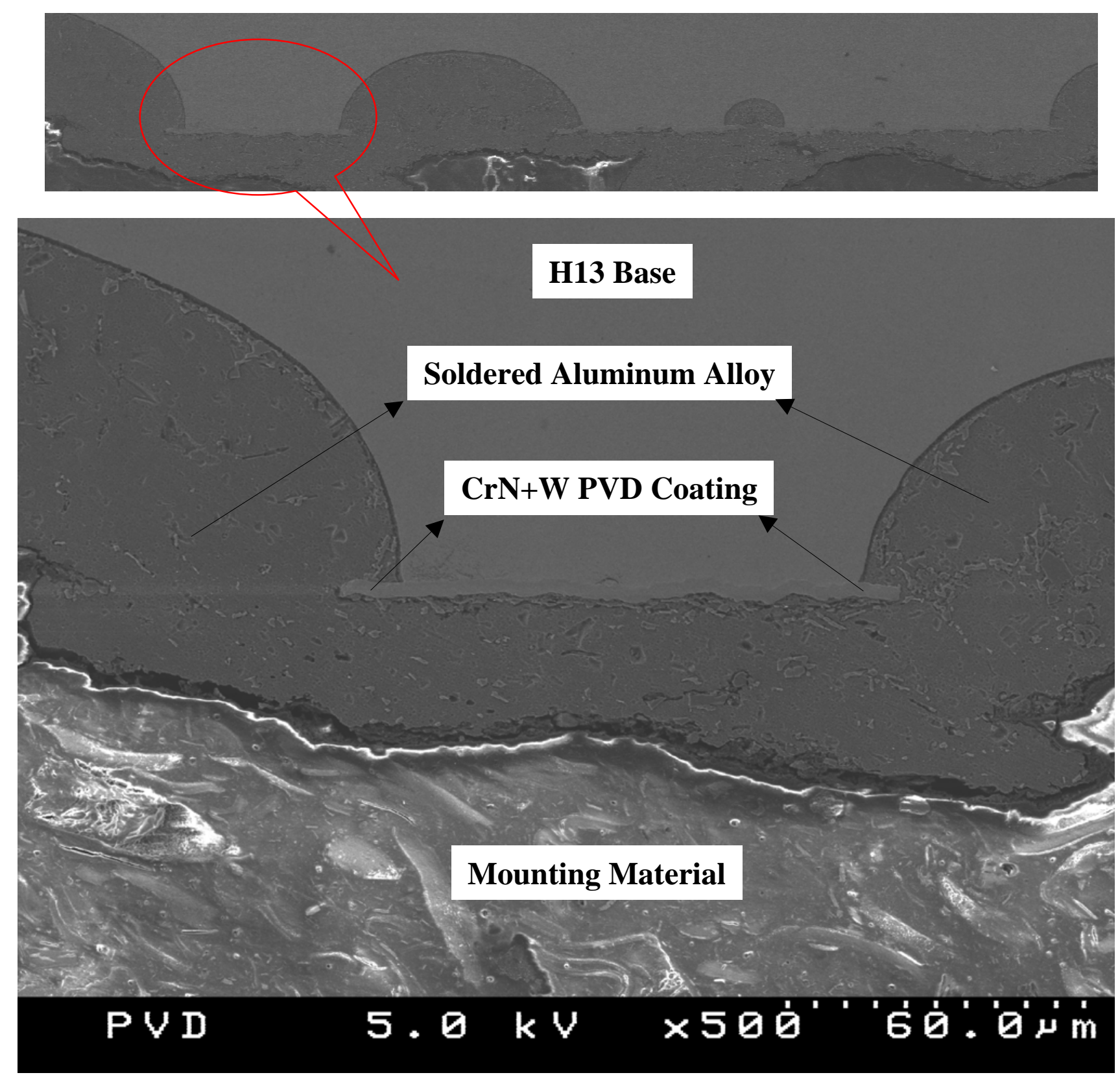


Figure 68: Cross Section View \& Failure Mode of CrN+W PVD Coated H13 Pin after 120 Shots

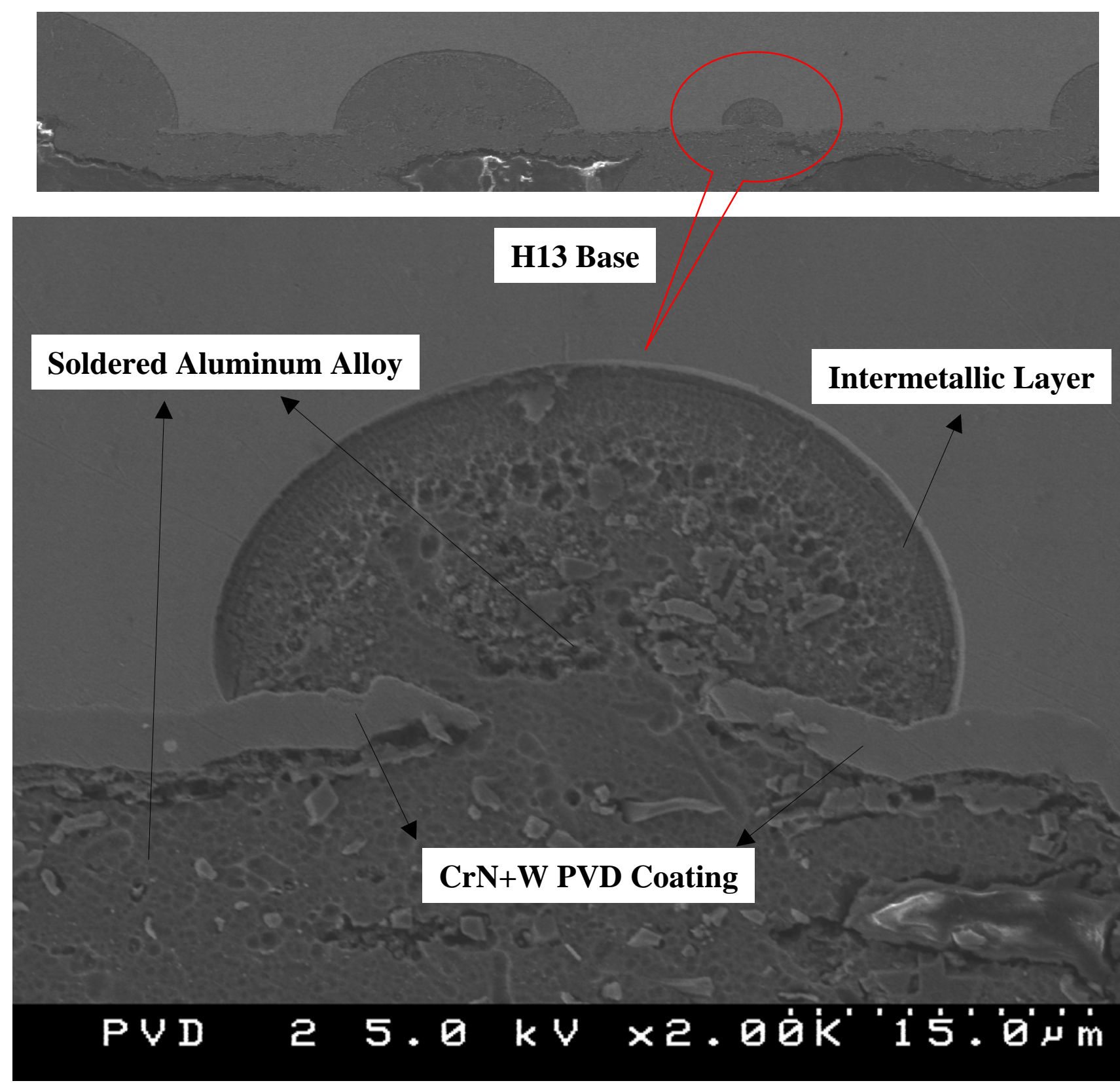

